
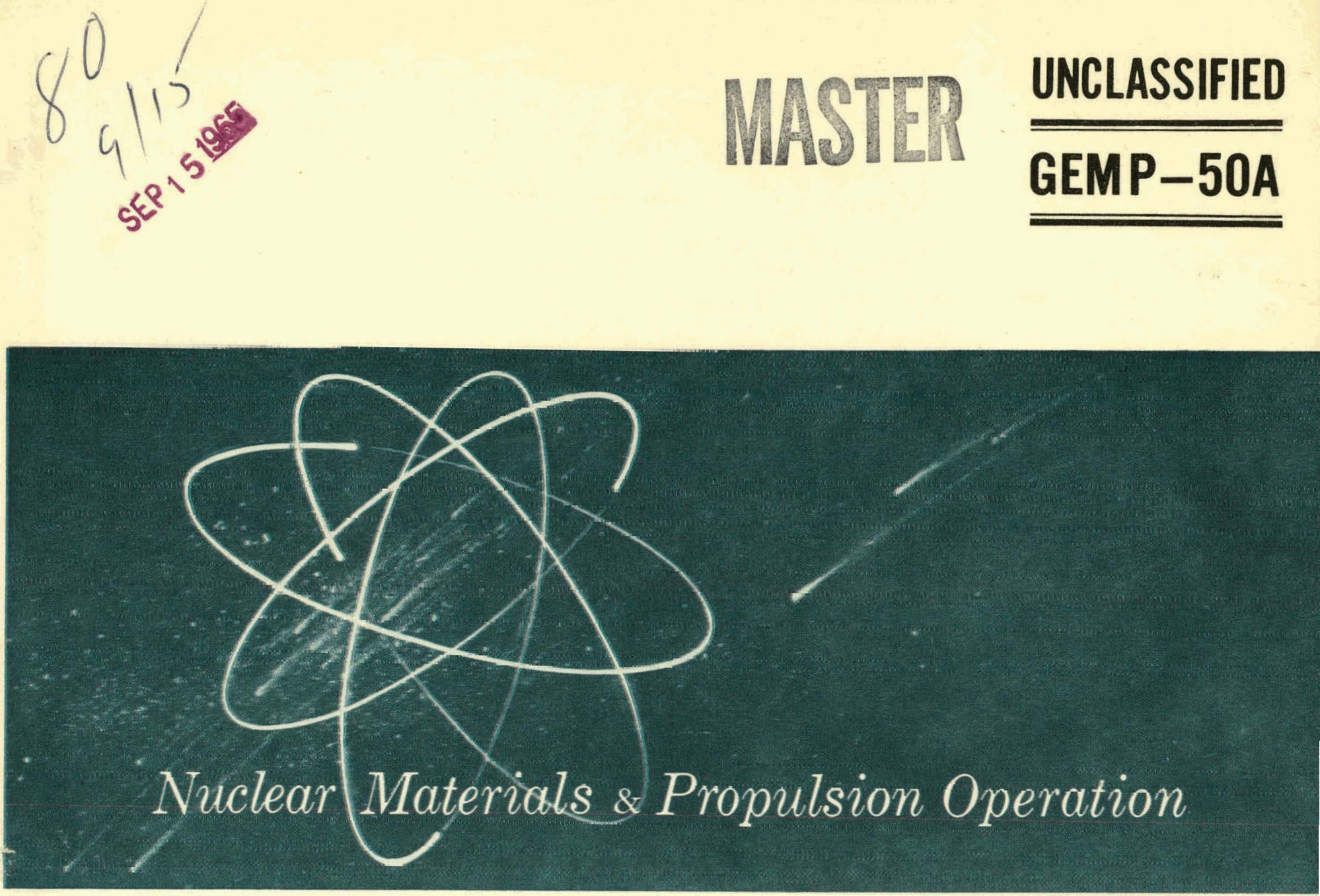

\title{
HIGH-TEMPERATURE MATERIALS PROGRAM PROGRESS REPORT No. 50, Part A
}

August 20, 1965

RELEASED FOR ARVOWPCENEN"

IN NUCLEAR SCIENCE AESTRACTS

\section{REPRODUCIBLE COPY}

\section{GENERAL ELECTRIC}




\section{LEGAL NOTICE}

This report was prepared as an account of Government sponsored work. Neither the United States, nor the Commission, nor any person acting on behalf of the Commission:

A. Makes any warranty or representation, expressed or implied, with respect to the accuracy, completeness, or usefulness of the information contained in this report, or that the use of any information, apparatus, material, method, or process disclosod in this report may not infringe privately owned rights; or

B. Assumes any liabilities with respect to the use of, or for damages resulting from the use of any information, apparatus, material, method, or process disclosed in this report.

As used in the above, "person acting on behalf of the Commission" includes any employee or contractor of the Commission, or employee of such contractor, to the extent that such employee or contractor of the Commission, or employee of such contractor prepares, disseminates, or provides access to, any information pursuant to his employment or contract with the Commission or his employment with such contractor.

Printed in USA. Price $\$ 3.00$. Available from the

Clearinghouse for Federal Scientific and

Technical Information,

National Bureau of Standards,

U.S. Department of Commerce,

5285 ruıl Ruyal Rual,

Springfield, Virginia 22151 


\section{DISCLAIMER}

This report was prepared as an account of work sponsored by an agency of the United States Government. Neither the United States Government nor any agency Thereof, nor any of their employees, makes any warranty, express or implied, or assumes any legal liability or responsibility for the accuracy, completeness, or usefulness of any information, apparatus, product, or process disclosed, or represents that its use would not infringe privately owned rights. Reference herein to any specific commercial product, process, or service by trade name, trademark, manufacturer, or otherwise does not necessarily constitute or imply its endorsement, recommendation, or favoring by the United States Government or any agency thereof. The views and opinions of authors expressed herein do not necessarily state or reflect those of the United States Government or any agency thereof. 


\section{DISCLAIMER}

Portions of this document may be illegible in electronic image products. Images are produced from the best available original document. 


\section{UNCLASSIFIED}

\section{GEMP-50A}

UC-25 Metals, Ceramics, and Materials

TID-4500 (43rd Ed.)

\section{HIGH-TEMPERATURE MATERIALS PROGRAM \\ PROGRESS REPORT No. 50, Part A}

August 20, 1965

United States Atomic Energy Commission

Contract No. AT $(40-1) \cdot 2847$

\section{NUCLEAR MATERIALS and PROPULSION OPERATION ATOMIC PRODUCTS DIVISION \\ GENERAL ELECTRIC}

Cincinnati 15, Ohio 


\section{DISTRIBUTION}

\section{EXTERNAL}

AEC Headquarters

G. K. Dicker W. R. Voigt

F. C. Schwenk G. W. Wensch

J. M. Simmons M. J. Whitman

AEC, CAO

C. L. Karl

J. F. Weissenberg

AEC, OROO

D. F. Cope (3) D. S. Zachry, Jr. AEC, SAN

Col. J. B. Radcliffe, Jr.

Argonne National Laboratory

R. Noland

Atomics International

S. C. Carniglia C. E. Weber

Battelle - Northwest

F. W. Albaugh R. E. Nightingale

J. J. Cadwell

$\underline{B M I}$

S. Paprocki

Chase Brass and Copper

J. Port

General Atomic

D. Ragone
Institute for Defense Analyses

R. C. Hamilton

Jet Propulsion Laboratory

J. Davis

LASL

R. D. Baker

Lawrence Radiation Laboratory

C. Cline A. J. Rothman

NASA Headquarters

J. J. Lynch

NASA, Lewis Research Center

J. W. Creagh T. A. Moss N. Saunders

T. P. Moffitt L. Rosenblum N. D. Sanders

ORNL

R. E. Blanco W. O. Harms

W. R. Grimes P. Patriarca (2)

Universal-Cyclops Steel Corp.

L. M. Bianchi

Wah Chang Corporation

S. Worchester

Westinghouse, Astronuclear Lab.

D. C. Goldberg

\section{INTERNAL}

E. A. Aitken

W. G. Baxter

J. R. Beeler

J. C. Blake

K. M. Bohlander

B. Bonini

H. C. Brassfield

R. W. Brisken

V. P. Calkins

C. L. Chase (3)

K. P. Cohen, APD

C. G. Collins (2)

E. S. Collins

J. F. Collins
P. K. Conn

J. B. Conway (2)

E. B. Delson

H. S. Edwards

E. W. Filer

P. N. Flagella

R. E. Fryxell

E. S. Funston

G. F. Hamby

J. O. Hibbits

A. N. Holden, APED (2)

R. E. Honnell

L. D. Jordan

F. Kingsbury
G. Korton

W. H. Long

L. R. McCreight, MSD

J. W. Morfitt

J. Moteff

R. E. Motsinger

G. T. Muehlenkamp

C. E. Niemeyer

W. E. Niemuth

G. W. Pomeroy

2) W. Z. Prickett

F. C. Robertshaw

E. J. Schmidt, ATS

L. H. Sjodahl
T. Slot

J. P. Smith

R. J. Spera

C. L. Storrs

R. E. Tallman

P. P. Turner

F. O. Urban

H. Wagner

J. F. White

V. C. Wilson, RL

O. G. Woike

R. E. Wood

J. F. Young, APD

Library (10) 


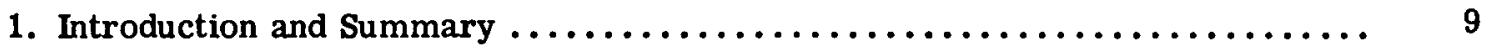

2. Effect of Radiation on Refractory Metals and Alloys (57004) ............ 13

3. Evaluations of the Plastic Fatigue Properties of

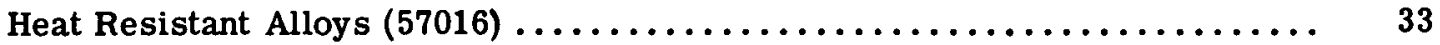

4. Effect of Radiation on Heat Resistant Metals and Alloys (57018) ......... 41

5. Radiation Effects in $\mathrm{BeO}(57063) \quad \ldots \ldots \ldots \ldots \ldots \ldots \ldots \ldots \ldots \ldots \ldots \ldots . \ldots \ldots$

6. Fission Product Transport Processes in Refractory-Metal Fuel Systems (57070) ................................. 59

7. Physico-Chemical Studies of Clad $\mathrm{UO}_{2}$ in Potential Meltdown

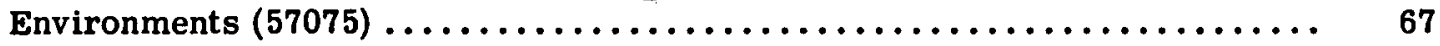

8. Phy sico-Chemical Studies of Fe-Cr-Al-Clad Fuel Systems (57076)....... 71

9. Fission Gas Diffusion in Unfueled Ceramic Materials (57069) ........... 73

10. Internal Conversion Ceramic Fuel Element Research (57072) ........... 77

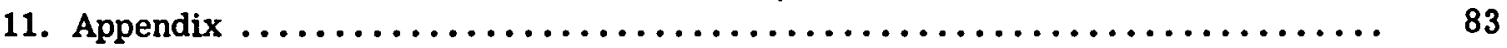




\section{FIGURES}

2.1 - ETR irradiation capsule GEFP2-232 assembled and backfilled with

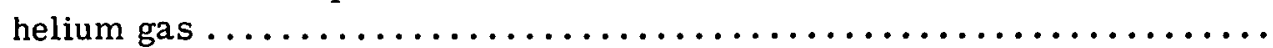

2.2 - Hardness of tungsten single crystals irradiated at reactor ambient

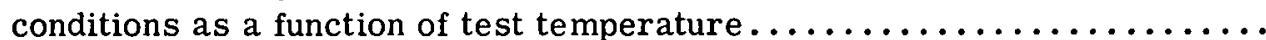

2. 3 - Room-temperature hardness of tungsten single crystal irradiated at reactor ambient temperatures to a fast neutron dose of $\sim 2.4 \times 10^{19} \mathrm{nvt}$

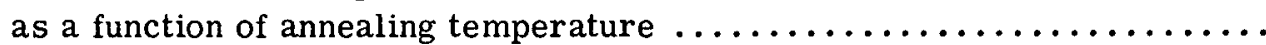

2.4 - Possible isotopes formed from tungsten in a thermal neutron

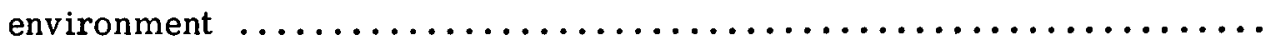

2.5 - Production of rhenium atoms as a result of transmutations from
tungsten for various values of the $\mathrm{W}^{187}(\mathrm{n}, \gamma) \mathrm{W}^{188}$ reaction

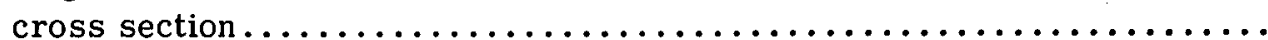

2.6 - Production of osmium atoms as a result of transmutations from tungsten for various values of the $\mathrm{W}^{187}(\mathrm{n}, \gamma) \mathrm{w}^{188}$ reaction

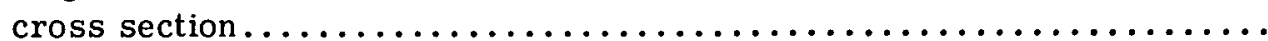

2.7 - A dislocation line held in a minimum energy configuration by barriers ... 22

2.8 - Block section representation of a 15 -kev displacement in $\alpha$-iron ....... 23

2.9 - Displacement spike geometrical cross sections in the slip plane

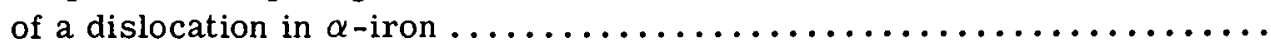

2. 10 - Collided atom distribution map for the center section of a 5-kev

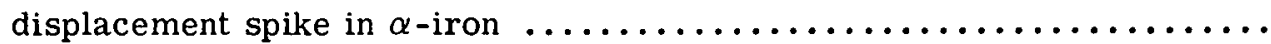

2.11 - Vacancy and interstitial atom deployment in the section shown in

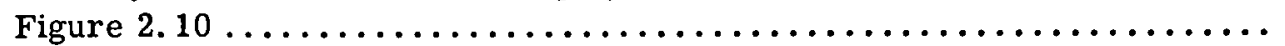

2.12 - A three-dimensional model of a collided atom volume for 5 -kev

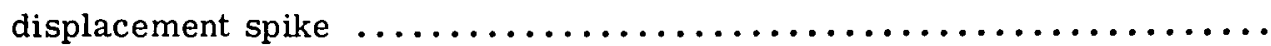

2.13 - Average number of displacements $\nu(E)=\mathrm{K}(E) E$ in a displacement spike produced by a PKA atom with energy $E \ldots \ldots \ldots \ldots \ldots \ldots$

2.14 - Displacement density, $d$, and displacement spike density, y, per unit of neutron exposure as functions of neutron energy $\ldots \ldots \ldots \ldots \ldots \ldots 28$

3.1 - Servo-controlled hydraulic materials testing machine $\ldots \ldots \ldots \ldots \ldots \ldots \ldots 34$

3.2 - Control panel of materials testing machine................... 35

3.3 - Specimen fixture assembly ............................... 36

3.4 - Fatigue test with load control (low load level) ................. 38

3.5 - Fatigue test with strain control (low strain level) ................ 39

3.6 - Fatigue test with strain control (high strain level) ............... 40

4.1 - Stress-rupture properties of Hastelloy $\mathrm{N}$ at $650^{\circ} \mathrm{C} \ldots \ldots \ldots \ldots \ldots \ldots \ldots$

4.2 - Stress-rupture properties of Hastelloy $\mathrm{N}$ at $815^{\circ} \mathrm{C} \ldots \ldots \ldots \ldots \ldots \ldots \ldots . \ldots 3$

4. 3 - Strain versus time for Hastelloy $\mathrm{N}$ specimens tested in air at

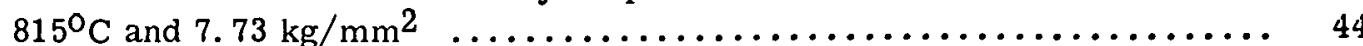


5.1 - Comparison of strength - temperature properties of EBOR, EBOR-composition (UOX +1 wt \% Bentonite), and AOX-grade BeO ......

5.2 - Comparison of strength - temperature properties of AOX-grade BeO and UOX-grade BeO containing 1 weight percent of various

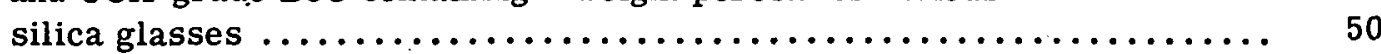

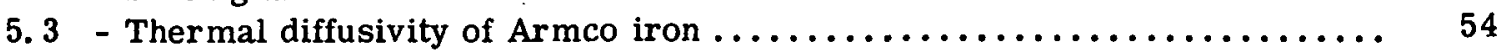

5.4 - Thermal diffusivity of $\mathrm{BeO}(\mathrm{UOX}+0.5 \mathrm{MgO}) \ldots \ldots \ldots \ldots \ldots \ldots \ldots \ldots \ldots$

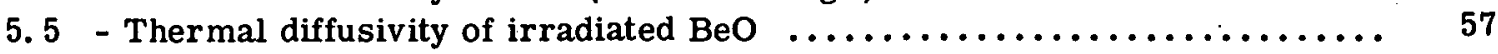

6. 1 - Distribution profiles for two tantalum samples of different grain sizes loaded under stressed conditions at $1730^{\circ} \mathrm{C}$ for 10 minutes under krypton

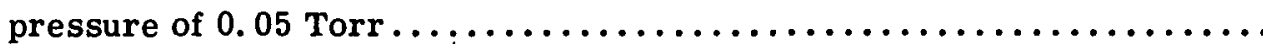

6. 2 - Distribution profiles of various stressed tantalum samples loaded for 10 minutes at various temperatures $\ldots \ldots \ldots \ldots \ldots \ldots \ldots \ldots \ldots \ldots . \ldots \ldots . \ldots \ldots$

6. 3 - Comparison of krypton distribution data with depth of penetration and

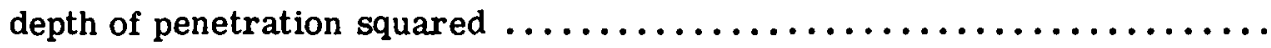

6. 4 - Photomicrograph of arc-cast tantalum specimen wall (Ta-9) after

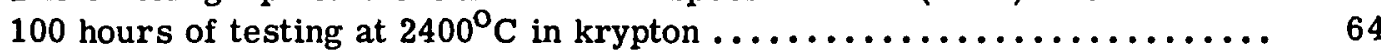

9.1 - Krypton fractional release from single crystals of $\mathrm{Al}_{2} \mathrm{O}_{3}$ bombarded at $35 \mathrm{kev}$ to a total flux of about $2 \times 10^{12}$ atoms $/ \mathrm{cm}^{2} \ldots \ldots \ldots \ldots \ldots \ldots$

9.2 - Krypton fractional release from BeO bombarded at $35 \mathrm{kev}$ to a total

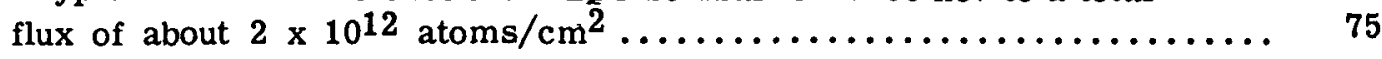

10.1 - Fission gas release and thermal history of irradiation test LTC-74 .....

10.2 - Photomicrograph showing a cross section of BeO-coated 11.5BF-230 fuel element (LTC-74) sintered for 1 hour at $1800^{\circ} \mathrm{C}$ in hydrogen .......

10.3 - Photomicrographs showing sections of BeO coatings modified with 3 weight percent $\mathrm{ZrO}_{2}$ sol on $11.5 \mathrm{BF}-230$ fuel elements sintered at

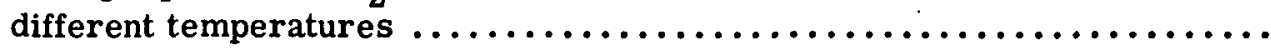




\section{TABLES}

\section{Page}

2.1 - Summary of major experiments in the refractory metals and alloys radiation effects program $\ldots \ldots \ldots \ldots \ldots \ldots \ldots \ldots \ldots \ldots \ldots \ldots \ldots \ldots$

2.2 - Nuclear data for the isotopes of $W$, Re, and Os ................ 18

2.3 - Fraction of vacancies contained in $n$-vacancy clusters .............. 29

2.4 - Vacancy cluster production function....................... 29

2.5 - Interstitial cluster production function $\ldots \ldots \ldots \ldots \ldots \ldots \ldots \ldots \ldots \ldots \ldots$

2.6 - Irradiation hardening in ferritic steel $\ldots \ldots \ldots \ldots \ldots \ldots \ldots \ldots \ldots \ldots \ldots \ldots$

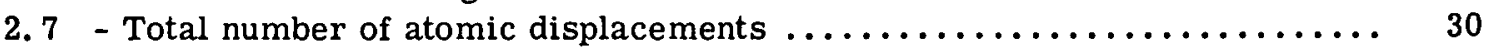

2.8 - Displacement spike density .......................... 31

4.1 - Irradiation data for high-temperature alloy capsules............. 41

4.2 - Stress-rupture test results of Hastelloy $\mathrm{N}$ specimens ............. 42

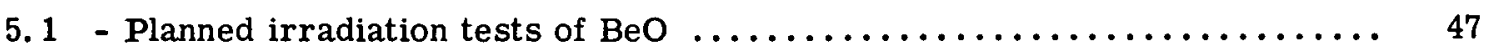

5.2 - Modulus of rupture of unirradiated $\mathrm{BeO} \ldots \ldots \ldots \ldots \ldots \ldots \ldots \ldots \ldots \ldots$

5.3 - Summary of radiation effects in BeO specimens irradiated at approximately $1000^{\circ} \mathrm{C}$ to $4.7 \times 10^{21} \mathrm{nvt}(\geq 1 \mathrm{Mev}) \ldots \ldots \ldots \ldots \ldots \ldots \ldots \ldots$

5.4 - Comparison of thermal diffusivity data on Armco iron ............. 53

5.5 - Comparison of thermal diffusivity data on unirradiated $\mathrm{BeO} \ldots \ldots \ldots \ldots . . .55$

5. 6 - Thermal diffusivity of UOX-MgO BeO before and after irradiation to $2.5 \times 10^{21} \mathrm{nvt}(\geq 1 \mathrm{Mev})$ at approximately $1000^{\circ} \mathrm{C} \ldots \ldots \ldots \ldots \ldots \ldots \ldots$

6.1 - Summary data on $\mathrm{Kr}^{85}$ migration in arc-cast tantalum samples prepared under glow discharge and simultaneous resistance heating ..... 60

6.2 - Deposition of fission products in an in-pile test assembly containing a W-Mo-Re alloy fuel container irradiated for 1015 hours at $2000^{\circ} \mathrm{C} \ldots . .65$

10.1 - Irradiation test program of BeO fueled with $\mathrm{UO}_{2}-\mathrm{ThO}_{2}-\mathrm{Y}_{2} \mathrm{O}_{3}$

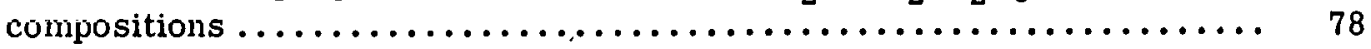

10.2 - Fission product release from test LTC $-74 \ldots \ldots \ldots \ldots \ldots \ldots \ldots \ldots \ldots \ldots$ 


\section{CONVERSION TABLE}

To Convert From

Atmospheres

Calories (mean)

Calories/gram $-{ }^{\circ} \mathrm{C}$

Calories/sec-cm- ${ }^{\circ} \mathrm{C}$

Calories/sec-cm ${ }^{2}$

Calories/ $\mathrm{sec}-\mathrm{cm}^{2}{ }^{\circ} \mathrm{C}$

Centimeters

Cubic centimeters

Grams

Grams $/ \mathrm{cm}^{3}$

Grams $/ \mathrm{cm}^{2}$

Kilograms

Kilograms $/ \mathrm{cm}^{2}$

Kilograms $/ \mathrm{mm}^{2}$

Kilowatts

Liters

Meters

Millimeters of mercury

Square centimeters

Torr

Watts $/ \mathrm{cm}-{ }^{\circ} \mathrm{C}$

Watt-seconds

Watts $/ \mathrm{cm}^{2}$

Watts $/ \mathrm{cm}^{2}-{ }^{\circ} \mathrm{C}$

Centimeters/sec

Meters/sec
To

Multiply By

Pounds/inch ${ }^{2}$

14.7

Btu (mean) ................ 0.00397

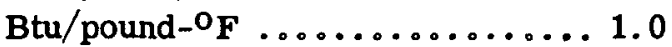

$\mathrm{Btu} / \mathrm{hr}-\mathrm{ft}-{ }^{\circ} \mathrm{F} \ldots \ldots \ldots \ldots \ldots \ldots . \ldots 241.8$

$\mathrm{Btu} / \mathrm{hr}-\mathrm{ft}^{2} \ldots \ldots \ldots \ldots \ldots \ldots \ldots 1.32 \times 10^{4}$

$\mathrm{Btu} / \mathrm{hr}-\mathrm{ft}^{2}{ }^{\circ}{ }^{\circ} \mathrm{F} \ldots \ldots \ldots \ldots \ldots \ldots . \ldots 7370$

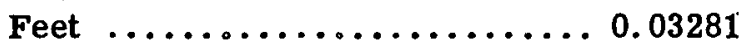

Inches . .................. 0.3937

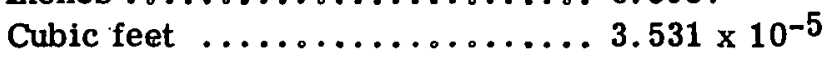

Cubic inches .............. 0.06103

Pounds ................... 0.002205

Pounds $/ \mathrm{ft}^{3} \ldots \ldots \ldots \ldots \ldots \ldots \ldots 6 . \ldots \ldots$

psi ................... 0.01422

Pounds ...................2.205

Atmospheres .............. 0.9678

Pounds $/ \mathrm{ft}^{2} \ldots \ldots \ldots \ldots \ldots \ldots \ldots \ldots 2048$

Pounds/inch 2 .............. 14.22

Pounds $/$ inch $^{2}$.............. 1422. 32

Btu/sec ................... 0.948

Cubic feet................ 0.0353

Inches .................. 39.37

Atmospheres ................. 0.001316

Square feet ............... 0.001076

Square inches ............. 0.155

$\mathrm{mm}$ of $\mathrm{Hg} \ldots \ldots \ldots \ldots \ldots \ldots \ldots \ldots$

Atmospheres .............. 0.001316

$\mathrm{Btu} / \mathrm{hr}-\mathrm{ft}-{ }^{\circ} \mathrm{F} \ldots \ldots \ldots \ldots \ldots \ldots . . \ldots 57.8$

Btu .................... 0.000948

$\mathrm{Btu} / \mathrm{hr}-\mathrm{ft}^{2} \quad 3170$

$\mathrm{Btu} / \mathrm{hr}-\mathrm{ft}^{2}-\mathrm{o}_{\mathrm{F}} \ldots \ldots \ldots \ldots \ldots \ldots . \ldots 1760$

Feet $/$ sec .................. 0.03281

Feet $/$ sec.................. 3.281 
THIS PAGE

\section{WAS INTENTIONALLY \\ LEFT BLANK}




\section{INTRODUCTION AND SUMMARY}

\section{Introduction}

This report, Volume A of GEMP-50, is the unclassified portion of the fiftieth in a series of monthly reports of the work in progress on the High-Temperature Materials Program for the Atomic Energy Commission under Contract AT(40-1)-2847 in which each task under the program is reported on a bimonthly basis.

The period covered by this report, May 15, 1965 to July 15, 1965, encompasses the transition from the FY -65 to the FY -66 programs. Three tasks that terminated at the end of FY -65 are summarized, two ("Fission Gas Diffusion in Unfueled Ceramic Materials," Job 57069, and "Internal Conversion Ceramic Fuel Element Research," Job 57072) in GEMP-50A (unclassified) and one ("High-Flux Reactor Materials Gaseous Fuels Research," Job 57074) in GEMP-50B (classified). The schedule for the reporting of each FY-66 task is shown in the following breakdown for the monthly reports.

\section{EVEN-NUMBERED REPORTS \\ Unclassified - GEMP-50A, -52A, etc.}

1. Effect of Radiation on High-Temperature Metals and Alloys (57004) (Continuation: formerly reported in odd-numbered reports).

2. Evaluations of the Plastic Fatigue Properties of Heat Resistant Alloys (57016) (Initiated FY -66).

3. Effect of Radiation on Heat Resistant Metals and Alloys (57018) (Initiated FY -66, formerly reported under task 57004).

4. Radiation Effects in $\mathrm{BeO}$ (57063) (Continuation)

5. Fission Product Transport in Refractory Metals (57070) (Continuation)

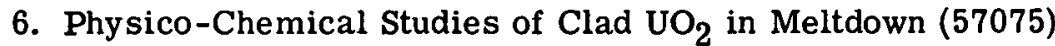
(Initiated FY -66)

7. Physico-Chemical Studies of $\mathrm{Fe}-\mathrm{Cr}-\mathrm{Al}-\mathrm{Y}-\mathrm{Clad}$ Fuel Elements (57076) (Initiated FY -66)

Classified - GEMP-50B, $-52 \mathrm{~B}$, etc.

1. Burnup Capability of $\mathrm{Y}_{2} \mathrm{O}_{3}$-Stabilized $\mathrm{UO}_{2}$ and BeO-Stabilized Fuel Materials (57068) (Continuation).

2. High-Temperature Studies of Substoichiometric Urania and Urania Solid Solutions (57071) (Continuation).

3. High-Temperature Research on Carbides for Fuel and Structural Application (57073) (Continuation). 


\section{ODD-NUMBERED REPORTS}

Unclassified - GEMP-51A, -53A, etc.

1. Oxidation Resistant Fuel Element Materials Research (57001) (Continuation).

2. High-Temperature Reactor Materials Research (57003) (Continuation).

3. High-Temperature Thermocouples and Electrical Materials Research (57014) (Continuation).

4. Refractory-Metal Alloy Research and Development (57015) (Initiated FY-66, formerly reported under task 57003).

Classified - GEMP-51B, -53B, etc.

1. Moderator (Fueled and Unfueled), Controls and Shield Materials Research (57002) (Continuation).

2. Refractory-Metal Fuel Element Materials Research (57005). (Continuation).

3. High-Temperature Materials Engineering Properties Evaluation (57017) (Initiated FY-66).

\section{Summary}

\section{EFFECT OF RADIATION ON REFRACTORY METALS AND ALLOYS (57004)}

Creep-rupture testing of $\mathrm{W}-25 \mathrm{Re}$ between $800^{\circ}$ and $900^{\circ} \mathrm{C}$ is continuing. Preliminary results indicate that the creep activation energy is approximately $125 \mathrm{kcal} / \mathrm{g}$-mole in this temperature range.

Hot hardness measurements of tungsten single crystals irradiated to two fast neutron dosage levels ( $4.6 \times 10^{18}$ and $2.4 \times 10^{19} \mathrm{nvt}$ ) indicate that the hardness is retained to a higher temperature at the higher dosage. The hardness of both specimens was the same at room temperature, but the hardness of the higher dosage specimen was approximately 20 percent higher at $500^{\circ} \mathrm{C}$. This effect is believed to be caused by the greater percentage of Re formed during irradiation.

Studies of the transmutation of tungsten atoms into rhenium and osmium atoms as a result of thermal neutron $(n, \gamma)$ reactions indicated that a considerable number of rhenium atoms and only a small number of osmium atoms are produced. A thermal neutron dose of $2 \times 10^{20}$ nvt ( 23-day irradiation time) results in 0.19 percent rhenium atoms and 0.0012 percent osmium atoms; the quantity of these elements increases as the long half life (65 and 74 days) tungsten isotopes decay. Preliminary radiochemical analysis indicates that the cross section for the $\mathrm{W}^{187}(\mathrm{n}, \gamma) \mathrm{W}^{188}$ reaction may be larger than published values.

Computer studies indicate that the displacement spike density model shows better agreement with experimental irradiation hardening data than the more conventional models based on total displacement density or on only those atoms displaced by neutrons with energies above 1 Mev.

\section{EVALUATIONS OF THE PLASTIC FATIGUE PROPERTIES OF HEAT RESISTANT} ALLOYS (57016)

The progress made to date on this program consists of the selection and partial acquisition of testing equipment, preparation of laboratory facilities, development of testing methods, and procurement of Type 304 stainless steel test specimens. 
EFFECT OF RADIATION ON HEAT RESISTANT METALS AND ALLOYS (57018)

The Hastelloy N specimens from capsule GEFP2-128 were creep-rupture tested at temperatures of $815^{\circ} \mathrm{C}$ and $650^{\circ} \mathrm{C}$. Annealing irradiated Hastelloy $\mathrm{N}$ specimens at a temperature of $870^{\circ} \mathrm{C}$ for 4 hours resulted in a slight increase in the creep-rupture life when tested at $650^{\circ} \mathrm{C}$ and about a factor of two decrease at $815^{\circ} \mathrm{C}$ when compared to corresponding as-irradiated data. This additional heat treatment on the control specimens did not change the time to rupture at the lower test temperature but did increase the time to rupture about a factor of two at the higher temperature.

\section{RADIATION EFFECTS IN BeO (57063)}

Modulus-of-rupture measurements on unirradiated specimens indicated that 1 to 2 weight percent concentrations of glass-phase additives in $\mathrm{BeO}$ decrease the strength of materials of 5-micron grain size. A silica glass additive increased the strength of 20-micron grain size material throughout the range from room temperature to $1200^{\circ} \mathrm{C}$.

$\mathrm{BeO}$ specimens irradiated at $1000^{\circ} \mathrm{C}$ to dosages of 3.5 to $4.7 \times 10^{21} \mathrm{nvt}(\geq 1 \mathrm{Mev}$ ) appeared in good condition. Although open porosity measurements indicate that some microcracking occurred, the strength of the specimens of 5-micron grain sizes was equal to that of the unirradiated material while the strength of EBOR specimens appeared to have decreased about 40 percent. Expansion of the specimens of 5-micron grain size was 2 to 3 percent.

Thermal diffusivity measurements were completed on UOX-MgO specimens of 4-micron grain size and $2.9 \mathrm{~g} / \mathrm{cm}^{3}$ over the temperature range from $300^{\circ}$ to $1000^{\circ} \mathrm{C}$. The diffusivity of a specimen irradiated at $1000^{\circ} \mathrm{C}$ to $2.6 \times 10^{21} \mathrm{nvt}(\geq 1 \mathrm{Mev})$ decreased in comparison to the unirradiated specimen by amounts ranging from approximately 15 percent at $400^{\circ} \mathrm{C}$ to 4 percent at $1000^{\circ} \mathrm{C}$.

FISSION PRODUCT TRANSPORT PROCESSES IN REFRACTORY-METAL FUEL SYSTEMS (57070)

Krypton was concurrently dissolved and diffused in arc-cast tantalum cathode samples which were self-resistively heated at various temperatures, pressures, and discharge voltages while under glow discharge. Sections of $100 \AA$ and $200 \AA$ thicknesses were taken in order to establish the distribution profile of krypton in the various samples. The distribution profiles for various temperatures and grain sizes (via high-temperature annealing) gave strong indication that some complex short-circuiting mechanisms are responsible for the bulk transport of the diffusant even in the region near the surface of the sample $(<500 \AA)$.

Permeation studies on evacuated samples of arc-cast tantalum at $2400^{\circ} \mathrm{C}$ were continued. To date, the only sample penetrated by krypton probably was also penetrated by oxygen during the experiment, although the processes involved are not known.

The release of fission products which are solid in their standard reference states $\left(\mathrm{Cs}^{137}, \mathrm{Ba}^{140}, \mathrm{I}^{131}, \mathrm{Sr}^{89}, \mathrm{Ce}^{144}, \mathrm{Zr}^{95}\right)$ was determined for a $\mathrm{W}$-Mo-Re canned fuel sample irradiated for 1015 hours at $2000^{\circ} \mathrm{C}$ by means of leach data taken from the capsule and off-gas ducting. The release values of these fission products were in good agreement with those measured for $\mathrm{Xe}^{133}$ and $\mathrm{Kr}^{88,89}$ during the test. These results indicate that the release occurred via recoil from fuel contamination of the specimen surface. 
PHYSICO-CHEMICAL STUDIES OF CLAD-UO 2 IN POTENTIAL MELTDOWN ENVIRONMENTS (57075)

The initial tests of $\mathrm{Zr}-\mathrm{UO}_{2}$ reaction show that the $\mathrm{Zr}$ goes through a 3-mm thick $\mathrm{UO}_{2}$ container within 30 minutes at $2200^{\circ} \mathrm{C}$ in an $\mathrm{Ar}$ atmosphere.

The test apparatus to study the reaction between metal claddings and $\mathrm{H}_{2} \mathrm{O}$ at temperatures up to the metal melting point is being assembled and calibrated. The test apparatus for isothermal measurements of this reaction to about $1600^{\circ} \mathrm{C}$ is being assembled.

PHYSICO-CHEMICAL STUDIES OF Fe-Cr-Al CLAD FUEL SYSTEMS (57076)

This is a new task encompassing studies of reactions between oxidation-resistant $\mathrm{Fe}-$ $\mathrm{Cr}-\mathrm{Al}$ alloys and $\mathrm{UO}_{2}$ in the temperature region of $500^{\circ}$ to $1200^{\circ} \mathrm{C}$. Thus far, work has consisted of a general definition of problem areas and evaluation of several methods of approach to the work.

INTERNAL CONVERSION CERAMIC FUEL ELEMENT RESEARCH (57072)

An LITR irradiation test of BeO-coated BeO-base fuel elements containing 25 volume percent $\mathrm{UO}_{2}-\mathrm{ThO}_{2}-\mathrm{Y}_{2} \mathrm{O}_{3}$ operated at temperatures up to $1500^{\circ} \mathrm{C}$ at a fission product release level of 20 to 100 less than uncoated fuel elements.

Three ETR irradiation tests of fuel elements containing 25 volume percent $\mathrm{UO}_{2}-\mathrm{ThO}_{2}-$ $\mathrm{Y}_{2} \mathrm{O}_{3}$ continued on test at $1250^{\circ} \mathrm{C}$. Two tests have accumulated 3400 hours and one test 900 hours at the equivalent of full reactor power. 


\section{EFFECT OF RADIATION ON REFRACTORY METALS AND ALLOYS}

(57004)

The objective of this program is to determine the effect of radiation on the time-, temperature-, and stress-dependent properties of selected refractory metals and alloys, ${ }^{1}$ to identify the causes of any observed changes in these properties, and to develop remedial measures.

The experimental program to study the effects of neutron irradiation on the creep-rupture, tensile, resistivity, and hardness properties of refractory metals and alloys is continuing. In addition to studies on the above properties, theoretical calculations on the nature of the neutron-induced defects are also being performed as well as direct observations of defects by the use of the transmission electron microscope.

Some work on the measurement of the creep-rupture properties of irradiated $\mathrm{W}-25 \mathrm{Re}$ specimens at temperatures of $800^{\circ}$ to $900^{\circ} \mathrm{C}$, the hot hardness of irradiated tungsten, and theoretical studies on neutron-induced defects in bcc metals are discussed. A summary of the experimental program, test conditions, and preliminary results is presented in Table 2.1.

\section{EXPERIMENTAL PROGRAM}

Status of Irradiations

Two of the ETR series of ambient temperature capsules (GEFP2-232 and -233) to be irradiated to high dosages in the dose-dependency studies ${ }^{2}$ were fabricated and shipped to Idaho for insertion in the ETR. A third capsule (GEFP2-234) is being fabricated. The design of this new series of capsules permits a number of types and sizes of specimens to be accommodated in a single capsule. Each capsule contains seven tubes loaded with three specimens. Figure 2.1 shows the GEFP2-232 capsule. Each tube is evacuated and back-filled with helium before closure. The position of the nickel-cobalt dosimeters is evident in the photograph. GEFP2-232 contains 15 tungsten specimens: six creep-rupture, six tensile, and three resistivity specimens. GEFP2-233 contains 21 tungsten specimens: 12 tensile, six creep-rupture, and three resistivity specimens.

Capsule ORM-38 was shipped to Oak Ridge for irradiation in the ORR to a fast neutron dose of $5.4 \times 10^{19} \mathrm{nvt}$ ( $\sim 290$ hours). ORM-35 is still being irradiated in the ORR-A2 facility ( $\sim 600$ hours accumulated to date).

\section{Creep-Rupture Tests}

Results ${ }^{3}$ of creep-rupture tests on irradiated $\mathrm{W}-25 \mathrm{Re}$ specimens tested at $800^{\circ} \mathrm{C}$ and $900^{\circ} \mathrm{C}$ indicate that a significant change in flow properties occurred in this temperature range. Tests to determine the stress-dependency of the creep activation energy in this

\footnotetext{
${ }^{1}$ The experimental program on the heat-resistant metals and alloys previously reported in this section is now reported under job 57018 appearing in this series of even-numbered progress reports.

2“High-Temperature Materials Program Progress Report No. 49, Part A," GE-NMPO, GEMP-49A, July 28, 1965, Table 4.2, p. 64.

IIbid., Table 4.3, p. 66.
} 
TABLE 2.1

SUMMARY OF MAJOR EXPERIMENTS IN THE REFRACTORY METALS AND ALLOYS RADLATION E FFFETS PROGRAM

\begin{tabular}{|c|c|c|c|c|c|c|c|c|c|c|c|c|c|c|c|}
\hline \multirow[b]{2}{*}{$\begin{array}{l}\text { Exp. } \\
\text { No. }\end{array}$} & \multirow[b]{2}{*}{ Objective } & \multirow[b]{2}{*}{ Property } & \multicolumn{2}{|c|}{ Test Speeimen } & \multicolumn{4}{|c|}{ Irradiation Conditlons ${ }^{c}$} & \multicolumn{2}{|c|}{$\begin{array}{c}\text { Post- } \\
\text { Irradiation } \\
\text { Heat Treatment }\end{array}$} & \multirow{2}{*}{\multicolumn{2}{|c|}{ Test Conditions }} & \multirow{2}{*}{\multicolumn{2}{|c|}{ Percent Change In Propertyd }} & \multirow[b]{2}{*}{ Comments } \\
\hline & & & Matérlal ${ }^{\text {a }}$ Type & $\frac{\text { Lectmen }}{\text { Lusaber }}$ & $\begin{array}{l}\text { Capsule } \\
\text { Number }\end{array}$ & $\begin{array}{l}\text { Temp, } \\
{ }^{\circ} \mathrm{C}\end{array}$ & $\frac{\text { nvt, nev }}{\text { Thermal }}$ & $\frac{\text { utrons } / \mathrm{cm}^{2}}{\left(E_{n}=1 \mathrm{Mev}\right)}$ & 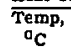 & $\begin{array}{c}\text { T7me, } \\
\mathrm{hr}\end{array}$ & & & & & \\
\hline \multirow[t]{4}{*}{1} & \multirow[t]{4}{*}{$\begin{array}{l}\text { To investigate the effects } \\
\text { of neutron irradiation on } \\
\text { the creep-rupture and } \\
\text { tensile propertes. To } \\
\text { perform supporting studes } \\
\text { on the effects of neutron } \\
\text { Irradiation on the hardness } \\
\text { and resistivity properttes. }\end{array}$} & Creep rupture & 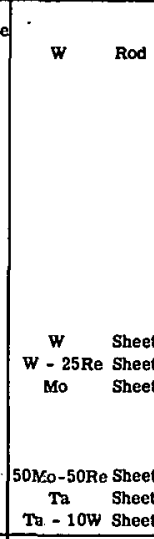 & 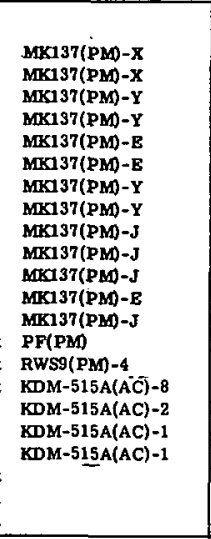 & \begin{tabular}{|l} 
ORM-4 \\
ORM-8 \\
ORM-6 \\
ORM-B \\
ORM-17 \\
ORM-19 \\
ORM-6 \\
ORM-8 \\
ORMM-19 \\
ORM-19 \\
ORM-19 \\
ORM-18 \\
ORMT-137 \\
ORM-17 \\
ORM-12 \\
ORM-20 \\
ORMM-23 \\
ORM-23 \\
ORM-13 \\
ORM-16 \\
ORM-16 \\
ORM-20 \\
ORM-23 \\
ORM-23
\end{tabular} & $\begin{array}{rl}70 & \\
70 & 8 \\
70 & \\
70 & 9 \\
70 & \\
70 & 3 \\
70 & 2 \\
70 & 8 \\
70 & 3 \\
70 & 9 \\
70 & 9 \\
1300 & 2 \\
70 & 7 \\
70 & 8 \\
70 & 5 \\
70 & 5 \\
70 & 5 \\
70 & 1 \\
70 & 1 \\
70 & 5 \\
70 & 5 \\
70 & 5\end{array}$ & $\begin{array}{l}2.2 \times 10^{18} \\
9.5 \times 10^{19} \\
2.0 \times 10^{19} \\
9.5 \times 10^{19} \\
7.5 \times 10^{19} \\
3.9 \times 10^{20} \\
2.0 \times 10^{19} \\
9.5 \times 10^{19} \\
3.9 \times 10^{20} \\
3.9 \times 10^{20} \\
3.9 \times 10^{20} \\
2.2 \times 10^{20} \\
7.5 \times 10^{19} \\
9.1 \times 10^{9} \\
3.5 \times 10^{20} \\
5.2 \times 10^{19} \\
5.5 \times 10^{19} \\
1.4 \times 10^{20} \\
1.4 \times 10^{20} \\
3.5 \times 10^{20} \\
5.2 \times 10^{19} \\
5.2 \times 10^{19}\end{array}$ & $\begin{array}{l}5.8 \times 10^{17} \\
2.5 \times 10^{19} \\
3.7 \times 10^{18} \\
2.5 \times 10^{19} \\
1.6 \times 10^{19} \\
8.2 \times 10^{19} \\
3.7 \times 10^{18} \\
2.5 \times 10^{19} \\
8.2 \times 10^{19} \\
8.2 \times 10^{19} \\
8.2 \times 10^{19} \\
1.8 \times 10^{20} \\
1.8 \times 10^{19} \\
3.2 \times 10^{19} \\
8.0 \times 10^{19} \\
1.4 \times 10^{19} \\
6.9 \times 10^{18} \\
3.7 \times 10^{19} \\
3.7 \times 10^{19} \\
8.0 \times 10^{19} \\
1.4 \times 10^{19} \\
1.4 \times 10^{19}\end{array}$ & & & $\begin{array}{l}\frac{T}{T_{1}} \mathrm{C} \\
11100 \\
1100 \\
1100 \\
1100 \\
1100 \\
1100 \\
1400 \\
1400 \\
1400 \\
1100 \\
1700 \\
800 \\
900 \\
1100 \\
1100 \\
580 \\
980 \\
580 \\
600\end{array}$ & \begin{tabular}{c|}
$\frac{\sigma\left(\mathrm{kg}^{\mathrm{g}} / \mathrm{mm}^{2}\right)}{18.34}$ \\
19.34 \\
20.35 \\
20.95 \\
18.28 \\
18.28 \\
13.01 \\
19.01 \\
10.55 \\
8.44 \\
5.62 \\
22.64 \\
37.26 \\
49.9 \\
21.09 \\
10.55 \\
21.09 \\
21.09
\end{tabular} & 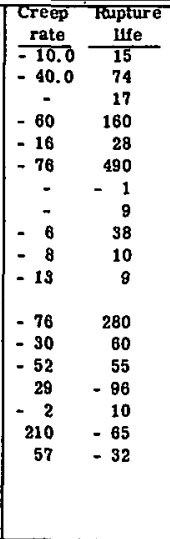 & $\begin{array}{c}\text { Blongation } \\
-1 \\
-1 \\
-7 \\
-7 \\
-10 \\
-6 \\
10 \\
14 \\
19 \\
-29 \\
-26 \\
-26 \\
8 \\
-56 \\
-4 \\
14 \\
- \\
-\end{array}$ & $\begin{array}{l}\text { To be tested. } \\
\text { To be tested. } \\
\text { To be tested. }\end{array}$ \\
\hline & & Tensile & Rod & 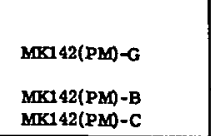 & $\begin{array}{l}33 \mathrm{MT}-138 \\
\text { ORM-9 } \\
\text { ORM-10 }\end{array}$ & $\begin{array}{l}705 \\
702 \\
708\end{array}$ & $\begin{array}{l}3.6 \times 10^{20} \\
2.8 \times 10^{19} \\
9.3 \times 10^{19}\end{array}$ & $\begin{array}{l}1.3 \times 10^{20} \\
5.1 \times 10^{18} \\
1.7 \times 10^{19}\end{array}$ & & & 371 & & \begin{tabular}{|c|c|} 
Yyeld & Tensile \\
strength Strength \\
(Brittle fracture)
\end{tabular} & Elongation & $\begin{array}{l}\text { Testlng continulug at } \\
\text { higher temperatures. } \\
\text { To be tested. } \\
\text { To be tested. }\end{array}$ \\
\hline & & Reststivity & $\begin{array}{c}\text { W Rod } \\
\text { W- 25Re Rod } \\
\text { Mo Rod } \\
\text { Mo-TZM Rod }\end{array}$ & 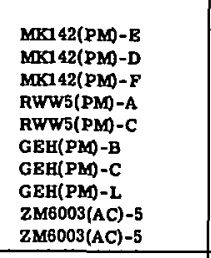 & \begin{tabular}{|l} 
ORM-7 \\
ORM-11 \\
39MT-113 \\
ORM-14 \\
33MT-113 \\
ORM-14 \\
ORM-14 \\
33MT-113 \\
ORM-18 \\
39MT-113 \\
\end{tabular} & $\begin{array}{rl}70 & 2 \\
70 & 1 \\
1300 & 2 \\
70 & 8 \\
1300 & 2 \\
70 & 6 \\
70 & 8 \\
700 & 2 \\
70 & 1 \\
700 & 2 \\
\end{array}$ & $\begin{array}{l}2.5 \times 10^{19} \\
1.2 \times 10^{20} \\
2.2 \times 10^{20} \\
8.2 \times 10^{19} \\
2.2 \times 10^{20} \\
6.2 \times 10^{19} \\
8.2 \times 10^{19} \\
2.2 \times 10^{20} \\
1.1 \times 10^{20} \\
2.2 \times 10^{20} \\
\end{array}$ & $\begin{array}{l}5.3 \times 10^{18} \\
3.3 \times 10^{19} \\
8.0 \times 10^{19} \\
1.2 \times 10^{19} \\
8.0 \times 10^{19} \\
1.2 \times 10^{19} \\
1.2 \times 10^{19} \\
8.0 \times 10^{19} \\
3.7 \times 10^{19} \\
8.0 \times 10^{19} \\
\end{array}$ & & & $\begin{array}{l}-196 \\
-186 \\
-196 \\
-196 \\
-196 \\
-196 \\
-196 \\
-196 \\
-196 \\
-196 \\
\end{array}$ & & $\begin{array}{c}\text { Reslsthrth } \\
105 \\
315 \\
39 \\
10 \\
15 \\
80 \\
118 \\
2 \\
74 \\
7 \\
\end{array}$ & & Warm-worked. \\
\hline & & Hardness & $\begin{array}{ll}\text { w } & \text { Sheet } \\
\text { Mo } & \text { Sheet }\end{array}$ & $\begin{array}{l}411-1 \\
\text { KDM-515A(AC)-M(10) }\end{array}$ & $\begin{array}{l}\text { ORM-15 } \\
\text { ORM-30 }\end{array}$ & 70 & $\begin{array}{l}\text { i. } 3 \times 10^{226} \\
\theta .2 \times 10^{10}\end{array}$ & $\begin{array}{l}3.5 \times 10^{19} \\
2.6 \times 10^{19}\end{array}$ & & & $\begin{array}{r}15 \\
650 \\
1300 \\
15 \\
300 \\
1200 \\
\end{array}$ & $\begin{array}{l}\text { Load } \\
500 \text { grams } \\
500 \text { grams }\end{array}$ & $\begin{array}{c}\text { DPH Hardne } \\
8 \\
60 \\
5 \\
18 \\
55 \\
0\end{array}$ & & $\begin{array}{l}\text { Single crystal. } \\
\text { From isochronal } \\
\text { annealliog studies. } \\
\text { Polycrystal. } \\
\text { From isocthronal } \\
\text { annealing studies. }\end{array}$ \\
\hline
\end{tabular}


TABLE 2.1 (Cont.)

SUMMARY OF MAJOR BXPBRIMBNTS IN THB RBFRACTORY METALS AND ALLOYS RADIATTON BFFECTS PROGRAM

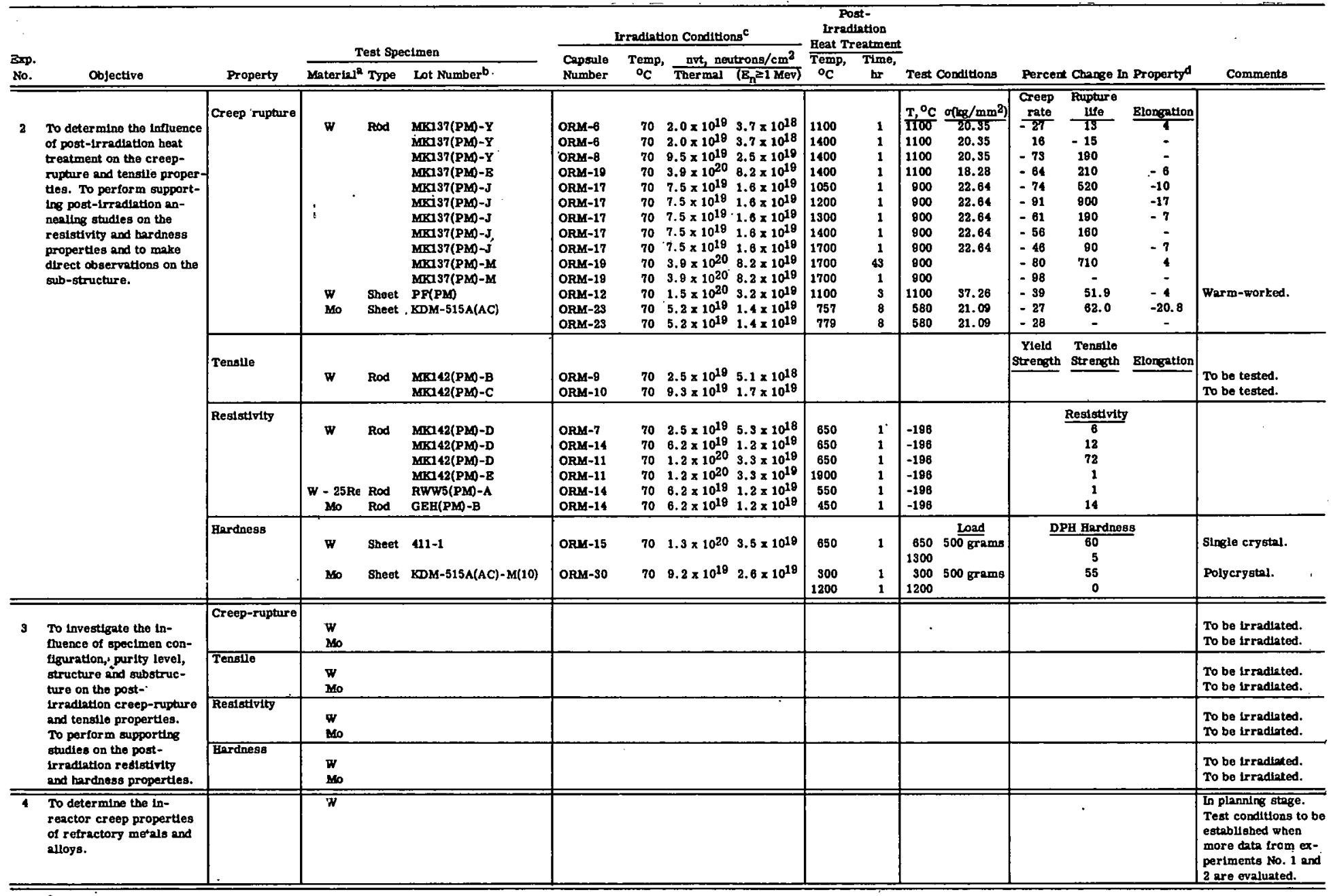

${ }_{b}^{2}$ All materi2als are in the recrystallized conditton unless otherwise noted.

Dowder. metallurgy (PHA or arc-cast (AC) processing. The last letter or number ldentifies the sheet or rod

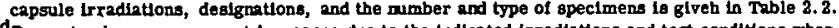

Dep compared to a corresponding unirradiated test specimen. Negative values 


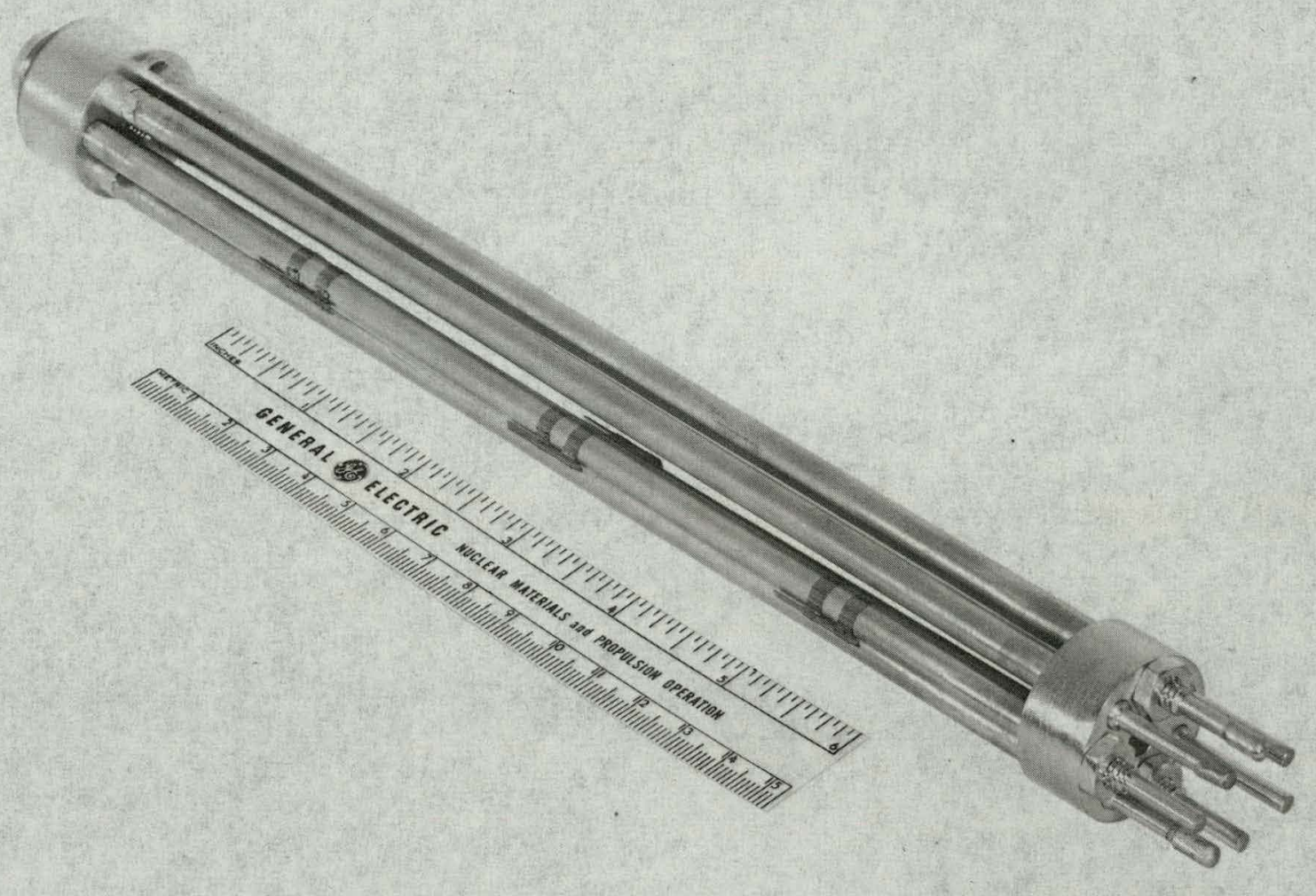

Fig. 2.1 - ETR irradiation capsule GEFP2-232 assembled and backfilled with helium gas (Neg. P65-7-9A)

temperature range are being conducted. Preliminary testing has been concentrated on control specimens fabricated from commercial W -25 Re sheet produced by powdermetallurgy techniques. Initial results indicate the creep activation energy is approxi$125 \mathrm{kcal} / \mathrm{g}$-mole in the $800^{\circ}$ to $875^{\circ} \mathrm{C}$ temperature range. Tests were begun on $\mathrm{W}-25 \mathrm{Re}$ sheet specimens produced by GE-NMPO. Irradiated specimens from the same material will be tested during the next reporting period.

\section{Hardness Tests}

Hot hardness measurements were conducted on two specimens cut from a tungsten single crystal; one was irradiated to $4.6 \times 10^{18} \mathrm{nvt}$ and the other to $2.4 \times 10^{19} \mathrm{nvt}$ $\left(E_{n} \geq 1 \mathrm{Mev}\right)$. The measurements were made over the temper ature range from $25^{\circ}$ to $1200^{\circ} \mathrm{C}$; results are shown in Figure 2.2. The room temperature hardness of the two specimens was the same although the dosages differed by a factor of 5 . At $500^{\circ} \mathrm{C}$ the higher-dosage specimen was 20 percent harder. The rate of decrease in hardness of the higher-dosage specimen between $300^{\circ}$ and $800^{\circ} \mathrm{C}$ was less than for the lowerdosage specimen. This tendency to retain the hardness to higher temperatures is believed to be due to the greater amount of rhenium formed during irradiation in the specimen receiving the higher dose.

An annealing study was performed on the specimen irradiated to $2.4 \times 10^{19}$ nvt similar to that performed on molybdenum. ${ }^{4}$ The results, shown in Figure 2.3, show a marked increase in hardness after annealing at $300^{\circ} \mathrm{C}$. On a homologous comparison, these results are in good agreement with the molybdenum data.

4'“High-Temperature Materials Program Progress Report No. 47, Part A,"' GE-NMPO, GEMP-47A, May 28, 1965, pp.94-95. 


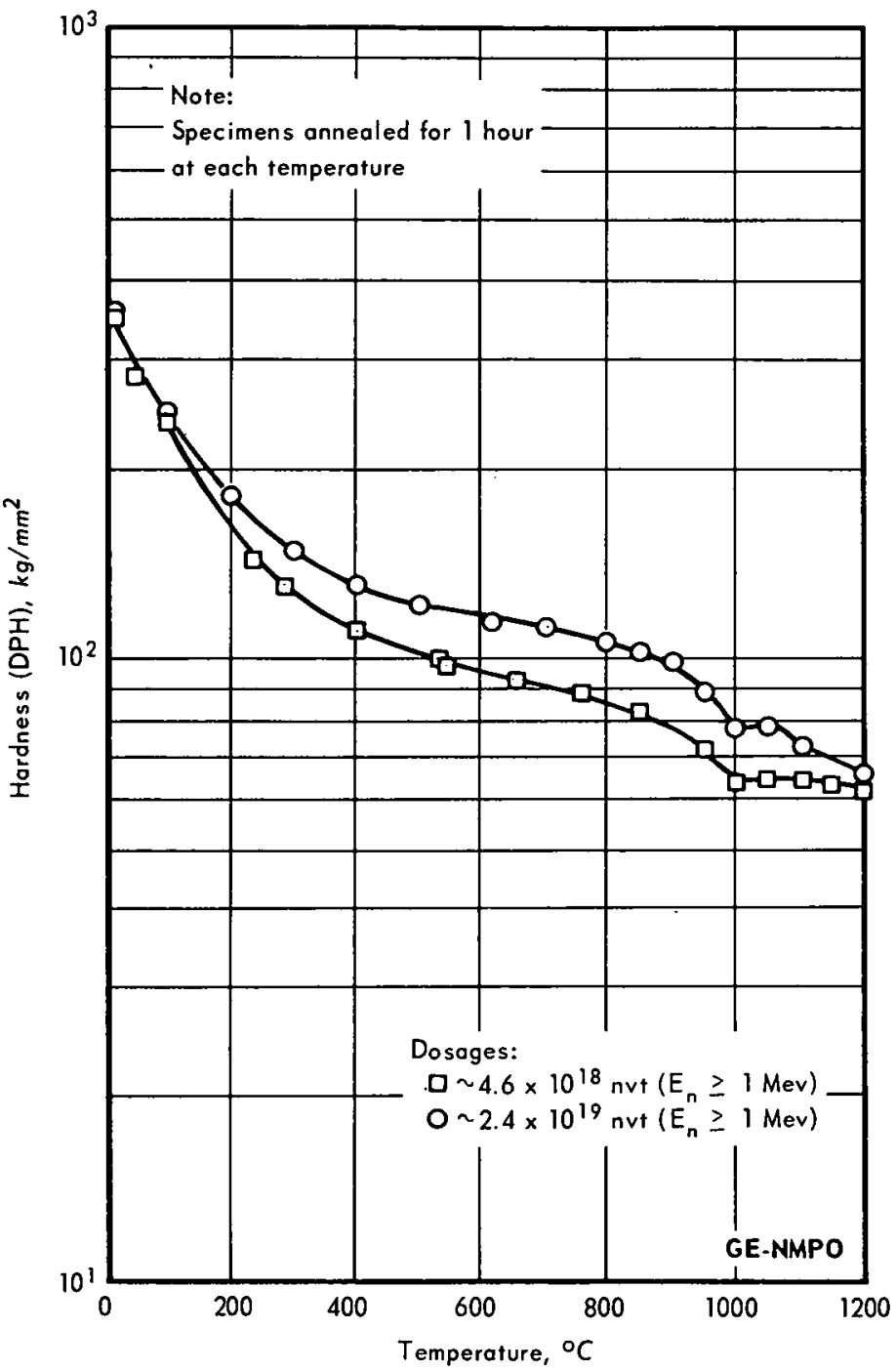

Fig. 2.2-Hardness of tungsten single crystals irradiated at reactor ambient conditions as a function of test temperature

The unirradiated control specimen from this particular cry stal will be tested during the next reporting period.

\section{Tungsten Transmutation Studies}

Studies were initiated to determine qualitatively the number of rhenium and osmium atoms produced as a result of tungsten transmutations in a thermal neutron environment. Figure 2. 4 is a flow chart illustrating the possible isotopes which are formed from tungsten in a thermal neutron flux. The corresponding nuclear data are listed in Table 2.2.

Computer calculations ${ }^{5}$ and experimental data suggest that significant quantities of rhenium atoms are produced from tungsten at thermal neutron dosages as low as $1 \times 10^{20}$ nvt. Preliminary results from radiochemical analyses also indicate that significant quantities of some short half-life isotope ( $\sim 17$ hours) of rhenium is decaying into osmium

$5_{W}$. E. Browning, Jr., and C. E. Miller, Jr., "Calculated Radiation-Induced Changes in Thermocouple Composition,"

Tomperature, Its .l/casureme'nt and Control in Science and /ndustry, Vol. 3, Part 2, Reinhold, New York, 1962, p 271 


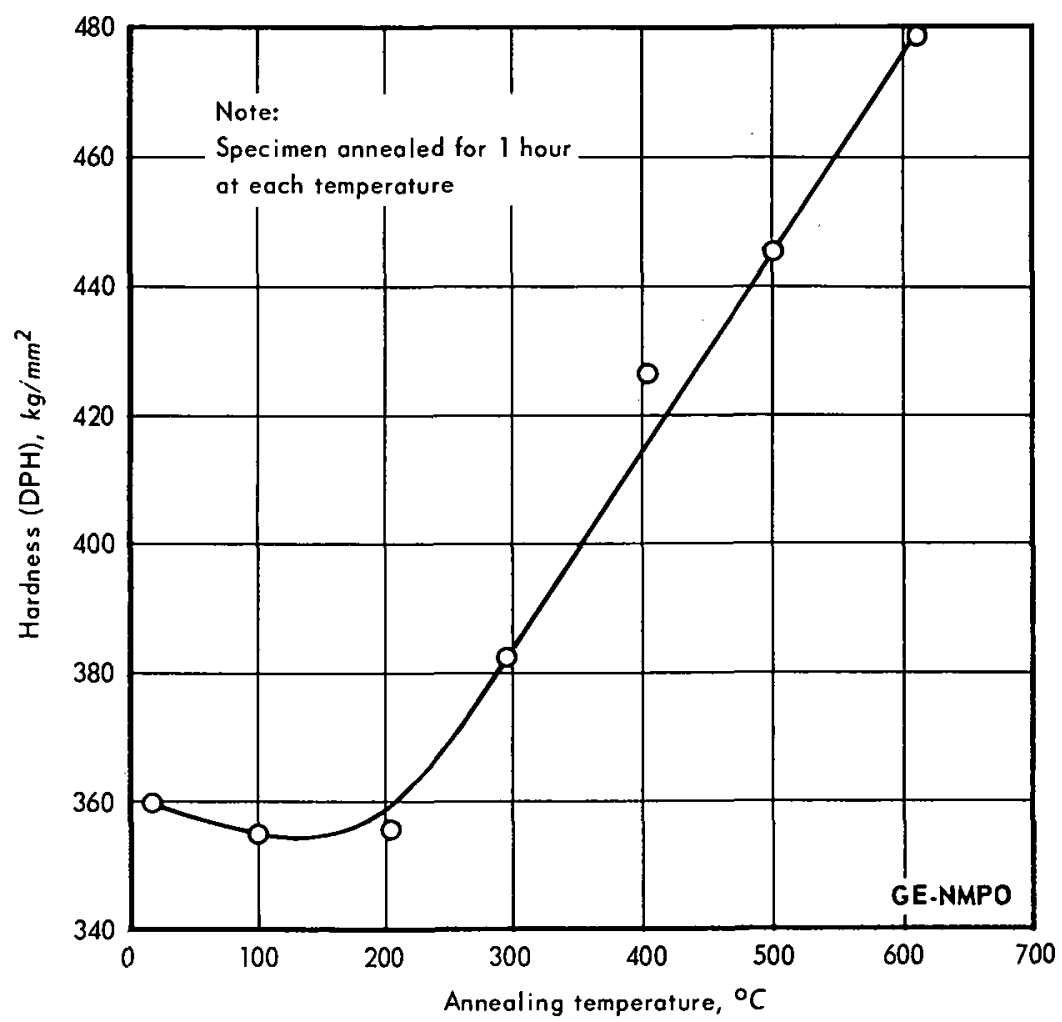

Fig. 2.3-Room-temperature hardness of a tungsten single crystal irradiated at reactor ambient temperatures to a fast neutron dose of $\sim 2.4 \times 10^{19} \mathrm{nvt}$ as a function of annealing temperature

TABLE 2.2

NUCLEAR DATA FOR THE ISOTOPES OF W, Re, AND Os

\begin{tabular}{cccc}
\hline Isotope & $\begin{array}{c}\text { Abundance, } \\
\%\end{array}$ & $\begin{array}{c}\text { Cross Section } \\
\left(\sigma_{\text {th }}\right), \text { barns }\end{array}$ & Half-Life \\
\hline $\mathrm{W}^{182}$ & 26.4 & 20 & - \\
$\mathrm{W}^{183}$ & 14.4 & 11 & - \\
$\mathrm{W}^{184}$ & 30.6 & 2 & - \\
$\mathrm{W}^{185}$ & - & - & 74 days \\
$\mathrm{W}^{186}$ & 28.4 & 40 & - \\
$\mathrm{W}^{187}$ & - & $90^{\mathrm{a}}$ & 24 hours \\
$\mathrm{W}^{188}$ & - & - & 65 days \\
$\operatorname{Re}^{185}$ & 37.1 & 100 & - \\
$\operatorname{Re}^{186}$ & - & - & 91 hours \\
$\operatorname{Re}^{187}$ & 62.9 & 69 & - \\
$\operatorname{Re}^{188}$ & - & - & 17 hours \\
$\mathrm{Os}^{186}$ & 1.6 & $\sim 0$ & - \\
$\mathrm{Os}^{188}$ & 13.0 & $\sim 0$ & - \\
\hline
\end{tabular}

${ }^{a}$ Calculations for the formation of Re and Os atoms also assume values of 900 and 9000 barns for this reaction. 
$\begin{array}{ll}\text { GE-NMPO } & \text { Key; } \\ \downarrow & \begin{array}{l}\text { Radiooctive } \beta \text { decay } \\ \text { Transmutation by }(n, y) \text { reaction }\end{array}\end{array}$

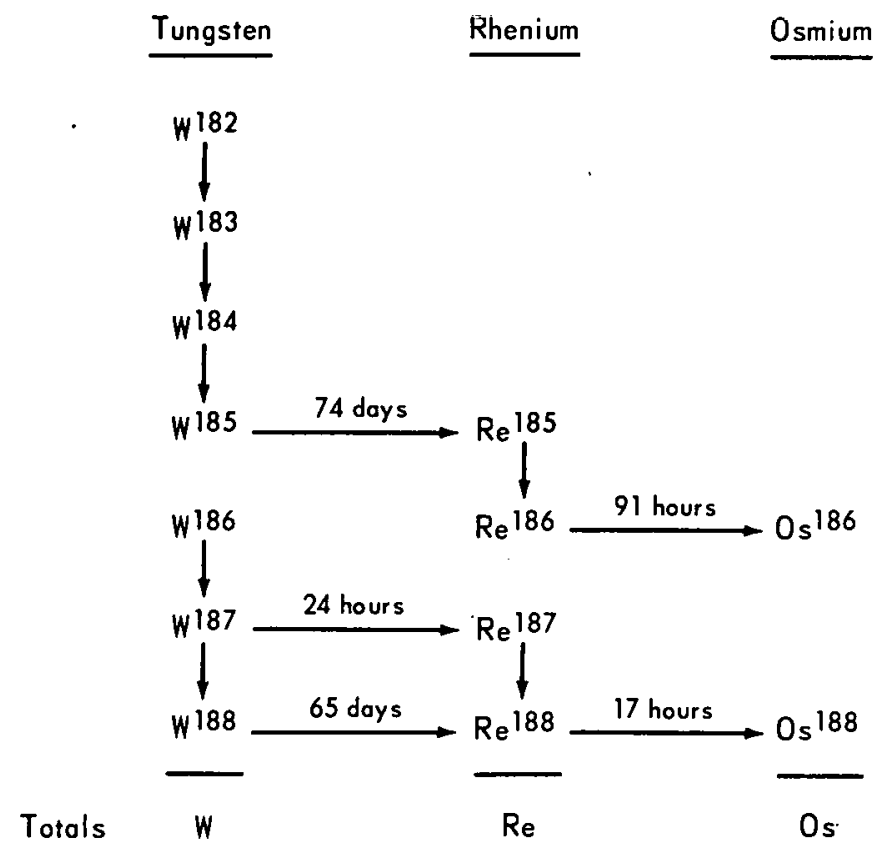

Fig. 2.4-Possible isotopes formed from tungsten in o thermal neutron environment

atoms. This rhenium activity was evident when a rhenium separation was made from a solution of irradiated tungsten samples. Since the chemical analysis was performed approximately a year after the tungsten specimens were irradiated, it appeared that Os 188 was being formed as a result of the decay of $R^{188}$. The presence of $R^{188}$ would, therefore, probably be due to the $\beta$ decay of the 65 -day $W^{188}$ isotope which is formed by the $(n, \gamma)$ reaction with $W^{187}$.

Recent calculations were performed by ORNL personnel ${ }^{6}$ to determine the number of rhenium and osmium atoms formed from tungsten in a thermal neutron flux of $1 \times 10^{14} \mathrm{nv}$. A radiochemical analysis indicated that a relatively high osmium concentration may have been present; this indicates that the cross section of 90 barns reported in the literature for the $\mathrm{W}^{187}(\mathrm{n}, \gamma) \mathrm{W}^{188}$ reaction may be too low and that a high cross section, possibly a resonance reaction, may be present. Therefore, the calculations were performed assuming cross section values of 90,900 , and 9000 barns for $\mathrm{W}^{187}$ to determine the influence of this reaction on the total osmium produced as a result of transmutations. Preliminary results of these computer calculations for the atom fractions of rhenium and osmium are presented in Figures 2.5 and 2.6, respectively. These figures show that the increase by a factor of 100 in the $w^{187}$ cross section did not significantly change the number of rhenium atoms formed but did increase the number of osmium atoms by a factor of 2.5 at zero time after the end of the exposure.

It should be pointed out that the data represent the formation of these two isotopes as a function of the time that the tungsten material is exposed in a constant thermal neutron flux of $1 \times 10^{14} \mathrm{nv}$. When the specimens a.re removed from the neutron environment,

${ }^{6}$ C. W. Miller, Jr., Reactor Chemistry Division, Oak Ridge National Laboratory, Oak Ridge, Tennessee. 


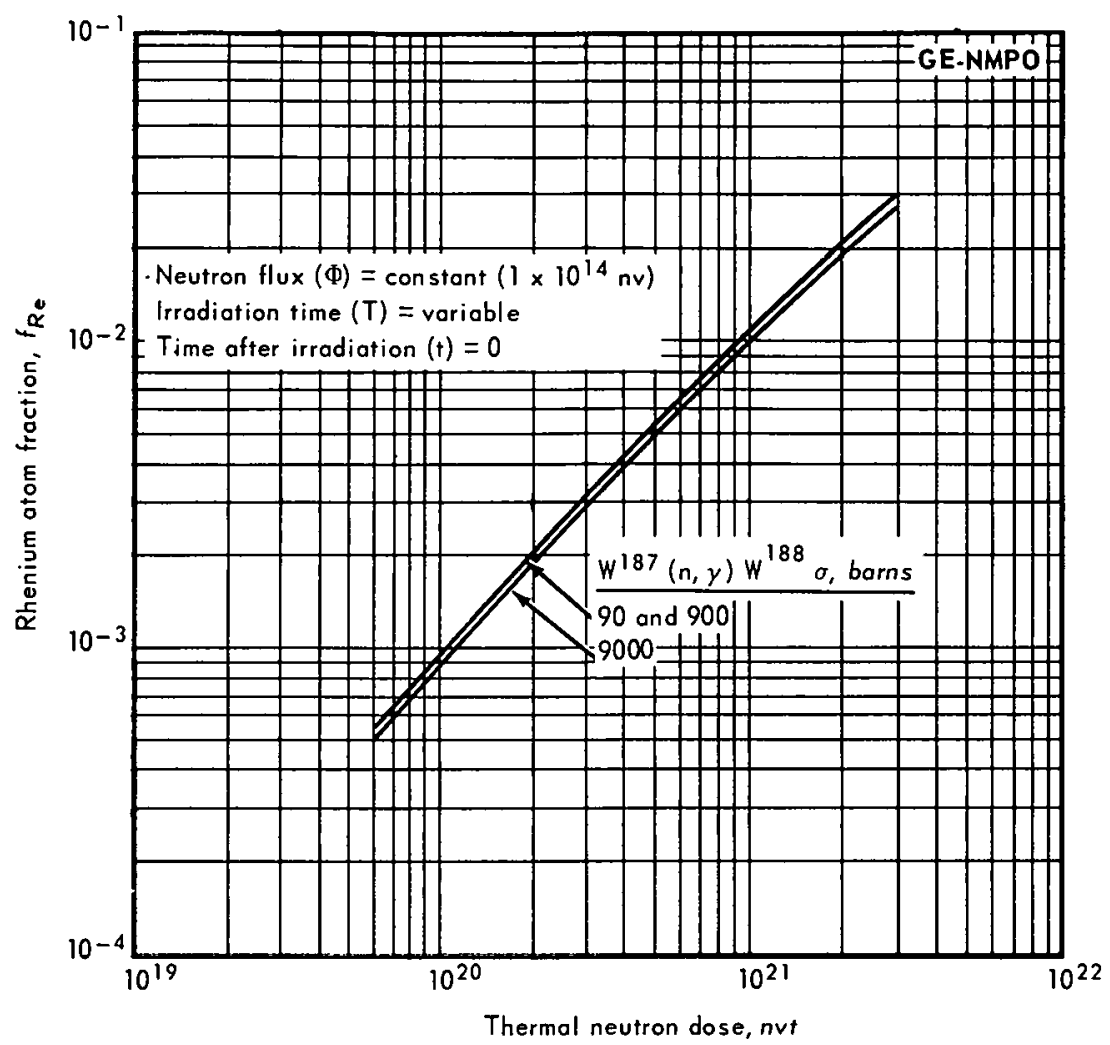

Fig. 2.5 - Production of rhenium atoms as a result of transmutations from tungsten for various values of the $W^{187}(n, y)$ w 188 reaction cross section

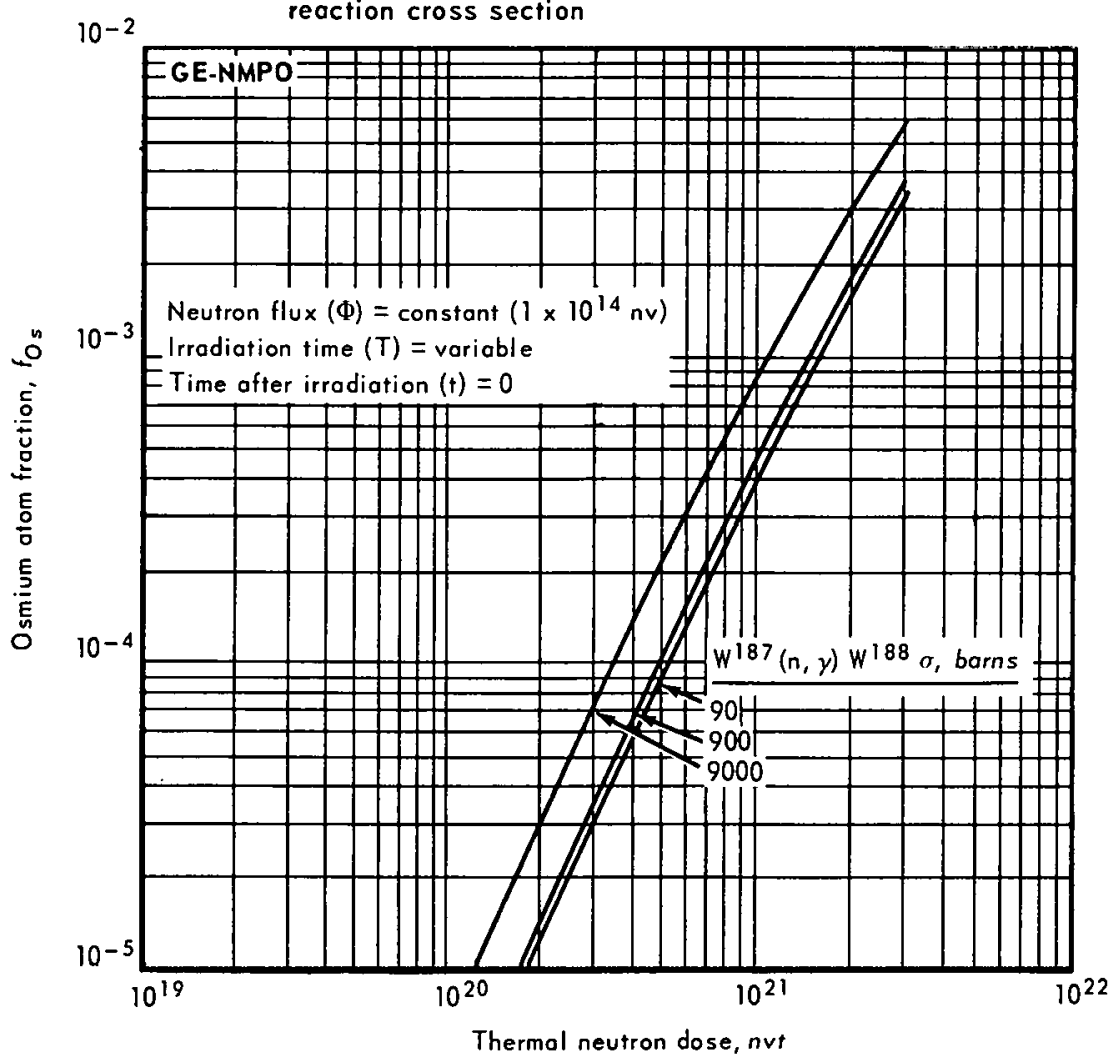

Fig. 2.6-Production of osmium atoms as a result of transmutations from tungsten for various values of the $W^{187}(n, y) W^{188}$ reaction cross section 
there will be a continual increase in the number of rhenium and osmium atoms as a result of the decay of the tungsten isotopes (74- and 65-day half-lives) until equilibrium concentration levels have been reached. For instance, for a thermal neutron dose of $2 \times 10^{20}$ nvt ( $\sim 23$ days at a flux of $\left.1 \times 10^{14} \mathrm{nv}\right)$ the rhenium atom concentration is about 0.12 percent; this concentration approaches 0.5 percent after most of the tungsten isotopes have decayed. Further computer calculations are being performed at ORNL to determine the concentration of these isotopes for various reactor operating times, shutdown times, and neutron flux values.

\section{FUNDAMENTAL STUDIES}

\section{Introduction}

The mechanical properties of an irradiated metallic specimen are determined by interactions among dislocations, impurity atoms, vacancies, and interstitials. ${ }^{7-9}$ These interactions depend strongly upon the structure and deployment of defect clusters and defect - impurity atom complexes at the atomic dimension scale of observation. This indicates that an absolute computational method should be used if damage calculations are to be of significant service in the interpretation of mechanical property changes caused by irradiation. In this context, an absolute method is one which gives the spatial distribution of vacancies and interstitials produced by irradiation at the level of atomic dimensions. This section describes the application of an absolute method of computing the number of atomic displacements produced per unit exposure in neutron-irradiated $\alpha$-iron specimens. The development and use of this approach was motivated by an interest in the interpretation of irradiation effects data on the mechanical properties of metals. The calculations were performed by simulating atomic elastic collision cascades in the exact bcc atomic array of $\alpha$-iron on an IBM 7094 computer at $0^{\circ} \mathrm{K}$. The collection of vacancies and interstitials produced by such a cascade in $\alpha$-iron is called a displacement spike. ${ }^{10}$

The Erginsoy - Vineyard interatomic potential ${ }^{11}$ was used to characterize atomic col lisions in the cascade simulations. The energy spectrum and spatial distribution of primary knock-on atoms (PKA) displaced by neutrons, which initiate these cascades, were obtained by simulating neutron collision chains in an $\alpha$-iron rod $6.3 \mathrm{~cm}$ long and $0.28 \mathrm{~cm}$ in diameter. As shown elsewhere ${ }^{12}$ the PKA energy spectrum results for this particular rod also apply to rods with diameters ranging from 0.05 to $0.5 \mathrm{~cm}$ and with lengths greater than $.5 \mathrm{~cm}$. This computational procedure accounts for the effects of the neutron energy spectrum, neutron angular distribution, specimen size, crystal structure, and current damage state upon the production and distribution of new damage. ${ }^{12}$ An estimate of the damage state produced at a finite irradiation temperature $\mathrm{T}$ was made by annealing displacement spikes, initially produced at $0^{\circ} \mathrm{K}$, on a computer at temperature $\mathrm{T}$.

Defects produced by irradiation are believed to cause hardening in the same way as do solute atom aggregates, ${ }^{13}$ namely, by impeding the movement of dislocations. As pointed

${ }^{7}$ D. S. Billington and J. H. Crawford, Jr., Radiation Damage in Solids, Princeton University Press, New Jersey, 1961.

${ }^{8}$ G. J. Dienes and G. H. Vineyard, Radiation Effects in Solids, Interscience, New York, 1957.

${ }^{9}$ D. K. Holmes, "Radiation Damage in Non-Fissionable Metals," The Interaction of Radiation with Solids, edited by

R. Strumane, J. Nihoul, R. Gevers, and S. Amelinckx, North Holland Publishing Company, Amsterdam, Netherlands, 1964.

${ }^{10} \mathrm{~J}$. A. Brinkman, "Production of Atomic Displacements by High-Energy Particles," American Journal of Physics, Vol. 24, 1956, p. 246.

${ }^{11}$ C. Erginsoy, G. H. Vineyard, and A. Englert, "Dynamics of Radiation Damage in a Body-Centered Cubic Lattice," Physical Review, Vol. 133, January 1964, p. A595.

${ }^{12}$ J. R. Beeler, Jr., "Primary Damage State in Neutron-Irradiated Iron," Journal of Applied Physics, Vol. 35, July 1964, p. 2226.

${ }^{13}$ R. L. Fleischer, "Solid Solution Hardening," The Strength of Metals, Reinhold Press, New York, 1962. 
out by Fleischer, ${ }^{14-17}$ any deviation from a perfect crystal structure acts as a barrier to dislocation motion with an asymmetrical distortion tending to be a more effective barrier than a symmetrical one. Figure 2.7 is a schematic of a dislocation line held in a minimum energy configuration by barriers. Our results, in conjunction with experimental data of Harries, et al. ${ }^{18,19}$ indicate that irradiation hardening in neutron-irradiated ferritic steels is associated with the displacement spike density produced by PKA's with energies above $3 \mathrm{kev}$. This model for the source of irradiation hardening is similar in concept to the PKA threshold energy model proposed by Harries, et al. ${ }^{18}$ and is closely related to the cluster population model of Williamson and Edmondson. ${ }^{20}$

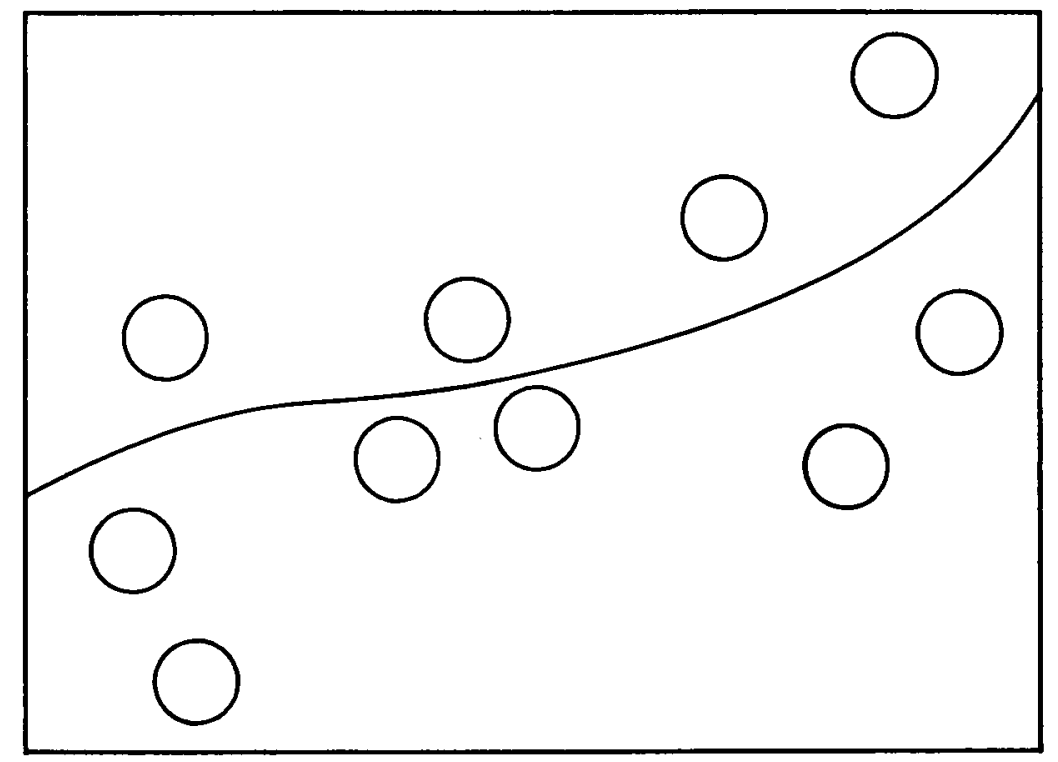

Fig. 2.7 - A dislocation line held in a minimum energy configuration by barriers

The shape of a displacement spike produced by a collision cascade in $\alpha$-iron, initiated by a $15-\mathrm{kev}$ PKA, is depicted in Figure 2. 8. Each block section in this figure approximates the volume of the damaged region produced in four successive $\{002\}$ planes. The thickness of each section, therefore, corresponds to two lattice constants $(\sim 5.7 \AA)$. A detailed description of how to interpret this three-dimensional, stack-block representation of a displacement spike is given later. At this point it is sufficient to state that the spike shapes were always irregular. Hence, the geometric cross sections of the distorted crystal region barriers, associated with displacement spikes in an irradiated specimen, might manifest themselves in the slip plane of a dislocation, as shown in Figure 2.9.

${ }^{14}$ R. L. Fleischer, "Substitutional Solution Hardening," Acıa Metallurgica, Vol. 11, March 1963, p. 203.

${ }^{15}$ R. L. Fleischer, "Rapid Solution Hardening Dislocation Mobility, and the Flow Stress of Crystals," Journal of Applied Physics, Vol. 33, December 1962, p. 3504.

${ }^{16}$ R. L. Fleischer, "Solution Hardening by Tetragonal Distortions: Application to Irradiation Hardening in F.C.C. Crystals," Acta Metallurgica, Vol. 10, September 1962, p. 835.

${ }^{17}$ R. L. Fleischer, "Effects of Non-Uniformities on the Hardening of Crystals," Acta Iletallurgica, Vol. 8, September 1960, p. 598.

${ }^{18}$ D. R. Harries, P. J. Barton, and S. B. Wright, "Effects of Neutron Spectrum and Dose Rate on Radiation Hardening and Embrittlement in Steels," Journal of the British Nuclear Energy Society, Vol. 2, 1963, p. 398.

${ }^{19} \mathrm{~S}$. B. Wright and D. R. Harries, private communication.

${ }^{20} \mathrm{G}$. K. Williamson and B. Edmondson, quoted by Harries, Bagley, Bell, Gibson, Gillis, Pfeil, and Wright in "Irradiation Behavior of Steel as a Structural and Cladding Material," Geneva Conference, 1964. 


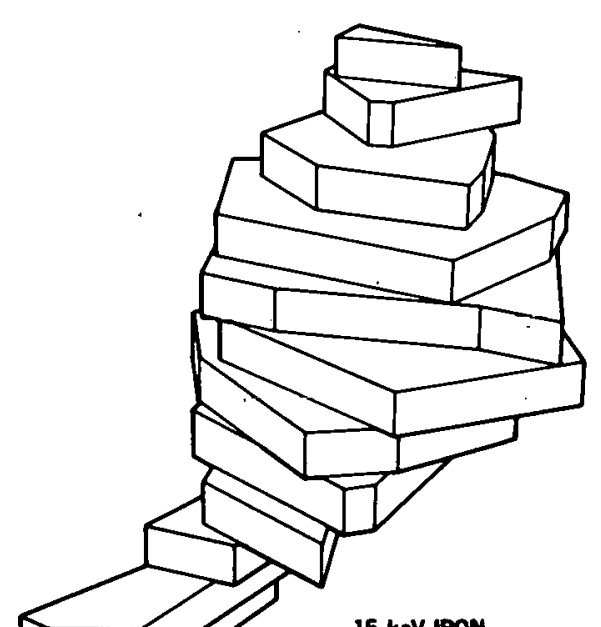

Fig. 2.8 - Block section representation of a 15-kev displacement spike in (1) $\alpha$-iron

Fig. 2.9 - Displacement spike geometrical cross sections in the slip plane $\checkmark$ of a dislocation in $\alpha$-iron.

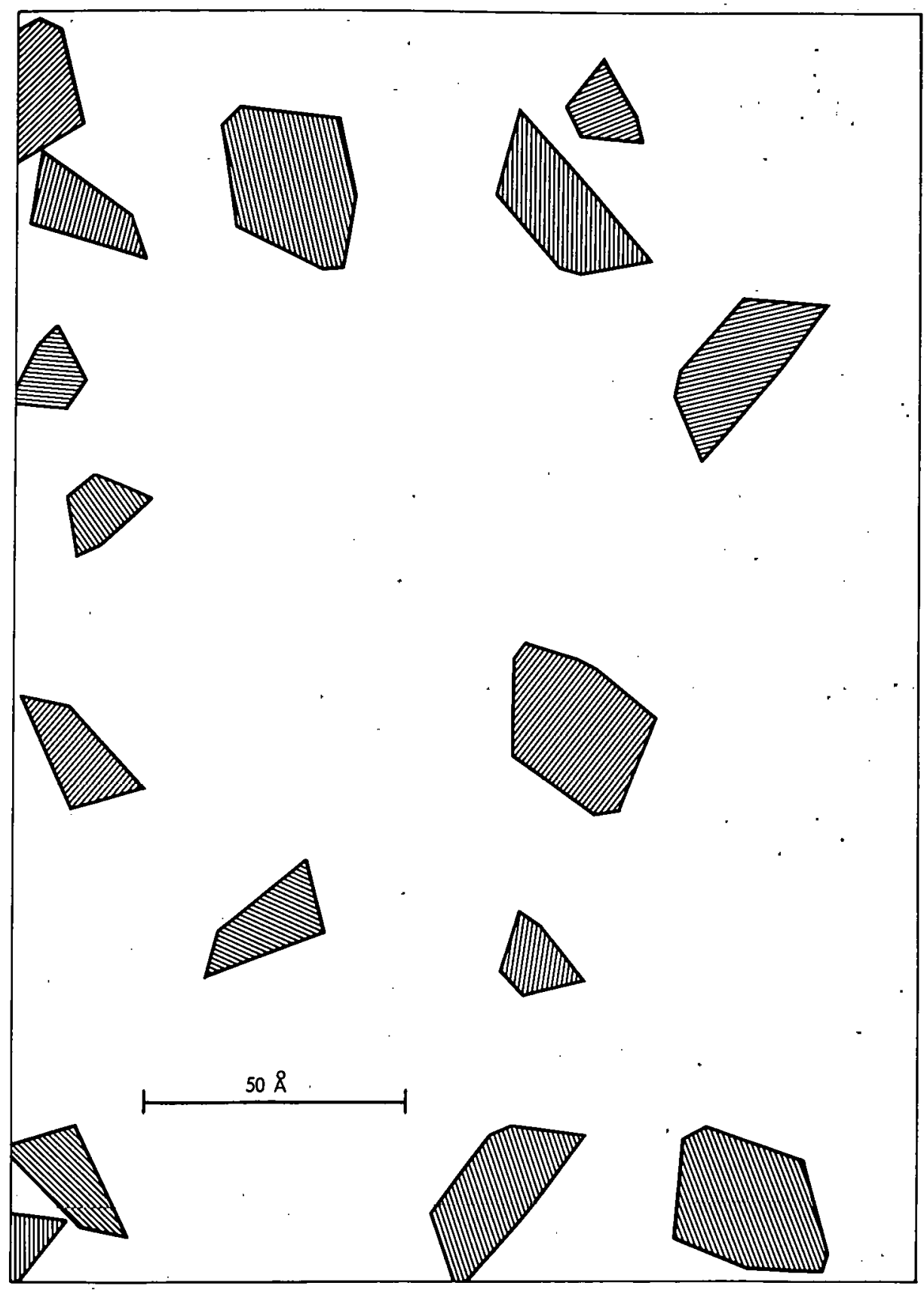


Computational Model and Procedure

Detailed descriptions of the computational model and procedure have been published previously. ${ }^{12,21}$ For the convenience of the reader, however, it is appropriate to remark that (1) it was assumed that a collision cascade can be represented as a branching sequence of binary atomic collision events, (2) all collision events were determined by the Erginsoy Vineyard potential, ${ }^{11}$ and (3) all vacancy - interstitial pairs formed which were unstable at $0^{\circ} \mathrm{K}$, in terms of the stability criteria of Erginsoy, et al., were annihilated and not counted in the displaced-atom tally.

\section{Displacement Spike Characteristics}

A fundamental entity in the discussion of a displacement spike is the distribution of collided atoms $\mathrm{s}^{22}$ in the associated collision cascade. Some atoms are hit with sufficient force to be knocked out of their normal positions in the metallic lattice, while others are merely disturbed somewhat, but not hit hard enough to be forced out of their normal position potential energy well. An average of about $3 \mathrm{ev}$ was deposited per atomic site in a collided atomic volume in $\alpha$-iron as shown in Figure 2.10. The map is a [001] projection of all collided-atom positions in four successive (002) planes. Filled circles represent atoms which were hit hard enough to be forced out of their normal positions. Filled circles bounded by a square symbol denote the positions of vacancies, i. e., the initial position of atoms which were later permanently displaced. All other filled circles represent atomic positions which were vacated and subsequently re-occupied, but not necessarily by the same atom which were originally located at a particular position. Any atom receiving more than twice the sublimation energy $\left(2 \mathrm{E}_{\mathrm{S}}=8 \mathrm{ev}\right.$ in $\alpha$-iron $\left.{ }^{23}\right)$ was considered to be forced out of its normal position, at least temporarily. It was found that an effective energy transfer of about $45 \mathrm{ev}$ was required to produce a permanent displacement. ${ }^{24}$ Figure 2.11 is a map of the vacancy (open square) and interstitial atomic (filled circles) deployment in the same region concerned in Figure 2.10. The dashed line through the peripheral defects in Figure 2.11 defines how the shapes of the block sections in Figure 2.8 were determined.

Vacancy and interstitials tend to be segregated in a displacement spike. In addition, a marked unbalance exists between the vacancy and interstitial populations within individual sub-regions of a spike, even though the total vacancy and interstitial populations are equal for the spike as a whole. Roughly speaking, defect segregation occurs in the form of an interstitial-rich blanket at the spike surface which encloses a vacancy-rich interior. Spike models and damage maps, such as those in Figures 2.8 and 2.11, respectively, can be used to frame a more accurate description of vacancy - interstitial segregation. As mentioned before, the spike volume can be approximated as a stack of block sections with a common thickness (2 lattice constants), as in Figure 2. 8. When each section is examined individually, interstitials are found to be deployed more at the periphery of the associated damage map, for a section through the centroid of the spike, than in its interior. The converse is true for vacancies. This type of defect segregation is illustrated in Figure 2.11 which gives the damage distribution in a section through the

${ }^{21}$ J. R. Beeler, Jr. and D. G. Besco, "Range and Damage Effects of Tunnel Trajectories in a Wurtzite Structure," Journal of Applied Physics, Vol. 34, September 1963, p. 2873.

${ }^{22}$ In a strict sense a "collided atom" must be defined here as an atom which experienced a collision in the particular cascade simulation given by our binary collision approximation. A less exact but more informative description, appropriate to more than 99.9 percent of the instances concerned, would designate any atom receiving more than $0.005 \mathrm{ev}$ in a collision as a collided atom.

${ }^{23}$ D. E. Harrison, Jr. and D. P. Magnuson, "Sputtering Thresholds," The Physical Review, Vol. 122, June 1961, p. 1421.

${ }^{24}$ J. R. Beeler, Jr., "Displacement Spikes in $\alpha$-Iron and Copper," Bulletin of the:American Physical Society, Vol. 10, HD7, March 1965, p. 361. 


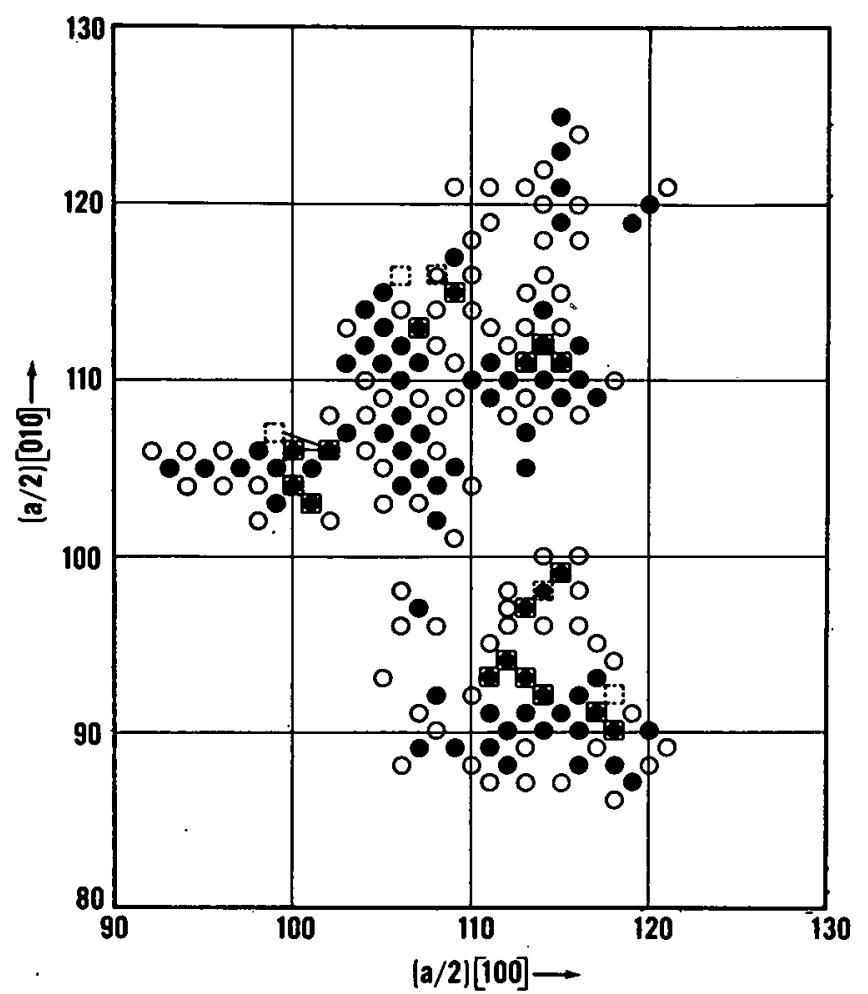

Fig. 2.10 - Collided atom distribution map for the center section of a 5-ker displacement spike in $\alpha$-iron

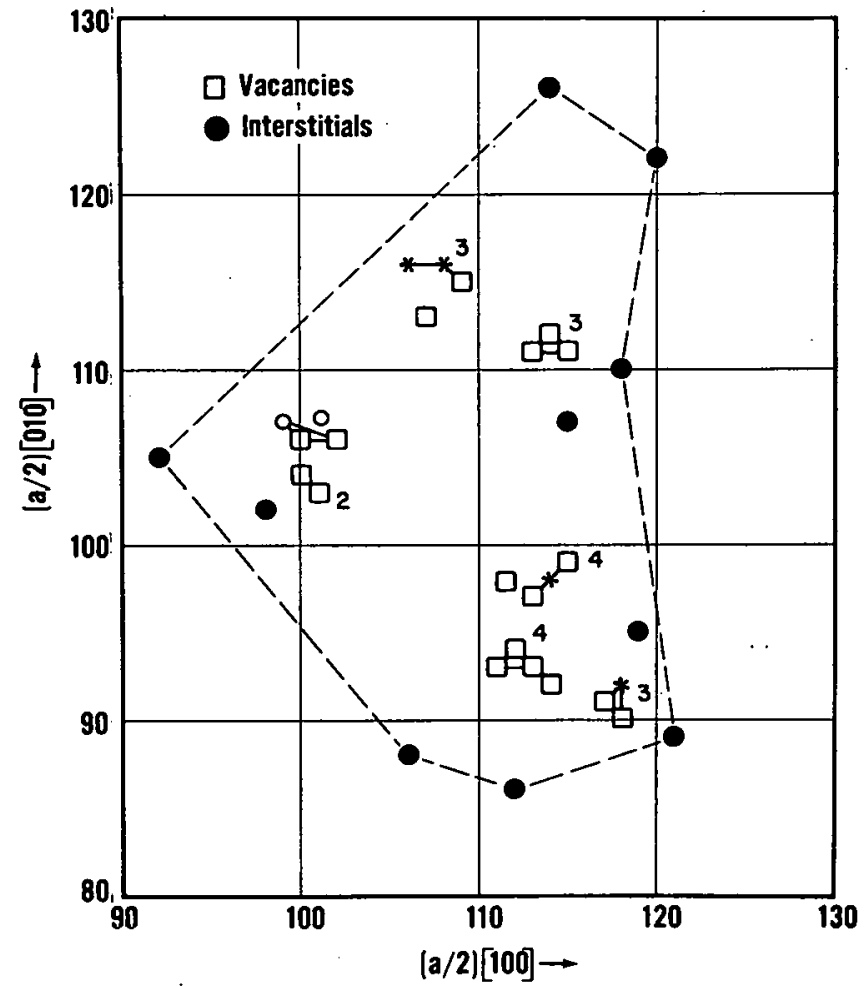

Fig. 2.11-Voconcy and interstitial atom deployment in the section shown in Figure 2.10 
centroid of a 5-kev displacement spike in $\alpha$-iron. The thickness of this section is 2 lattice constants. The local unbalance between the vacancy and the interstitial populations mentioned above is also illustrated by Figure 2.11. (Note that it contains 18 vacancies and 10 interstitials.) In a section at or near the centroid of a spike, the vacancy population is usually from 1.5 to 2.5 times the interstitial population. Proceeding away from the centroid, the relative number of interstitials increases; sections at the ends of a spike are interstitial-rich. This type of defect deployment would be expected to favor interstitial cluster and vacancy cluster formation as a result of point defect migration. This indeed occurred in our simulations of point defect annealing in a displacement spike at a finite temperature.

A three-dimensional representation of a collided atomic volume is given in Figure 2.12. Part (a) is a top view (looking along the negative Z-direction), part (b) is a view along the positive $\mathrm{X}$-direction, and part (c) is that seen along the negative $\mathrm{X}$-direction. The collided atomic volume is irregular, multiply-connected, and tends to propagate primarily with $<110>$ directions. It is within such a volume that the average energy deposition is about $3 \mathrm{ev}$ per atomic volume. It is possible that atomic re-arrangement processes and solid state chemical reaction rates would be enhanced in the collided atomic volume by virtue of the local excitation of the crystal lattice in this region. In this regard, Vineyard ${ }^{25}$ has computed isotherms in collided atomic volumes of low-energy cascades as a function of time. Such enhancement would affect the formation of impurity aggregates, for example. Displacement Production

Ninety-six independent collision cascades were run for each of several PKA energies in the range from 0.5 to $20 \mathrm{kev}$. Each initiating PKA was started off from a normal lattice site with an initial direction selected at random from an isotropic distribution. The average total number of displacements, $\nu(E)$, in a displacement spike produced at $0^{\circ} \mathrm{K}$ by a PKA with energy $E$ was obtained by taking a simple average over the 96 spikes run for that energy. It was found that $\nu(E)$ is given by:

$$
\nu(E)=K(E) E
$$

where

$$
K(E)=12.33\left[1-0.0411\left(\log _{e} E\right)\right]
$$

with $E$ being expressed in kev. $K(E)$ is the average number of displacements per unit PKA energy and is called the displacement efficiency. Figure 2.13 gives $\nu(E)=K(E) E$ from the present study and that predicted by the Kinchin - Pease model. ${ }^{26}$ The effect of crystal structure upon displacement production is explicitly considered in the present study but not in the Kinchin - Pease model. Hence, the difference between the two curves in Figure 2.13 represents the general effect of crystal structure on depressing displacement production, relative to that predicted for a structureless solid with the same average atomic density. The displacement function $\nu(E)$ was combined with the number of PKA's produced per unit volume per unit neutron exposure to give the total displacement density per unit neutron exposure. In particular, the displacement density $d\left(E_{N}\right)$ for a given neutron energy $\mathrm{E}_{\mathrm{N}}$ is,

$$
d\left(E_{N}\right)=y\left(E_{N}\right) \int(E) f\left(E ; E_{N}\right) d E
$$

where $y\left(E_{N}\right)$ is the number of PKA's produced per unit volume per unit exposure of neutrons with energy $E_{N}$, and $f\left(E ; E_{N}\right) d E$ is the fraction of these PKA's produced with an energy in the interval $d E$ at $E$. Both $y\left(E_{N}\right)$ and $f\left(E ; E_{N}\right)$ were computed by simulating neutron collision histories through the specimen concerned in a Monte Carlo calculation.

${ }^{23}$ G. H. Vineyard, "General Introduction," Discussions of the Faraday Soctety, No. 31, 1981, p. 1.

${ }^{26}$ G. H. Kinchin and R. S. Pease, Reports Progress in Physics, Vol. 18, 1955, p. 1. 


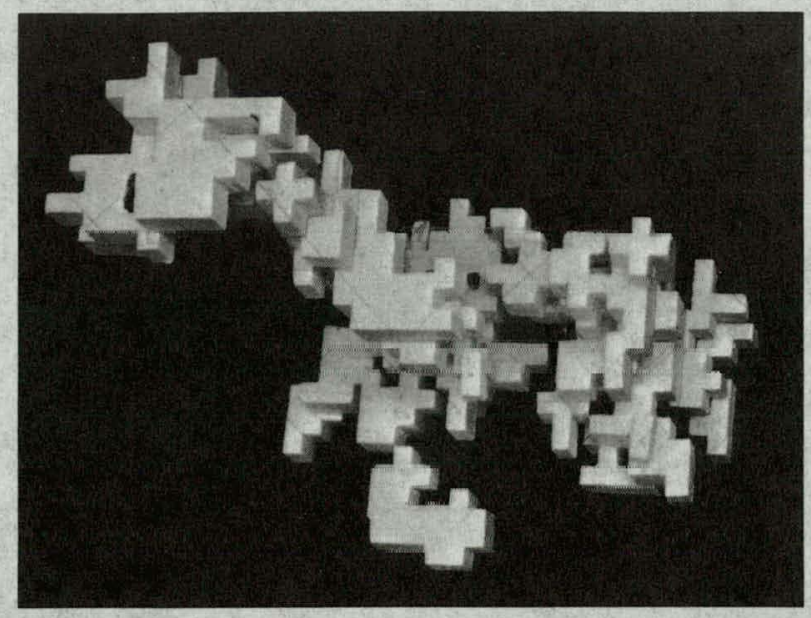

(a) Top view along the negative $Z$-direction

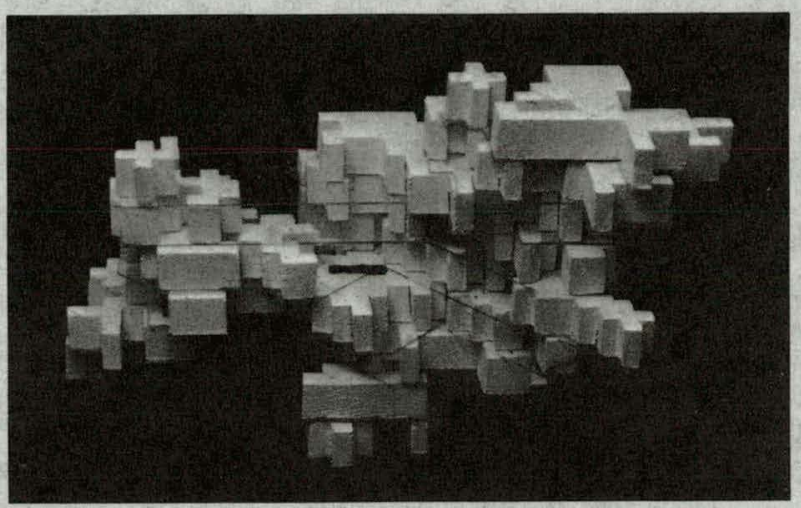

(c) View along the negative $X$-direction.

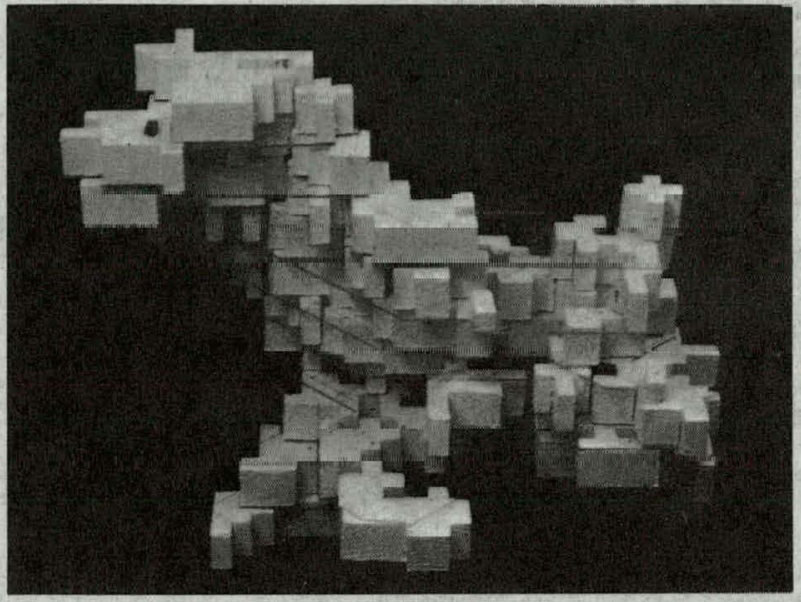

(b) View along the positive $X$-direction

Fig. 2.12-A three-dimensional model of a collided atom volume for a $5-k e v$ displacement spike. Note the general $<110>$ orientation of the spike.

The quantities $\mathrm{y}$ and $\mathrm{d}$ are plotted in Figure 2.14 as functions of neutron energy for a square base $\alpha$-iron column $6.33 \mathrm{~cm}$ long and having a base dimension of $0.28 \mathrm{~cm}$. The solid curves are for elastic neutron scattering only. Above $1 \mathrm{Mev}$, both densities are significantly dimenished by inelastic neutron scattering. The displaced-atom and displacement-spike densities obtained when the effects of mixed inelastic and elastic neutron scattering are accounted for are given by the dashed curves. These curves can also be used to predict the density of vacancy and interstitial clusters produced directly by a collision at $0^{\circ} \mathrm{K}$, i. e., without the aid of thermally activated defect migration in the manner explained below.

The number of vacancies and the number of interstitials produced in a displacement spike are equal and their common value is termed the number of atomic displacements. The vacancy population in a displacement spike is distributed among the different $\mathrm{n}$ vacancy clusters as described by Table 2.3. This table gives the fractions of all vacancies which appear in n-vacancy clusters as a function of the energy of the initiating PKA. 


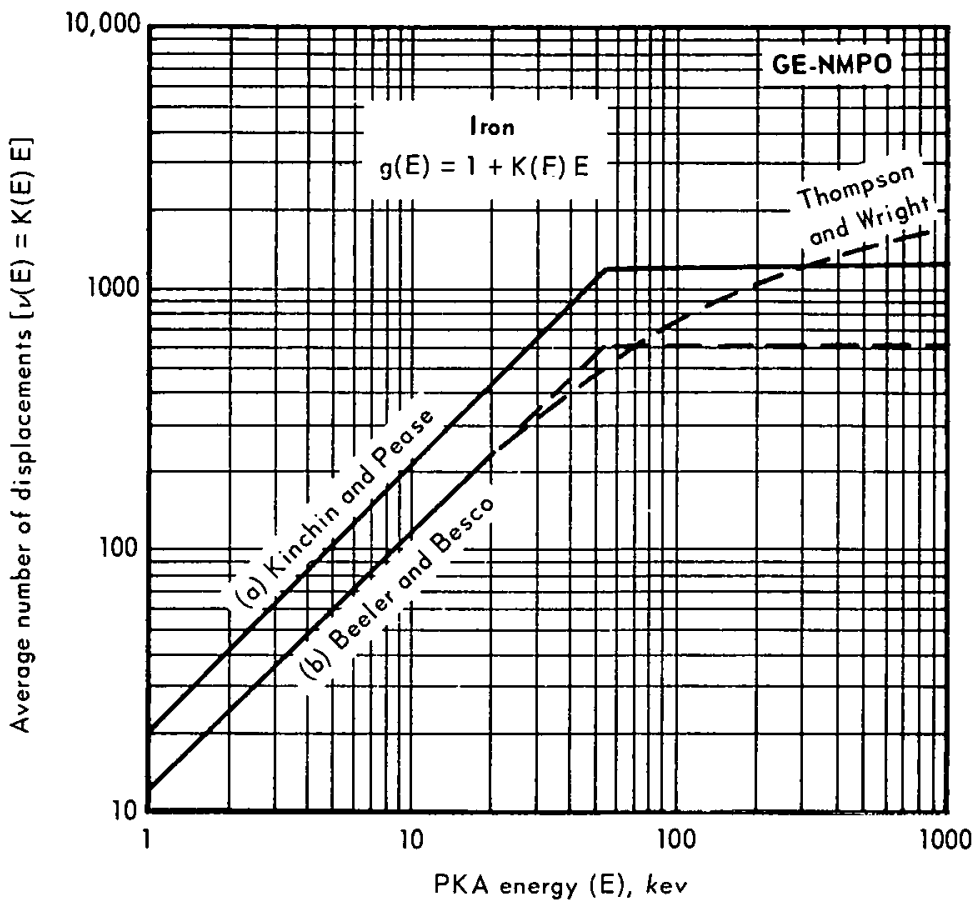

Fig. 2.13-Average number of displacements $\nu(E)=K(E) E$ in a displacement spike produced by a PKA atom with energy $E$. (o) Kinchin-Pease theory, (b) present study.

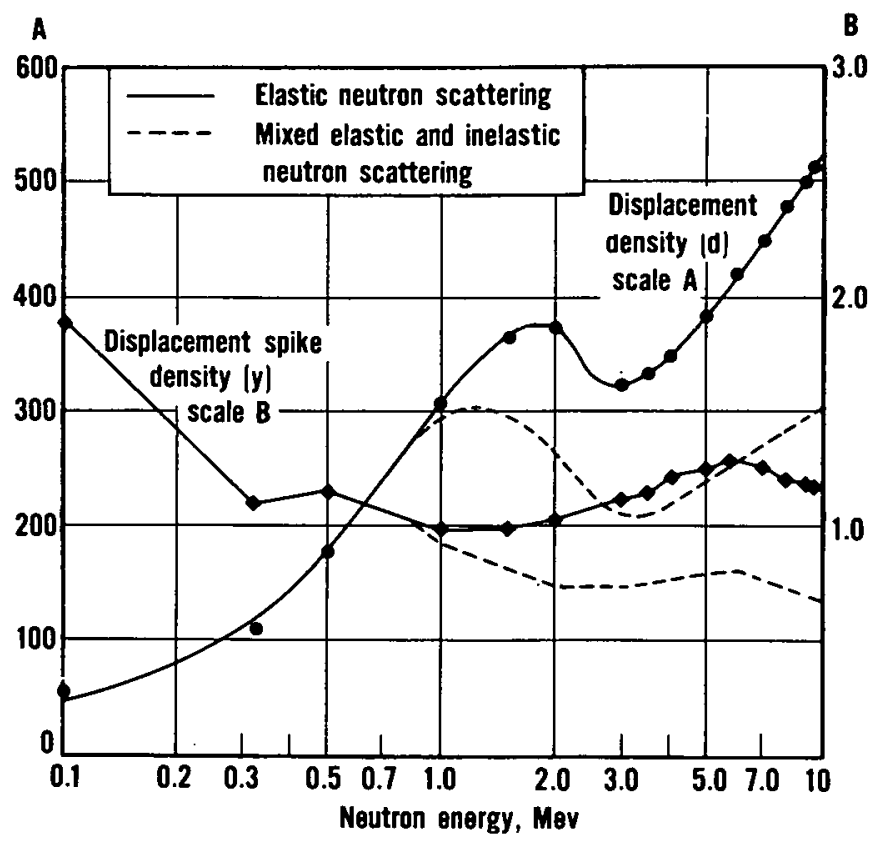

Fig. 2.14-Displacement density, $d$, and displacement spike density, $y$, per unit of neutron exposure as functions of neutron energy 
Combining the information given in Table 2.3 with the PKA energy spectra as a function of neutron energy gave the useful result that the density $d_{n}(v)$ of $n$-vacancy clusters per unit neutron exposure is given by

$$
d_{n}(v)=\alpha_{n}(v) d
$$

for neutron energies above $0.1 \mathrm{Mev}$, where $\mathrm{d}$ is the total displacement density per unit neutron exposure. The values of $\alpha_{n}(v)$ are listed in Table 2.4.

The interstitial cluster densities are given by

$$
d_{n}(i)=\alpha_{n}(i) d
$$

Table 2.5 gives the values of $\alpha_{n}(i)$. Together with the displacement density y, these data provide most of the information needed to discuss neutron irradiation hardening.

TABLE 2.3

FRACTION OF VACANCIES CONTAINED IN n-VACANCY CLUSTERS

\begin{tabular}{cccccccc}
\hline Cluster & \multicolumn{8}{c}{ PKA Energy (E), kev } \\
\cline { 2 - 8 } Size (n) & 0.5 & \multicolumn{1}{c}{1} & 2.5 & 5 & 10 & 15 & 20 \\
\hline 1 & 0.352 & 0.326 & 0.328 & 0.336 & 0.350 & 0.356 & 0.351 \\
2 & 0.208 & 0.194 & 0.211 & 0.191 & 0.202 & 0.193 & 0.203 \\
3 & 0.129 & 0.125 & 0.125 & 0.145 & 0.135 & 0.129 & 0.131 \\
$4-6$ & 0.254 & 0.243 & 0.196 & 0.244 & 0.202 & 0.196 & 0.203 \\
$7-9$ & 0.058 & 0.111 & 0.091 & 0.057 & 0.072 & 0.079 & 0.070 \\
$\geq 10$ & 0 & 0 & 0.050 & 0.055 & 0.038 & 0.046 & 0.042 \\
\hline
\end{tabular}

TABLE 2.4

VACANCY CLUSTER PRODUCTION FUNCTION

$$
d_{n}(v)=\alpha_{n}(v) d
$$

\begin{tabular}{llrc}
$n$ & $\alpha_{n}(v)$ & $n$ & $\alpha_{n}(v)$ \\
\hline 1 & 0.343 & $4-6$ & 0.0422 \\
2 & 0.100 & $7-9$ & 0.0096 \\
3 & 0.0438 & $\geq 10$ & 0.0038 \\
\hline
\end{tabular}

TABLE 2.5

INTERSTITIAL CLUSTER PRODUCTION FUNCTION

$$
d_{n}(i)=\alpha_{n}(i) d
$$

\begin{tabular}{ll}
$\mathrm{n}$ & $\alpha_{\mathrm{n}}(\mathrm{i})$ \\
\hline 1 & 0.942 \\
2 & 0.028 \\
3 & 0.001 \\
\hline
\end{tabular}

Comparison with Experimental Results

Harries, et al. ${ }^{18,19}$ have made an extensive study of the neutron irradiation hardening of ferritic steels. The relative increases in the lower yield point they observed for five different neutron spectra, along with the associated average neutron energies, are given by Table 2.6. As indicated in footnotes $b$ and $c$ in Table 2.6, their irradiations were performed in both graphite-moderated and heavy-water-moderated reactors. On the basis of our theoretical results for the irradiation-produced defect cluster size distribution, the PKA energy spectra, defect annealing, and the effect of inelastic neutron scattering, several suggested irradiation hardening models were compared to see which gives the best match to the experimental results of Harries, et al. In this regard, absolute damage calculations were done for the particular specimen size used by Harries, et al., using the neutron spectra computed by Wright ${ }^{27}$ for the irradiation facilities listed in Table 2.7. Specifically, the following possible measures of the amount of irradiation hardening were considered:

1. The total number of displaced atoms

\footnotetext{
${ }^{27}$ S. B. Wright, "The Use of Monte Carlo Calculations in the Analysis of Radiation Damage Experiments," Radiation Damage in Solids, Vol. II, International Atomic Energy Agency, Vienna, 1962.
} 
TABLE 2.6

IRRADIATION HARDENING IN FERRITIC STEEL ${ }^{a}$

\begin{tabular}{lcc}
\hline $\begin{array}{c}\text { Reactor } \\
\text { Spectrum }\end{array}$ & $\begin{array}{c}\text { Average Neutron } \\
\text { Energy }\end{array}$ & $\begin{array}{c}\text { Relative Irradiation } \\
\text { Hardening }\end{array}$ \\
\hline BEPO Empty $^{\mathrm{b}}$ & $0.332^{\mathrm{c}}$ & 1.00 \\
PLUTO Mk-II $^{\mathrm{d}}$ & 0.591 & 0.756 \\
PLUTO Empty $_{\text {BEPO Hollow }}$ & 0.397 & 0.741 \\
BErald Rig & 0.868 & 0.515 \\
Heral & 0.969 & 0.449 \\
\hline
\end{tabular}

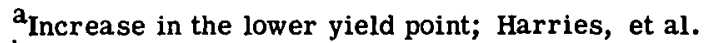

$b_{\mathrm{BEPO}}$ is graphite moderated.

$\mathrm{c}_{\text {Neutron energy in }} \mathrm{Mev}$.

d PLUTO is heavy-water moderated.

TABLE 2.7

TOTAL NUMBER OF ATOMIC DISPLACEMENTS(d) ${ }^{a}$

\begin{tabular}{llcc}
\hline $\begin{array}{c}\text { Neutron } \\
\text { Spectrum }\end{array}$ & $\mathrm{d}(\mathrm{all})$ & $\mathrm{d}(\geq 1 \mathrm{Mev})$ & $\begin{array}{c}\text { Hardening } \\
\text { Experimental }\end{array}$ \\
\hline BEPO Empty & 1.00 & $\mathbf{1 . 0 0}$ & 1.00 \\
PLUTO Mk-III & 0.522 & $\mathbf{0 . 6 3 7}$ & 0.756 \\
PLUTO Empty & 0.474 & $\mathbf{0 . 5 7 3}$ & 0.741 \\
BEPO Hollow & 0.558 & $\mathbf{0 . 7 1 4}$ & 0.515 \\
Herald Rig & 0.495 & $\mathbf{0 . 6 4 9}$ & 0.449 \\
\hline
\end{tabular}

${ }^{a}$ Calculations assume elastic neutron scattering.

2. The number of displaced atoms produced by neutrons with energies greater than $1 \mathrm{Mev}$

3. The total number of displacement spikes produced

4. The number of displacement spikes produced by PKA's with energies above a certain critical value $\mathrm{E}_{\mathrm{c}}$.

Assuming that irradiation hardening is measured by the total displacement density, then the ordering given by the column labeled $d($ all) in Table 2.7 is predicted. This ordering does not agree with experimental results. On the basis of the average neutron energy, the first three neutron spectra fall into a low-energy category relative to the last two. In each category, the predicted ordering given by the total displacement density model is the same as that found experimentally, but the model fails to serve as a general measure of irradiation hardening. On the assumption that only those displaced atoms produced by neutrons with energies above $1 \mathrm{Mev}$ measure irradiation hardening, then the ordering of the column labeled $d(>1 \mathrm{Mev})$ is predicted. This prediction also is not in accord with experimental results. Hence, neither of the two commonly suggested irradiation hardening measures which are based on the number of displaced atoms give results which are even in qualitative agreement with the experiments of Harries, et al.

The displacement spike density model almost gives the observed ordering as indicated by the column labeled y(all) in Table 2. 8. Except for the PLUTO Empty spectrum, the total displacement spike densities are ordered in the same way as the observed increases in the lower yield stress. The columns in Table 2.8 labeled $y(>2.5), y(>2.7), y(>3.6)$, and $y(>4.9)$ show the ordering which results upon considering only the density of displacement spikes produced by PKA with energies above those stated within the parentheses (in kev). Note that a correct ordering is achieved when only spikes produced by PKA's with energies greater than about $3 \mathrm{kev}$ are considered to be effective in producing irradiation hardening. 
TABLE 2.8

DISPLACEMENT SPIKE DENSITY $(y)$

\begin{tabular}{|c|c|c|c|c|c|}
\hline $\begin{array}{l}\text { Neutron } \\
\text { Spectrum }\end{array}$ & $y(a l l)^{a}$ & $y\left(E^{b}>2.5\right)$ & $y\left(E^{b}>2.7\right)$ & $y\left(E^{b}>3.6\right)$ & $\mathrm{y}\left(\mathrm{E}^{\mathrm{b}}>4.9\right)$ \\
\hline BEPO Empty & 1.00 & 1.00 & 1.00 & 1.00 & 1.00 \\
\hline PLUTO Mk-II & 0.418 & 0.654 & 0.517 & 0.529 & 0.550 \\
\hline PLUTO Empty & 0.565 & 1.003 & 0.506 & 0.502 & 0.501 \\
\hline BEPO Hollow & 0.288 & 0.404 & 0.460 & 0.498 & 0.532 \\
\hline \multirow[t]{2}{*}{ Herald Rig } & 0.244 & 0.360 & 0.412 & 0.454 & 0.489 \\
\hline & & \multicolumn{4}{|c|}{ Correct Order } \\
\hline
\end{tabular}

${ }^{2}$ Number of displacement spikes per unit volume per unit neutron exposure.

bPKA Energy (E) in kev.

This result is believed to be significant because the vacancy cluster size distribution changes from an energy-dependent to an energy-independent form just about $2.5 \mathrm{kev}$, as shown by Table 2.3, and annealing simulations show that spikes produced by PKA's with energies below $2.5 \mathrm{kev}$ should not survive thermal annealing at the irradiation temperature used by Harries, et al.

Eyre's ${ }^{28}$ experiments indicate that vacancies are immobile in $\alpha$-iron up to about $250^{\circ} \mathrm{C}$ and, hence, that any defect annealing below this temperature is the result of interstitial migration. Lucasson and Walker ${ }^{29,30}$ have shown that interstitials are mobile in $\alpha$-iron at and above $-153^{\circ} \mathrm{C}$. In view of these results, the migration of interstitials in displacement spikes produced at $0^{\circ} \mathrm{K}$ was simulated in an attempt to estimate the damage state produced at a finite irradiation temperature in the range from $-153^{\circ}$ to $250^{\circ} \mathrm{C}$. This damage state is that appropriate to the irradiation temperature $\left(60^{\circ} \mathrm{C}\right)$ used by Harries, et al.

The principal result of these annealing simulations was that displacement spikes which contained large vacancy clusters were found to be relatively immune to annihilation via interstitial - vacancy recombination during interstitial migration. In this context, a large vacancy cluster is one containing 10 or more vacancies. Vacancy clusters of this size were usually only slightly reduced in size by interstitial - vacancy recombination events. By virtue of their survival, so to speak, an equal number of interstitials also survive the annealing process. These interstitials are usually collected into clusters. Hence, the damage state predicted for pure $\alpha$-iron irradiated at $60^{\circ} \mathrm{C}$ is one composed of interstitial clusters and vacancy clusters. Attardo and Galligan ${ }^{31}$ have observed such a damage state in pure, neutron-irradiated platinum using the field ion microscope.

It is not suggested that the correlation between the observed ordering of irradiation hardening and that for the computed densities of displacement spikes which contain large clusters indicates that large vacancy clusters are the principal hardening agents. Rather, the occurrence of large vacancy clusters in a displacement spike is the sign of a particular type of defect deployment. When this deployment exists, annealing via interstitial migration is disposed to produce markedly more interstitial clusters and, consequently, far fewer recombination events than is the case when large vacancy clusters are absent. It is suggested that only those spikes which contain large vacancy clusters will contain a

${ }^{28}$ B. L. Eyre and A. F. Bartlett, "An Electron Microscope Study of Neutron Irradiation Damage in Alpha-Iron," AERE-R, 4752, November 1964.

${ }^{29}$ P. G. Lucasson and R. M. Walker, "Introduction and Recovery of Electron-Induced Radiation Damage in a Number of Metals," Physical Revieu. Vol. 127, July 1962, p. 485.

${ }^{30}$ P. G. Lucasson and R. M. Walker, "Variation of Radiation Damage Parameters in Metal," Physiral Revic'u, Vol. 127, August 1962, p. 1130.

${ }^{31}$ M. J. Attardo and J. M. Galligan, "Radiation Damage in Platinum," Physicul Rurion l,ellers. Vol. 14, April 1965, p. 641. 
sufficient number of interstitial atoms, after interstitial-atom migration annealing, to provide a significant irradiation hardening contribution.

Furthermore, the annealing simulations also show that the initial interstitial distribution is such that homogeneous nucleation of interstitial clusters should occur very rapidly. It was observed that clusters of as many as seven interstitials could form during a time interval of less than $50 \tau$, where $\tau$ is the average jump time for an interstitial. This is such a rapid rate at room temperature, for example, that such clusters could almost be considered to be directly formed by the collision cascade. This result is significant because it shows that the existence of interstitial clusters and an extremely fast interstitial clustering rate can be explained simply on the basis of the initial interstitial distribution in a displacement spike, even though clusters of more than two interstitials are rarely produced directly by a collision cascade.

\section{WORK PLANNED FOR NEXT PERIOD}

Creep-rupture testing of molybdenum specimens at the lower temperatures $\left(\sim 0.31 \mathrm{~T}_{\mathrm{m}}\right)$ and of GE-NMPO-produced W-25Re sheet specimens will be continued with the intention of defining the change in flow mechanism in the $800^{\circ}$ to $900^{\circ} \mathrm{C}$ temperature range.

Hot hardness testing of irradiated and control single-crystal tungsten specimens will be continued. The influence of dose on hardness, resistivity, and creep-rupture will be compared and evaluated.

Resistivity measurements on isothermally annealed irradiated molybdenum specimens will be continued in the temperature region of $0.31 \mathrm{~T}_{\mathrm{m}}$.

Substructure studies of irradiated and tested tungsten specimens using the transmission electron microscope will be continued.

Theoretical studies on neutron-induced defects in the bcc metals will continue, with emphasis on the absolute number of defect clusters produced in neutron irradiated $\alpha$-iron per unit exposure and on their annealing behavior. 


\section{EVALUATIONS OF THE PLASTIC Fatigue PROPERTIES OF HEAT RESISTANT ALLOYS}

\section{(57016)}

The objective of this program is to determine the parameters affecting low-cycle fatigue behavior of metals and alloys at elevated temperatures and to generate low-cycle fatigue data for use in the design of structural components of high-performance nuclear reactor systems.

\section{METHODS OF TESTING}

During Fiscal Year 1966, uniaxial low-cycle fatigue tests will be performed on Types 304 and 316 stainless steel in the temperature range $400^{\circ}$ to $800^{\circ} \mathrm{C}$. These tests will consist of subjecting specimens with an hour-glass gage section to push - pull loading.

\section{Fatigue Testing Machines}

A photograph of the servo-controlled hydraulic testing machine (MB Electronics Model TM6-20) that will be used in this program is shown in Figure 3.1. The photograph shows the hydraulic loading frame flanked on the right by the control console. The control console contains the electronic control equipment, function generating equipment, and recording equipment.

Figure 3.2 shows the control panel of the console and illustrates the versatility of the equipment. Three control modes may be used to operate the machines: stress, strain, and table position. The load frame is equipped with a load cell to furnish the feed-back signal required for stress control and a potentiometric transducer to furnish the feedback signal for table position control. For strain control, transducers with either strain gages or linear variable differential transformers as sensing elements may be used for generating the required feed-back signal.

For each of the control modes, there are five types of command signal available: linear rate (signal increasing linearly with time), set-point (signal produced instantaneously and maintained thereafter), cycling-unbiased (alternating signal only), cycling-biased (alternating signal on steady signal), and automatic program (arbitrary signal). A lowfrequency function generator (Hewlett-Packard Model 202A) furnishes the alternating signal (sinusoidal, triangular and square wave) and an automatic programmer (Research Inc., MTS Division Data-Trak Model FGE 5110) furnishes the arbitrary command signal. Also included in the control equipment are simulation circuits to facilitate accurate balancing of the servo-amplifier and precise calibration of the recorder scales.

The MB-machine is a general purpose machine and it will be used to define the test conditions of interest in terms of mode of control, cyclic mode shape, frequency, holdtimes, cycles to failure, and temperature level. Special purpose machines will be acquired for testing in which the test conditions are largely repetitive from test to test. 


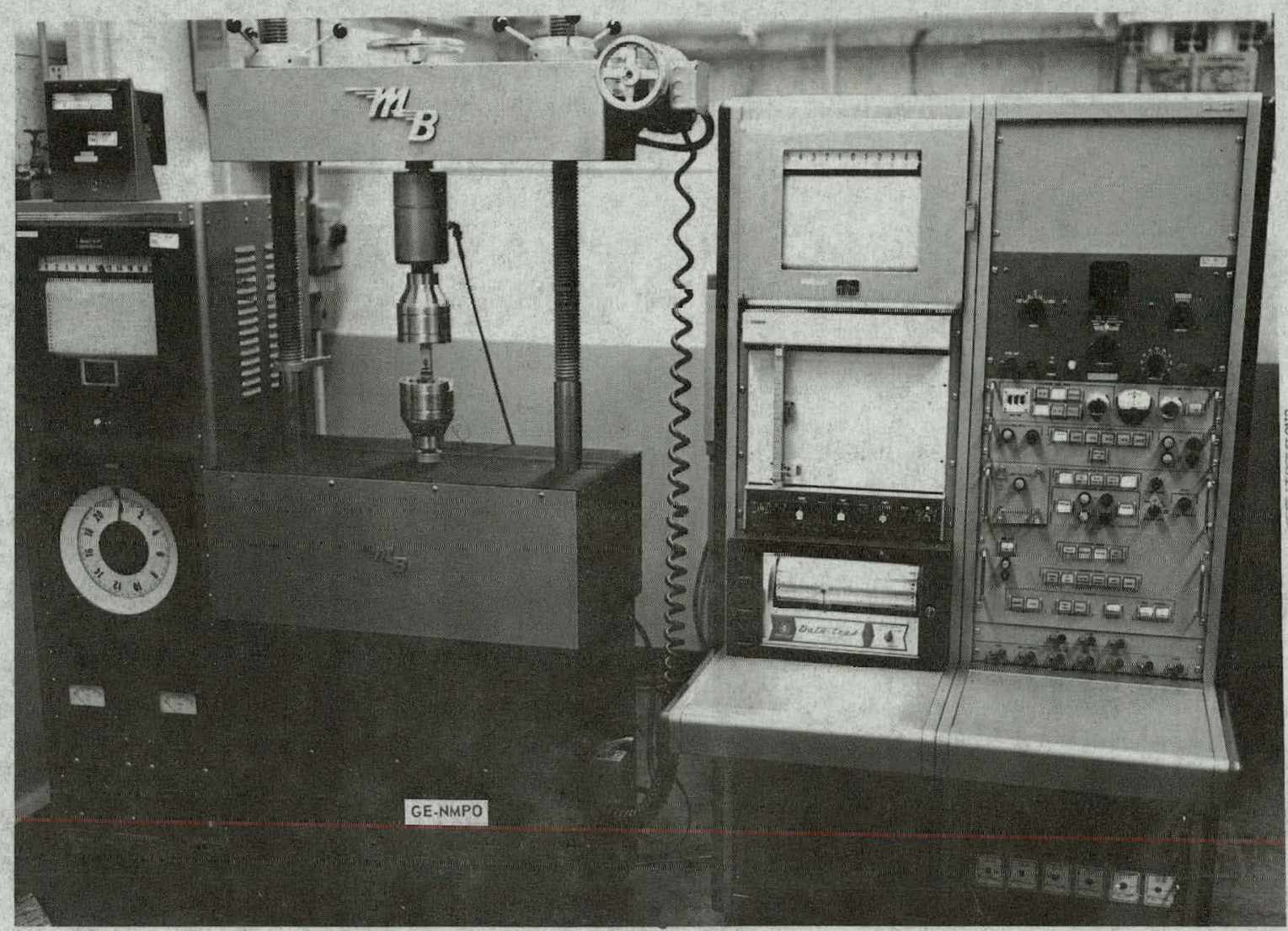

Fig. 3.1 - Servo-controlled hydraulic materials testing machining (Neg. P65-6-33A)

The fixtures built for mounting the fatigue specimen in the machine and preserving its alignment throughout the test is shown in Figure 3.3. A sketch of the interior parts of the assembly was included in an earlier report. ${ }^{1}$ (A three-post die set was selected instead of the four-post die-set that was shown on the sketch.)

Strain Measuring and Control Equipment

The minimum diameter of the specimen shown in Figure 3.3 is $0.635 \mathrm{~cm}$. In the earlier report mentioned above, a sketch was also shown of the extensometer built for measuring the diametral strain at the minimum diameter. Figures 3.4 through 3.6 show some roomtemperature results obtained with the extensometer on the MB-machine. Figure 3.4 shows the variation recorded in the diameter when the specimen was subjected to a small cyclic load, which was also recorded. The stress level achieved in the test was well below the yield stress of the material. Figure 3.5 shows a very similar result, but in this case the signal from the extensometer was used to control the machine, so that the specimen was subjected to a small cyclic diametral change. The amplitude of the diameter variation was quite small in both tests, approximately 60 micro-inches ( 1.5 microns), but the signal produced by the extensometer was nevertheless adequate for recording and control purposes. Figure 3.6 shows results obtained under test conditions that are more representative of the low-cycle fatigue tests to be performed. In this test, the specimen was subjected to a considerably larger cyclic diametral strain variation. The range of the corresponding longitudinal strain was approximately 1.7 percent. If the test had continued, the specimen would have failed well within 10,000 cycles. The material in this

1،'Fourth Annual Report - High-Temperature Materials and Reactor Component Development Program, Volume I -

Materials," GE-NMPO, GEMP-334A, February 26,1965 , p. 48. 


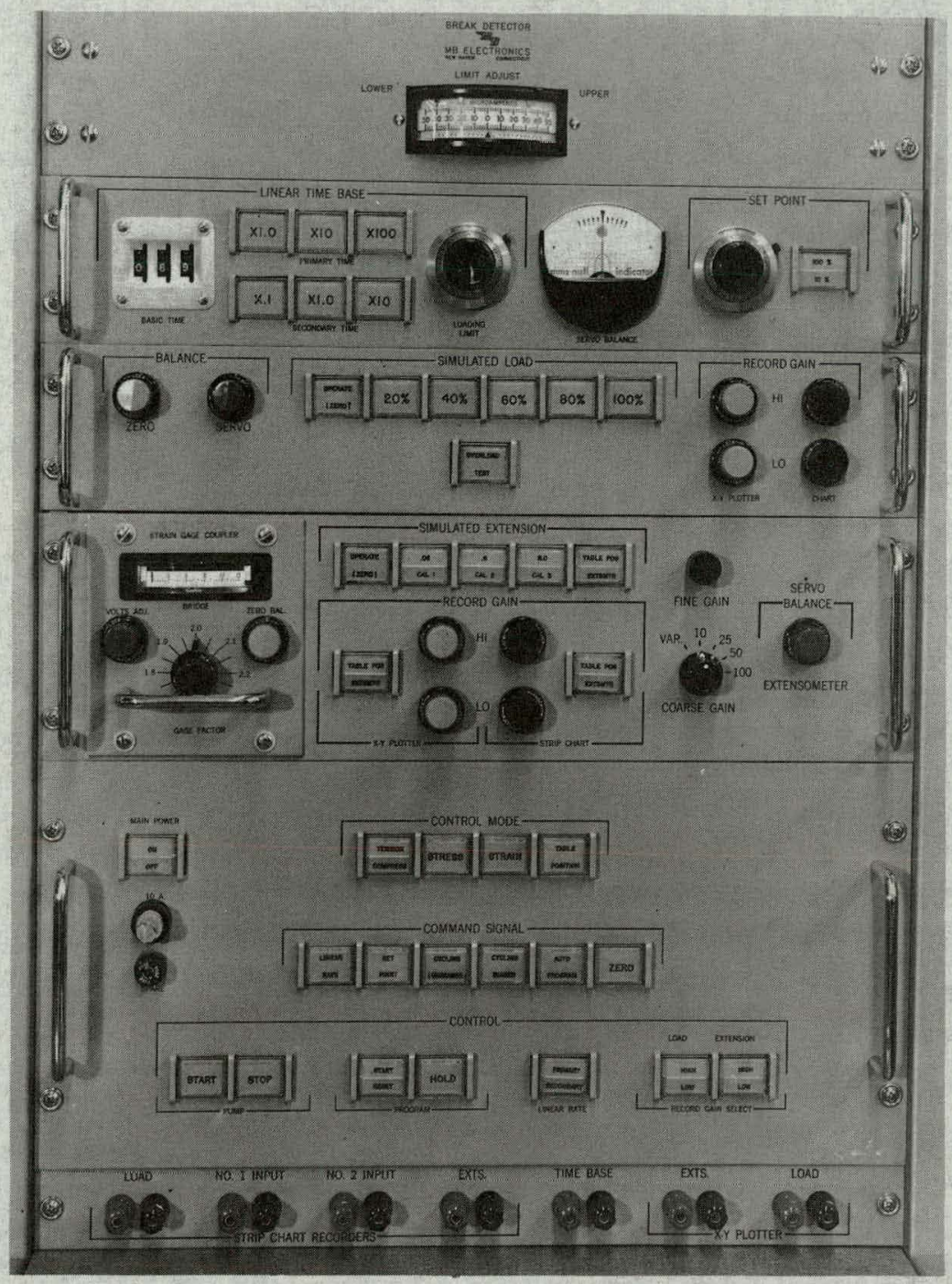

Fig. 3.2-Control panel of materials testing machine

test was subjected to large plastic straining in each cycle. Considerable strain-hardening was observed in the first few cycles. This is not apparent in Figure 3.6 as the load trace was obtained at a later stage in the test.

\section{LITERATURE SURVEY}

The purpose of this section is to periodically list published technical papers and reports that have particular significance in relation to the task objective. The papers listed below are either review papers or papers that contain a large number of references to the technical literature.

1. Carden, A. W., "An Abstracted Bibliography of the Thermal Fatigue Literature for the Years 1954-1963," University of Alabama, Bureau of Engineering Research Report No. 26, April 1964.

2. Coffin, L. F., Jr., "Low-Cycle Fatigue: A Review," Applied Materials Research, Vol. 1, No. 3, Octnher 1962 (76 references).

3. Coffin, L. F., Jr., "Low-Cycle Fatigue," ASM Metals Engineering Quarterly, Vol. 3, No. 4, November 1963 , pp. 15-24 (11 references). 


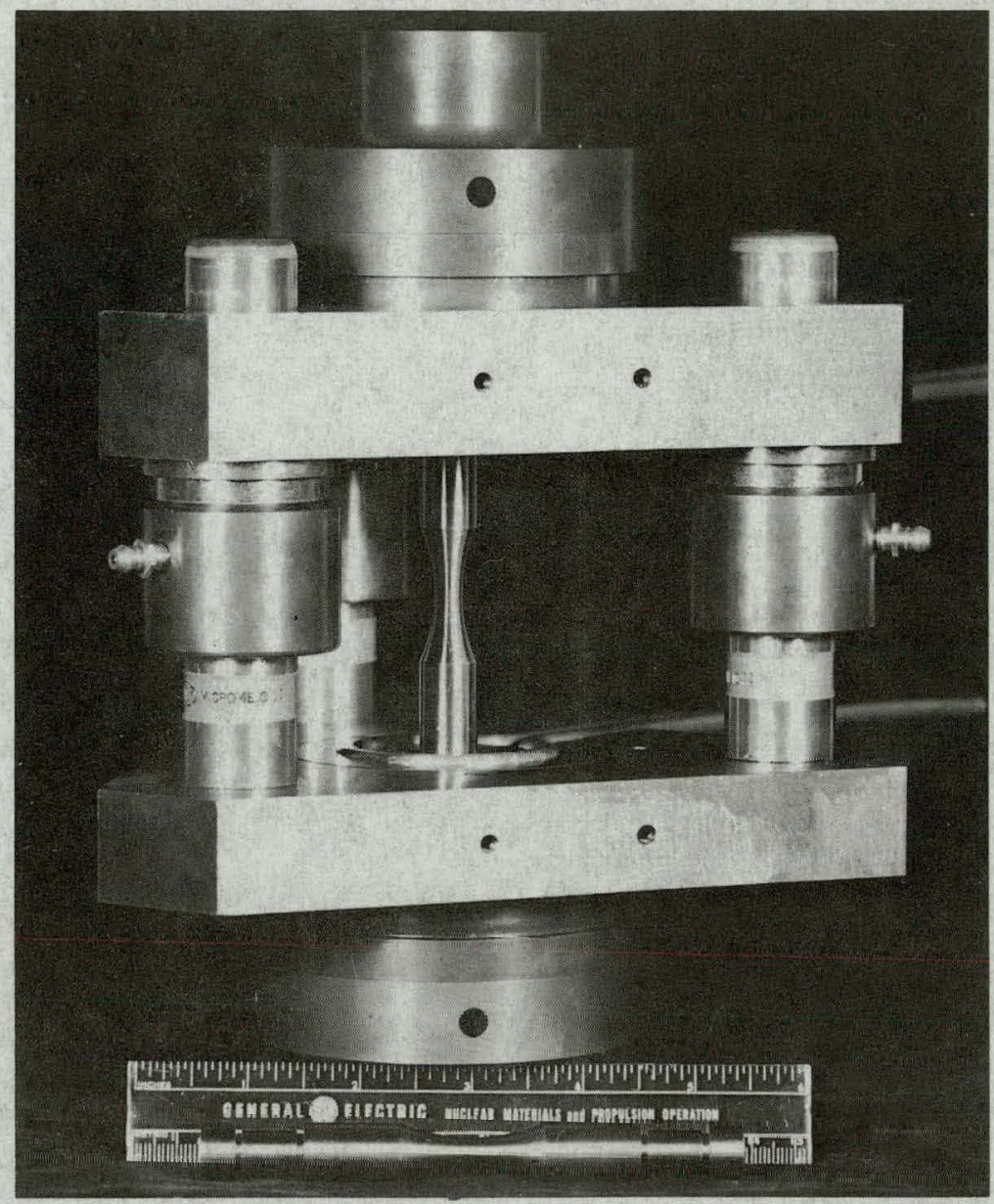

Fig. 3.3-Specimen fixture assembly (Neg. P65-6-33B)

4. Coffin, L. F., Jr., "Cyclic Strain and Fatigue Behavior of Metals in the Creep Range," General Electric Research Laboratory No. 64-RL-3830M, December 1964 (30 references).

5. Glenny, E., "Thermal Fatigue," Metallurgical Reviews, Vol. 6, No. 24, 1961, pp. 387-465 (151 references).

6. Langer, B. F., "Design of Pressure Vessels for Low-Cycle Fatigue," Trans. ASME, Journal of Basic Engineering, Vol. 84, Series D, No. 3, September 1962, pp. 389-402 (16 references).

7. Low, J. R., "The Fracture of Metals," Progress in Materials Science, Bruce Chalmers, Editor, Vol. 12, No. 1, 1963 (212 references).

8. Manson, S. S., and Hirschberg, M. H., "Fatigue Behavior in Strain Cycling in the Low and Intermediate Cycle Range, "prepared for 10th Sagamore Army Materials Research Conference, August 13-16, 1963, Sagamore, N. Y. (13 references).

9. Manson, S. S., "Design Considerations for Long Life at Elevated Temperatures," James Clayton Lecture prepared for Joint International Conference on Creep, London, 1963, NASA Lewis TPI-63, October 3, 1963 (45 references).

10. Manson, S. S., "Fatigue: A Complex Subject-Some Simple Approximations," William M. Murray Lecture, prepared for Society for Experimental Stress Analysis, Cleveland, October 1964, Experimental Mechanics, Vol. 5, No. 7, July 1965, pp. 193-226 (44 references). 
11. Valluri, Sitaram Rao, "A Unified Engineering Theory of High Stress Level Fatigue," Aerospace Engineering, October 1961 (37 references).

12. Yao, J. T. P., and Munse, W. H., "Low-Cycle Fatigue of Metals - Literature Review, "Ship Structure Committee Report No. SSC-137, October 31, 1961 (69 references).

13. Yen, T. C., "Thermal Fatigue-A Critical Review," Welding Research Council Bulletin No. 72, October 1961 (62 references).

\section{WORK PLANNED FOR NEXT PERIOD}

A number of modifications of the MB-machine and associated equipment will be made to suit the specific program needs.

Fatigue tests will be initiated at elevated temperatures using Type 304 stainless steel. 


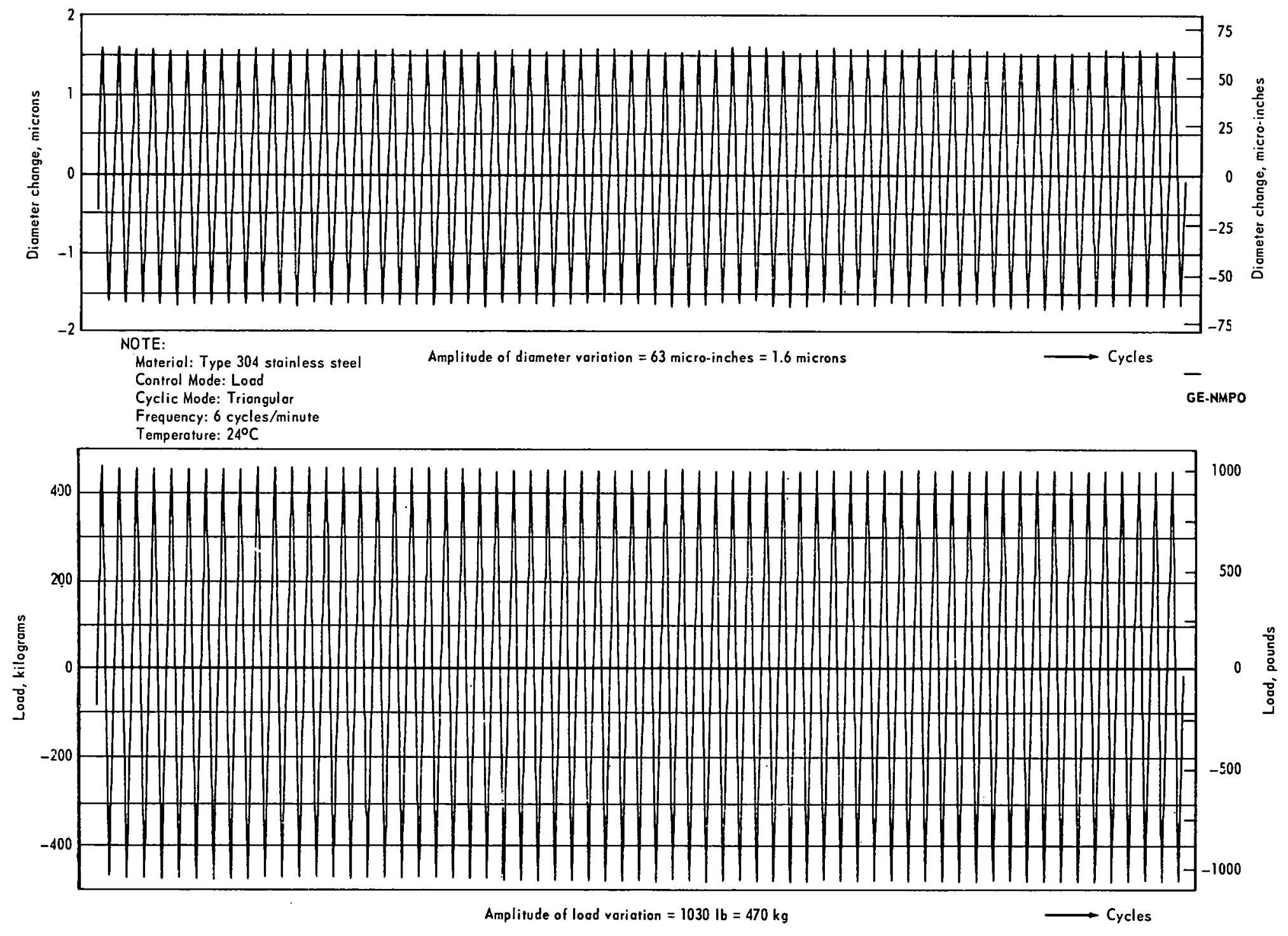

Fig. 3.4 - Fatigue test with load control (low load level) 


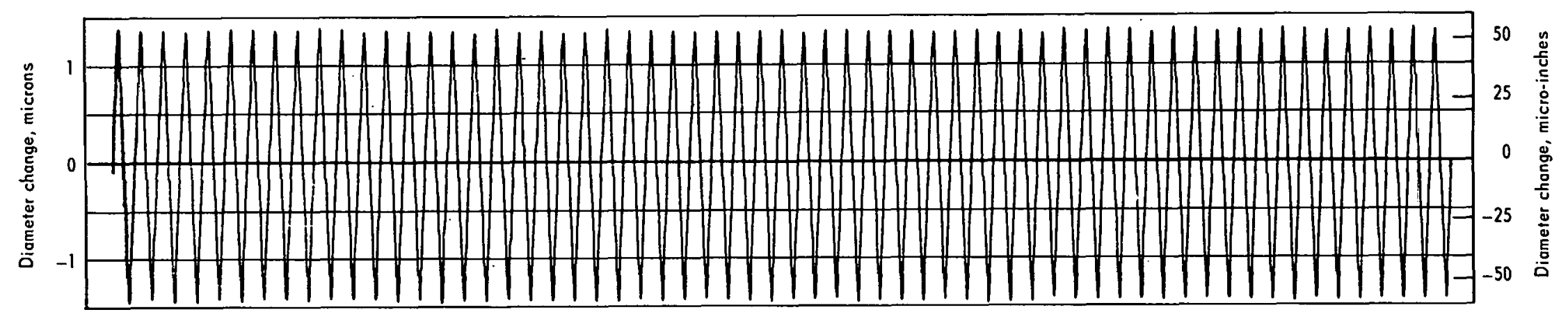

NOTE:

Moterial: Type 304 stainless steel

Control Mode: Strain

Amplitude of diameter variation $=56$ micro-inches $=1.4$ microns

$\longrightarrow$ Cycles

Cyclic Mode: Train

GE-NMPO

Frequency: 6 cycles/minute

Temperature: $24^{\circ} \mathrm{C}$

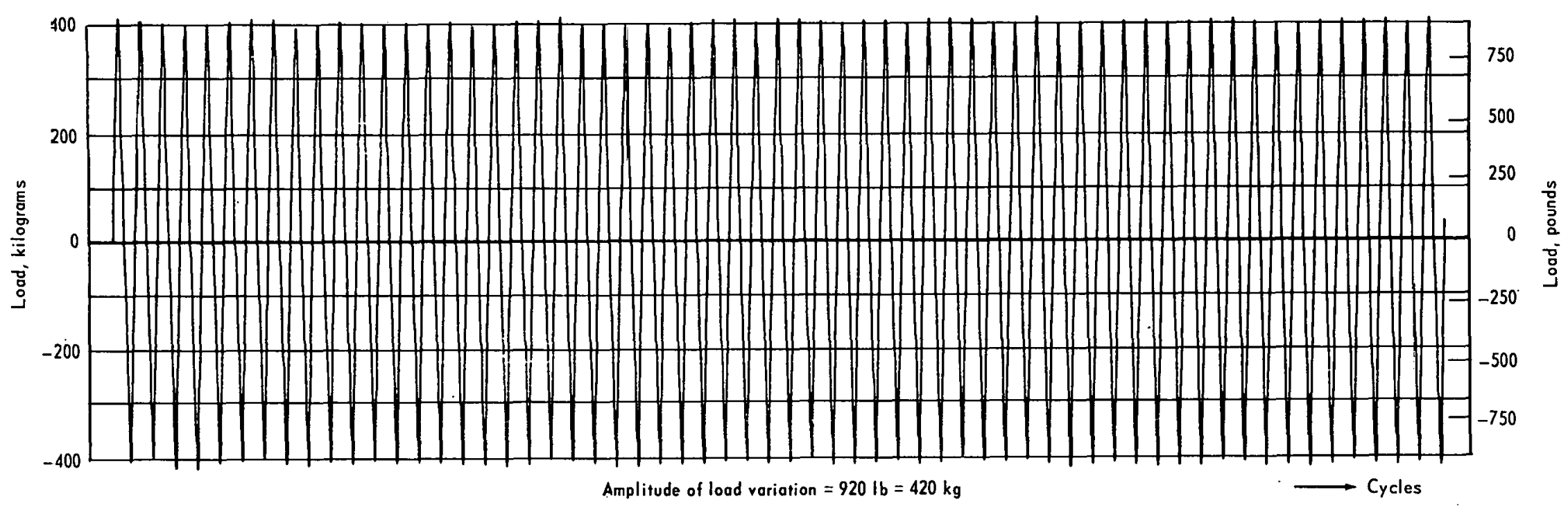

Fig. 3.5 - Fotigue test with strain control (low strain level) 


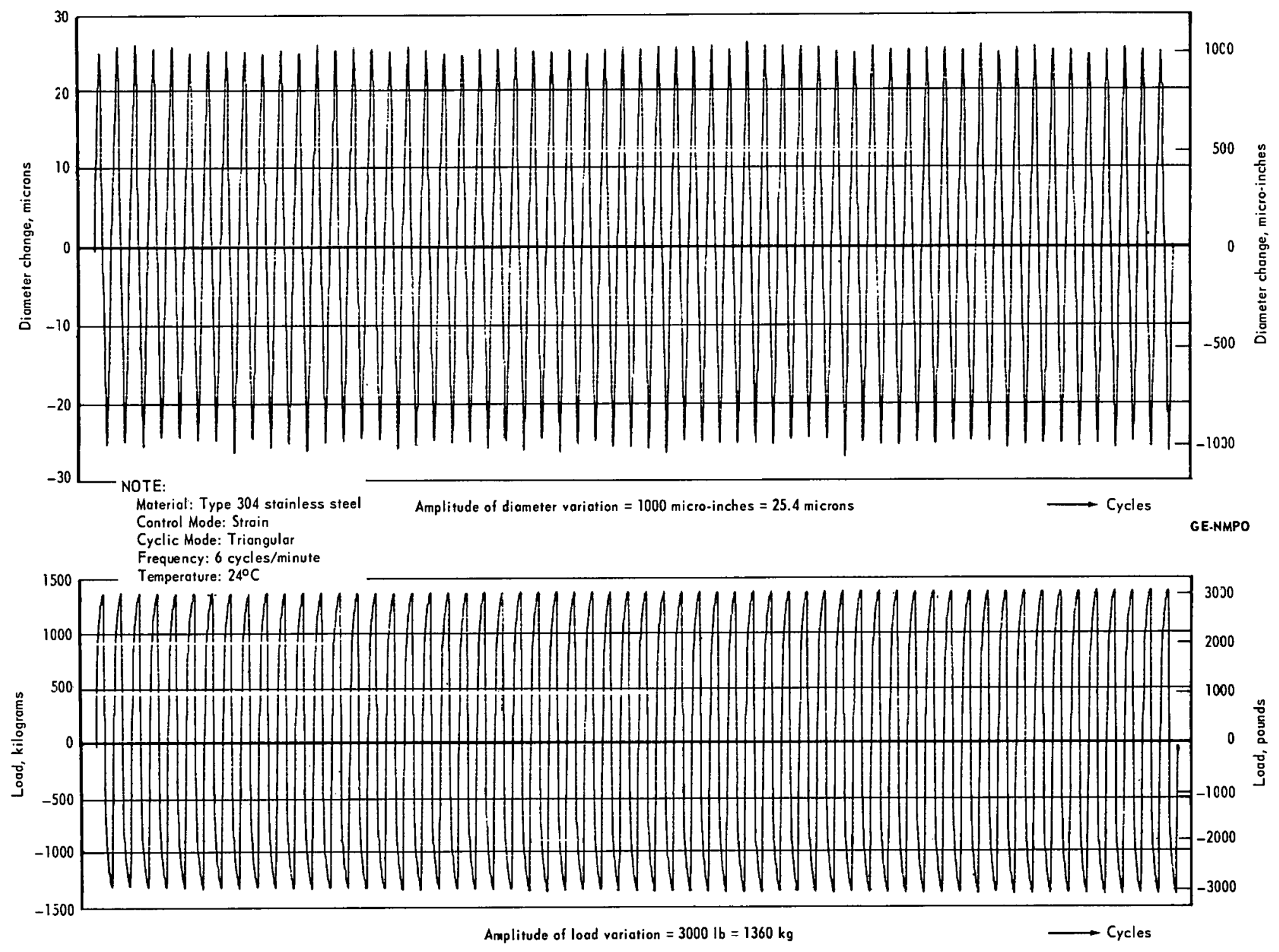

Fig. 3.6 - Fatigue test with strain control (high strain level) 


\section{EFFECT OF RADIATION ON HEAT RESISTANT METALS AND ALLOYS}

\section{(57018)}

The objective of this program ${ }^{1}$ is to determine the effect of radiation on the time-, temperature-, and stress-dependent properties of heat-resistant metals and alloys at elevated temperatures, to identify the causes of any observed changes in these properties and to develop remedial measures.

Materials to be investigated in this program include A-286, Hastelloy $\mathrm{X}$, Hastelloy $\mathrm{N}$, $\mathrm{Fe}-\mathrm{Cr}-\mathrm{Al}-\mathrm{Y}$ alloys, type 304 stainless steel, and A350-LF3 pressure vessel steel.

\section{EXPERIMENTAL PROGRAM}

\section{Status of Irradiations}

A summary of irradiation capsules for this program is shown in Table 4.1.

Elevated-temperature capsule GEFP2-148 was irradiated for 3348 MwD during ETR cycle 72. This capsule, containing 9 Hastelloy $\mathrm{N}$ and 9 A-286 specimens, operated at $650^{\circ} \mathrm{C}$ for the entire cycle. Capsule disassembly and examination of the specimens will be performed during the next report period. The fourth elevated-temperature capsule, GEFP2-151, ${ }^{2}$ was fabricated and shipped to ITS; it is awaiting insertion in ETR cycle 74 . This capsule contains 6 welded Hastelloy $\mathrm{N}$ specimens and 12 Hastelloy $\mathrm{N}$ specimens in the mill-annealed condition $\left(1175^{\circ} \mathrm{C}\right.$ for 0.5 hour, rapid air cooled).

TABLE 4.1

- IRRADIATION DATA FOR HIGH-TEMPERATURE ALLOY CAPSULES

\begin{tabular}{|c|c|c|c|c|c|c|c|c|c|}
\hline \multirow[b]{3}{*}{ Capsule } & \multirow{2}{*}{\multicolumn{4}{|c|}{ Test Specimens }} & \multicolumn{5}{|c|}{ Irradiation Conditions } \\
\hline & & & & & \multirow[b]{2}{*}{ Facility } & \multirow{2}{*}{$\begin{array}{c}\text { Exposure, } \\
\text { hr } \\
\end{array}$} & \multirow{2}{*}{$\begin{array}{c}\text { Temperature, } \\
{ }^{\circ} \mathrm{C} \\
\end{array}$} & \multicolumn{2}{|c|}{ nvt, ${ }^{b}$ neutrons $/ \mathrm{cm}^{2}$} \\
\hline & Material & Heat No. & Type $^{\mathrm{a}}$ & Quantity & & & & Thermal & Fast $\left(E_{n} \geq 1 \mathrm{Mev}\right)$ \\
\hline GEFP2-128 & Hastelloy $\mathbf{N}$ & 5081 & CR & 18 & ETR-E5-NW & 600 & c & $3.2 \times 10^{20}$ & $1.2 \times 10^{20}$ \\
\hline \multirow[t]{5}{*}{ GE FP2-139 } & Hastelloy N & 5081 & $\mathbf{C R}$ & 6 & ETR-E5-NW & 400 & d & $2.2 \times 10^{20}$ & $6.5 \times 10^{19}$ \\
\hline & A-286 & RV403-5A & CR & 4 & & & & & \\
\hline & A-286 & RV403-5B & CR & 1 & & & & & \\
\hline & A-286 & RV403-5C & CR & 3 & & & & & \\
\hline & A-286 & RV451 & CR & 4 & & & & & \\
\hline \multirow[t]{5}{*}{ GE FP2-148 } & Hastelloy $\mathbf{N}$ & 5081 & CR & 3 & ETR-N14-SE & 458 & 650 & $2.5 \times 10^{20}$ & $9 \times 10^{19}$ \\
\hline & Hastelloy N & 5085 & CR & 6 & & & & & \\
\hline & A-286 & RV $-403 A$ & CR & 3 & & & & & \\
\hline & A-286 & RV-403B & CR & 3 & & & & & \\
\hline & A-286 & RV $-403 \mathrm{C}$ & CR & 3 & & & & & \\
\hline GEFP2-151 & $\begin{array}{l}\text { Hastelloy N } \\
\text { Hastelloy } N\end{array}$ & $\begin{array}{c}5065,5067 \\
5081\end{array}$ & $\begin{array}{l}\text { CR(W) } \\
\text { CR }\end{array}$ & $\begin{array}{r}6 \\
12\end{array}$ & ETR-N14-SE & & 650 & & $1.2 \times 10^{20}$ \\
\hline
\end{tabular}

${ }^{\mathrm{a}} \mathrm{CR}=$ Round creep-rupture specimen

$(W)=$ Welded specimen (Filler metal is from Heat 5101).

$b_{\text {Estimated dose. }}$

Coperated 24 hours at $650^{\circ} \mathrm{C}$, the remainder at reactor ambient temperature.

${ }^{\mathrm{d} O p e r a t e d}$ for one-half cycle at $650^{\circ} \mathrm{C}$ and second one-half cycle at reactor amblent temperature.

equested dose.

'The work presented under this program was previously reported as part of the effort on Job 57004, "Effect of Radiation on High-Temperature Metals and Alloys."

2‘'High-Temperature Materials Program Progress Report No. 49, Part A," GE-NMPO, GEMP-49A, July 28, 1965 , section 4. 
Hastelloy N Creep-Rupture Tests

All of the 16 available specimens irradiated in capsule GEFP2-128 were creep-rupture tested to failure at temperatures of $650^{\circ} \mathrm{C}$ and $815^{\circ} \mathrm{C}$. A summary of the creep-rupture data from these irradiated specimens and the corresponding control specimens is shown in Table 4.2. In addition to the loss of rupture life, ductility, as measured by total elongation, is also reduced quite severely at both test temperatures as a result of irradiations to a fast neutron dosage of about $1.2 \times 10^{20}$ nvt. Annealing for 4 hours at $870^{\circ} \mathrm{C}$ did not appreciably aid in recovery of the ductility at the conditions examined.

TABLE 4.2

STRESS-RUPTURE TEST RESULTS OF HASTELLOY N SPECIMENS ${ }^{2}$

\begin{tabular}{|c|c|c|c|c|c|c|c|}
\hline \multirow[b]{2}{*}{ Specimen } & \multirow{2}{*}{$\begin{array}{c}\text { Test } \\
\text { Temperature, } \\
{ }^{\circ} \mathrm{C}\end{array}$} & \multicolumn{2}{|c|}{ Stress } & \multirow{2}{*}{$\begin{array}{c}\text { Rupture Time, } \\
\text { hr } \\
\end{array}$} & \multirow{2}{*}{$\begin{array}{l}\text { Elongation, percent in } \\
3.8-\mathrm{cm} \text { gage length }\end{array}$} & \multirow{2}{*}{$\begin{array}{c}\text { Reduction In } \\
\text { Area, } \% \\
\end{array}$} & \multirow{2}{*}{$\begin{array}{l}\text { Initial Elongation, percen } \\
\text { in } 3.8-\mathrm{cm} \text { gage length }\end{array}$} \\
\hline & & psi & $\mathrm{kg} / \mathrm{mm}^{2}$ & & & & \\
\hline \multicolumn{8}{|l|}{ Control } \\
\hline $5 \mathrm{~N}^{\mathrm{b}}$ & 648.8 & 35,000 & 24.61 & 760.5 & & 34.3 & \\
\hline $10 \mathrm{~N}$ & 648.8 & 35,000 & 24.61 & 842.1 & 9.47 & 15.2 & 1.33 \\
\hline $23 N$ & 648.8 & 35,000 & 24.61 & 759.4 & 8.53 & 12.7 & 1.09 \\
\hline $17 \mathrm{~N}$ & 648.8 & 37,500 & 26.37 & 239.8 & 7.53 & 11.2 & 2. 90 \\
\hline $8 N$ & 648.8 & 40,000 & 28.12 & 177.1 & 6.53 & 9.6 & 3.25 \\
\hline $7 \mathrm{~N}$ & 648.8 & 50,000 & 35.16 & 38.0 & 6.73 & 13.4 & 6. 60 \\
\hline $27 \mathrm{~N}$ & 815.6 & 11,000 & 7. 734 & 144.43 & $12^{c}$ & $12.6^{\mathrm{C}}$ & 0.20 \\
\hline $18 \mathrm{~N}^{\mathrm{b}}$ & 815.6 & 11,000 & 7.734 & 264.75 & 24.4 & 24.3 & 0.45 \\
\hline $28 \mathrm{~N}$ & 815.6 & 14,000 & 9.843 & 47.13 & 12.3 & 11.8 & 0.41 \\
\hline \multicolumn{8}{|l|}{ Irradiated $^{\mathrm{d}}$} \\
\hline \multirow[t]{2}{*}{$44 N$} & 648.8 & 18,000 & 12.66 & $>1994$ & & & \\
\hline & & 30,000 & 21.09 & 121 & & & \\
\hline $12 \mathrm{~N}$ & 648.8 & 30,000 & 21.09 & 94.85 & 1.1 & 7.8 & 0.79 \\
\hline $1 \mathrm{~N}$ & 648.8 & 35,000 & 24.61 & 49.87 & 1.3 & 7.8 & 1.02 \\
\hline $13 N^{f}$ & 648.8 & 35,000 & 24.61 & 51.18 & 1.4 & 9.1 & 0.11 \\
\hline $41 \mathrm{~N}^{\mathrm{b}}$ & 648.8 & 35,000 & 24.61 & 64.5 & $2.6 \mathrm{~g}$ & & 1.67 \\
\hline $50 \mathrm{~N}$ & 648.8 & 35,000 & 24.61 & 61.1 & 2.16 & & 1.21 \\
\hline $9 \mathrm{~N}$ & 648.8 & 37,500 & 26.37 & 21.78 & 2.2 & 18.1 & 1.84 \\
\hline $4 N$ & 648.8 & 45,000 & 31.64 & 6.96 & 3.1 & 20.2 & 3.21 \\
\hline $11 N$ & 648.8 & 50,000 & 35.16 & 0.77 & 7.6 & 29.2 & 7.60 \\
\hline $25 N$ & 815.6 & 7,500 & 5.273 & 388 & 2.58 & & 0.60 \\
\hline $39 N$ & 815.6 & 8,700 & 6.117 & 188.91 & 3.5 & 7.2 & 0.40 \\
\hline $21 \mathrm{~N}$ & 815.6 & 11,000 & 7. 734 & 41.84 & 2.7 & 6.6 & 0.33 \\
\hline $45 \mathrm{~N}^{\mathrm{b}}$ & 815.6 & 11,000 & 7.734 & 18.02 & 1. $2 \mathrm{~g}$ & & 0.41 \\
\hline $22 \mathrm{~N}$ & 815.6 & 14,000 & 9.843 & 16.23 & 4.6 & 8.6 & 0.60 \\
\hline $47 \mathrm{Nb}^{\mathrm{b}}$ & 815.6 & 11,000 & 7. 734 & 22.46 & 1. $2 \mathrm{~g}$ & & 0.43 \\
\hline $14 \mathrm{~N}$ & 815.6 & 21,110 & 14.84 & 1.31 & 1.7 & 9.9 & 0.97 \\
\hline
\end{tabular}

${ }^{a_{A}}$ all spectmens were from heat 5081 and were tested or irradiated in the mill-annealed condition $\left(1175^{\circ} \mathrm{C}\right.$ for

0.5 hour, rapid air cool).

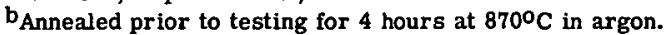

CDouble fracture, approximate values.

d Irradiated in capsule GE FP2-128 for 24 hours at $650^{\circ} \mathrm{C}$ plus 588 hours at reactor ambient. Estimated dosage

is $1.2 \times 10^{20} \mathrm{nvt}, \mathrm{E}_{\mathrm{n}} \geq 1 \mathrm{Mev}$.

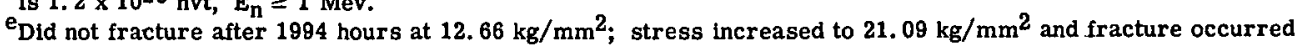

after 121 hours at new stress.

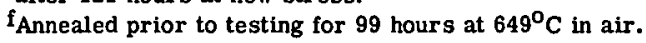

gApproximate values pending measurement of the fractured specimen. From dial indication readings.

Stress versus time to rupture for the $650^{\circ} \mathrm{C}$ and $815^{\circ} \mathrm{C}$ tests are plotted in Figures 4.1 and 4.2 , respectively. As reported previously, ${ }^{3,4}$ the rupture life is reduced by about a factor of 10 at a test temperature of $650^{\circ} \mathrm{C}$ whereas the effects at $815^{\circ} \mathrm{C}$ were not as pronounced. Also, there is a tendency for convergence of the test data of the irradiated and control specimens at low stress levels at the higher test temperatures as is seen in Figure 4.2. This tendency was observed previously ${ }^{5}$ in Hastelloy $X$ irradiated specimens.

\footnotetext{
3“"High-Temperature Materials Program Progress Report No. 47, Part A," GE-NMPO, GEMP-47A, May 28, 1965, p. 97.

A'High-Temperalure Materials Program Progrces Report No. 49, Part A," GF.-NMPO, GF.MP.49A. July 28, 1965, section 4.

5“'Second Annual Report - High-Temperature Materials and Reactor Component Development Programs, Volume I Materials," GE-NMPO, GEMP-177A, February 28, 1965, Figure 2.1-20, p. 80.
} 


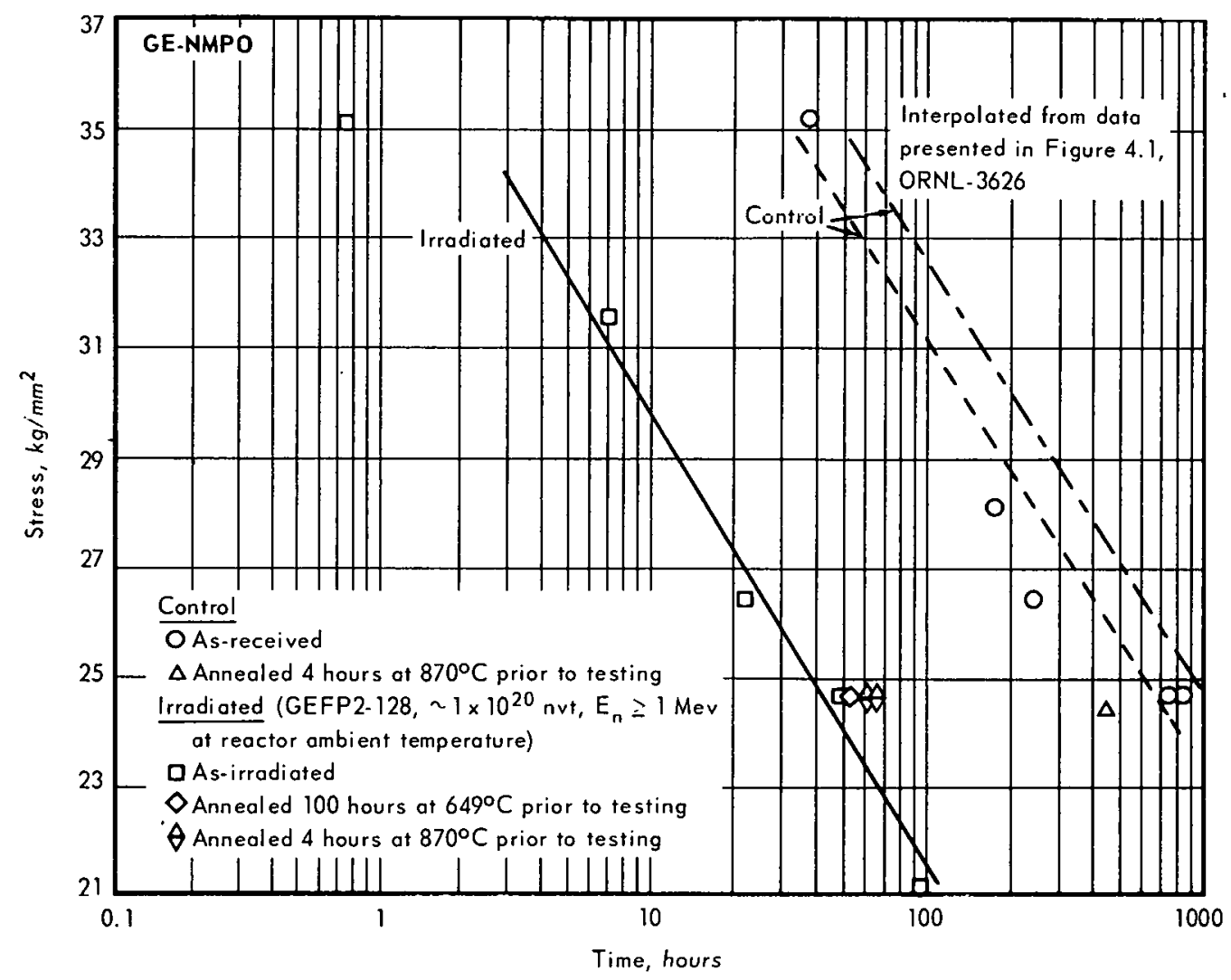

Fig. 4.1-Stress-rupture properties of Hostelloy N (INOR-8, heat No. 5081) at $650^{\circ} \mathrm{C}$

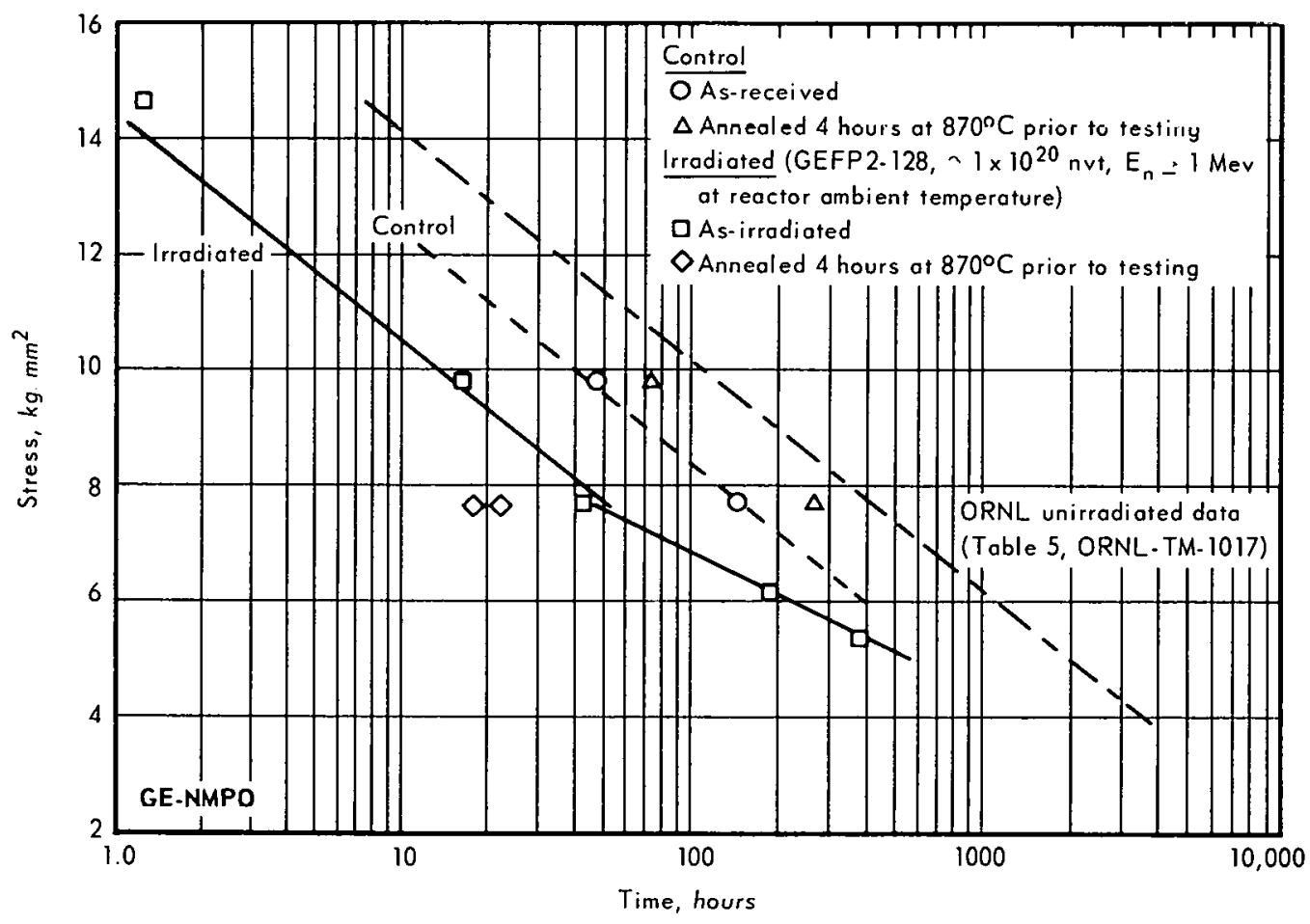

Fig. 4.2 - Stress-rupture properties of Hostelloy N (INOR-8, heot No. 5081) at $815^{\circ} \mathrm{C}$ 
Specimens annealed 4 hours at $870^{\circ} \mathrm{C}$ prior to rupture testing showed quite different effects when tested at the two test temperatures as shown in Figures 4.1 and 4.2. This additional heat treatment had no effect on the control specimen tested at $650^{\circ} \mathrm{C}$; however, there was a very slight recovery $(\sim 2 \%)$ in the rupture life of the irradiated plus annealed specimen when compared to the as-irradiated specimen. Specimens tested at $815^{\circ} \mathrm{C}$ following the $870^{\circ} \mathrm{C}$ annealing treatment behaved quite differently. The rupture life of the heat-treated control specimen was almost twice that of an as-received control specimen tested under the same conditions. On the other hand, the irradiated plus annealed specimen showed only one-half the life of that of a comparable test on an as-irradiated specimen.

The effect of the $870^{\circ} \mathrm{C}$ annealing treatment on the creep-rupture properties at $815^{\circ} \mathrm{C}$ is illustrated in Figure 4.3, which shows the strain versus time for the four specimens tested at the same stress and temperature. (Note the decrease in total elongation of the irradiated specimen following the heat treatment when compared to that of the asirradiated specimen.) The control specimen, however, shows improved ductility resulting in an increase in the time to rupture when compared to the corresponding as-received control specimen. This additional heat treatment also increased the initial strain (see Table 4.2) on applying the load to the specimens at both test temperatures.

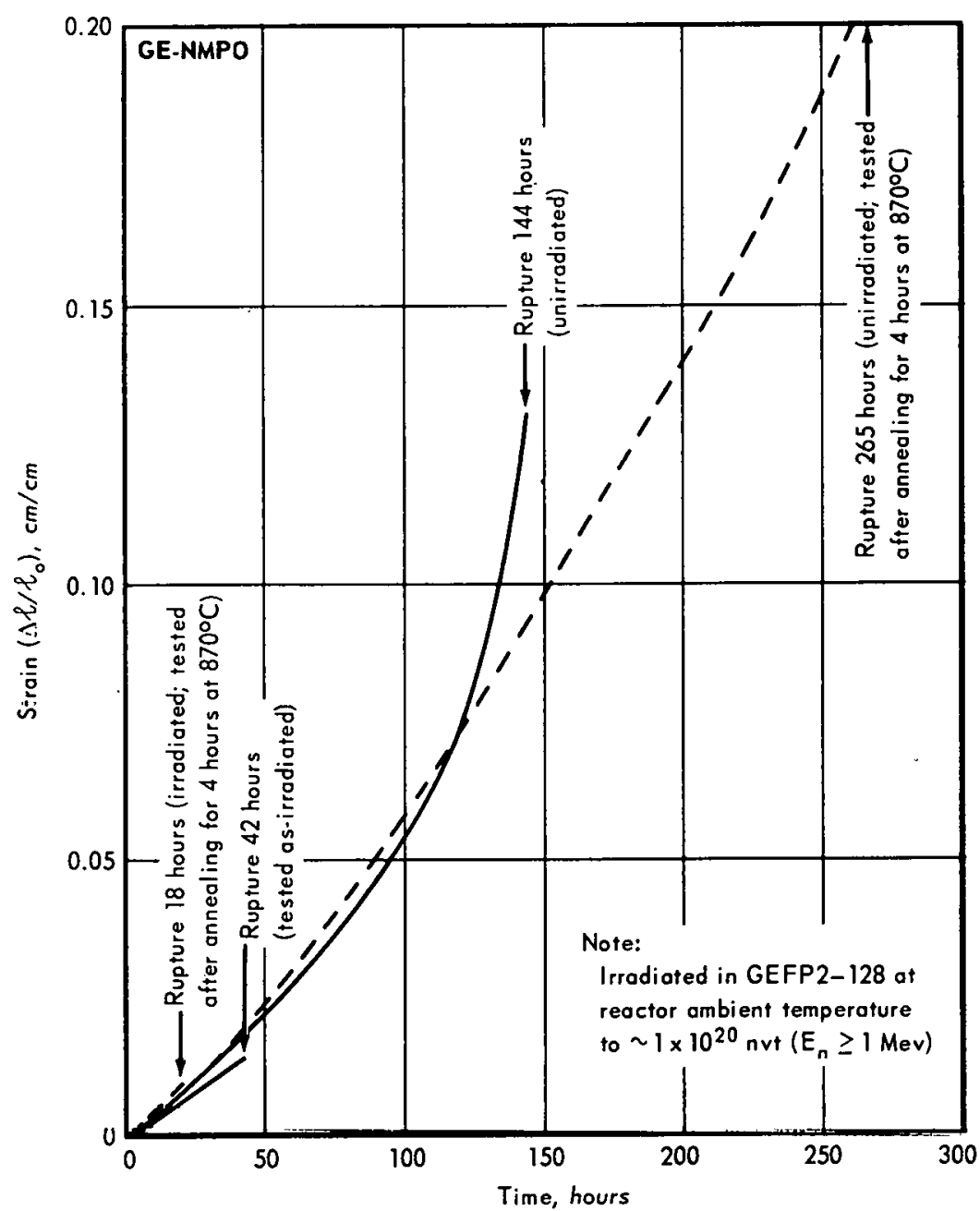

Fig. 4.3 - Strain versus time for Hostelloy $N$ specimens tested in oir of $815^{\circ} \mathrm{C}$ and $7.73 \mathrm{~kg} / \mathrm{mm}^{2}$ 


\section{WORK PLANNED FOR NEXT PERIOD}

Creep-rupture testing of irradiated Hastelloy $\mathrm{N}$ specimens will be continued and analysis of data from these specimens and the corresponding control specimens will be initiated.

Metallographic examination will be performed on selected ruptured specimens to determine the presence of any observable structural differences between control, irradiated, and also of those specimens given the additional heat treatment. Creep-rupture testing of Hastelloy N specimens from capsule GEFP 2-139 will be started.

Work will be initiated on the cooperative program with the Naval Research Laboratory on the Pressure Vessel Embrittlement in Depth Study on A350-LF3 steel (PM-2A material). The resistivity and hardness specimens will be heat treated and then a few specimens will be irradiated at low doses so that the threshold of irradiation-induced property change may be determined. 
THIS PAGE

WAS INTENTIONALLY

LEFT BLANK 


\section{RADIATION EFFECTS IN BeO}

\section{(57063)}

The purpose of this program is to define the irradiation behavior of $\mathrm{BeO}$ in terms of the composition and microstructure variables that contribute to extended radiation stability.

\section{IRRADIATION STATUS}

Test GEFP2-132 was inserted in the ETR during the shutdown in late June, and was operating satisfactorily at $1000^{\circ} \mathrm{C}$. This test is a further irradiation of specimens previously irradiated and examined after dosages of 2 to $4 \times 10^{21} \mathrm{nvt}(\geq 1 \mathrm{Mev}$ ). Extension of the test into 1966 is expected to raise the total exposure on the specimens to 6 to $8 \times 10^{21}$ nvt.

Test GEFP2-134, which contains large specimens $(2.5 \mathrm{~cm}$ diameter $)$ for determination of size effects on irradiation behavior, continued operation at $900^{\circ} \mathrm{C}$.

Table 5.1 is a summary of the status and conditions of the current series of tests.

TABLE 5. 1

PLANNED IRRADIATION TESTS OF BeO

\begin{tabular}{|c|c|c|c|c|c|}
\hline \multirow[b]{3}{*}{ Test Number } & \multicolumn{2}{|c|}{ Irradiation Conditions } & \multirow[b]{3}{*}{ Purpose } & & \\
\hline & \multirow{2}{*}{ Temperature, } & \multirow{2}{*}{$\begin{array}{c}\text { Dosage, } \\
10^{20} \text { nvt } \\
I(\geq 1 \mathrm{Mev})\end{array}$} & & \multicolumn{2}{|c|}{$\begin{array}{c}\text { Approximate } \\
\text { Irradiation Dates }\end{array}$} \\
\hline & & & & Start & End \\
\hline GEFP2-216, GEFP2-217 & 100 & 1 to 2 & Evaluation of $\mathrm{BeO}+\mathrm{Be}$ and & $1 / 1 / 65$ & $3 / 31 / 65$ \\
\hline GEFP2-223, GEFP2-226 & 100 & 2 to 5 & Thermalox 995 compositions & & \\
\hline GEFP2-134 & 1000 & 10 to 20 & $\begin{array}{l}\text { Size effect and relative } \\
\text { thermal conductivity }\end{array}$ & $3 / 29 / 65$ & $2 / 66$ \\
\hline GEFP2-132 & 1000 & 20 to $40^{a}$ & $\begin{array}{l}\text { Determine if saturation of } \\
\text { expansion occurs }\end{array}$ & $6 / 15 / 65$ & $1 / 15 / 66$ \\
\hline GEFP2-135 & 1200 & 2 to $4^{a}$ & $\begin{array}{l}\text { Determine in-pile annealing } \\
\text { of previously induced defects }\end{array}$ & Tent & ative \\
\hline
\end{tabular}

a Figures shown are dosages to be added in this irradiation. These specimens have accumulated dosages of 2 to $6 \times 10^{21} \mathrm{nvt}(\geqslant 1 \mathrm{Mev})$ at about $1000^{\circ} \mathrm{C}$ in previous irradiations.

\section{MEASUREMENTS OF UNIRRADIATED BeO}

Strength

Modulus-of-rupture data were obtained at room and elevated temperatures on unirradiated EBOR and other $\mathrm{BeO}$ compositions containing glass-phase additives, and on various other $\mathrm{BeO}$ compositions that have been subjected to irradiation testing. These measurements will be used as control data for comparison with irradiated specimens; accordingly, these test specimens were fabricated from the same production and sintering batches as the specimen used in the irradiation tests. The test temperatures of the 
control specimen correspond to those used in irradiations. Relatively complete curves up to $1200^{\circ} \mathrm{C}$ were obtained for a few of the compositions.

The test method was the standard bending modulus-of-rupture measurement. Fourpoint loading was employed in some cases; however, the majority of the specimens were only 2.5 to $3.8 \mathrm{~cm}$ long so that three-point loading was necessary. All specimens were $0.6 \mathrm{~cm}$ diameter and were tested at a loading rate of $0.15 \mathrm{~cm}$ per minute.

In the summary of these data in Table 5.2, all experimental values were normalized for comparison to values applicable to specimens of $8.8 \mathrm{~cm}$ length under four-point loading. Normalization factors were based on comparisons made previously between threeand four-point loading on several specimen lengths; in general, results for 2.5 to $3.8 \mathrm{~cm}$ specimens under three-point loading were 15 to 20 percent higher than those for specimens $8.8 \mathrm{~cm}$ long under four-point loading. These normalization factors have not been verified for the particular compositions in the present study; hence, differences of only 5 to 10 percent in the strength of different materials is of questionable significance unless the specimens were of the same length.

There appeared to be no common trend in the strength behavior of the glass-phase relative to the non-glass-phase compositions with the possible exception of a reversal of the usual grain size - strength relationship. In the three instances in which both 5- and 20-micron grain sizes of the same composition were available, the strength of the smaller grain size materials was the smaller. A somewhat similar, but smaller, deviation from the grain size - strength relationship occurs in the straight $\mathrm{BeO}$ (AOX) and $\mathrm{BeO}+0.5$ weight percent MgO (UOX-MgO) compositions; the strength of specimens of 5-micron grain sizes is comparable to, rather than greater than, that of the 10- and 20-micron grain sizes.

Comparisons of the strength - temperature curves of straight $\mathrm{BeO}$ and compositions containing glass-phase additives are shown in Figures 5.1 and 5.2. The curve for the EBOR material is comparable to that of the AOX material of similar grain size up to $800^{\circ}$ to $1000^{\circ} \mathrm{C}$ but shows a larger strength decrease at $1200^{\circ} \mathrm{C}$. The relatively lower strength of the EBOR material appears to be due to the larger grain size since at room temperature the data for the EBOR materlal fits the strength - grain size curve of the AOX materials. The strength of the 5-micron material is also similar to that of the comparable AOX material. It thus appears that the 1 percent Bentonite additive has little effect on the strength other than at high temperatures.

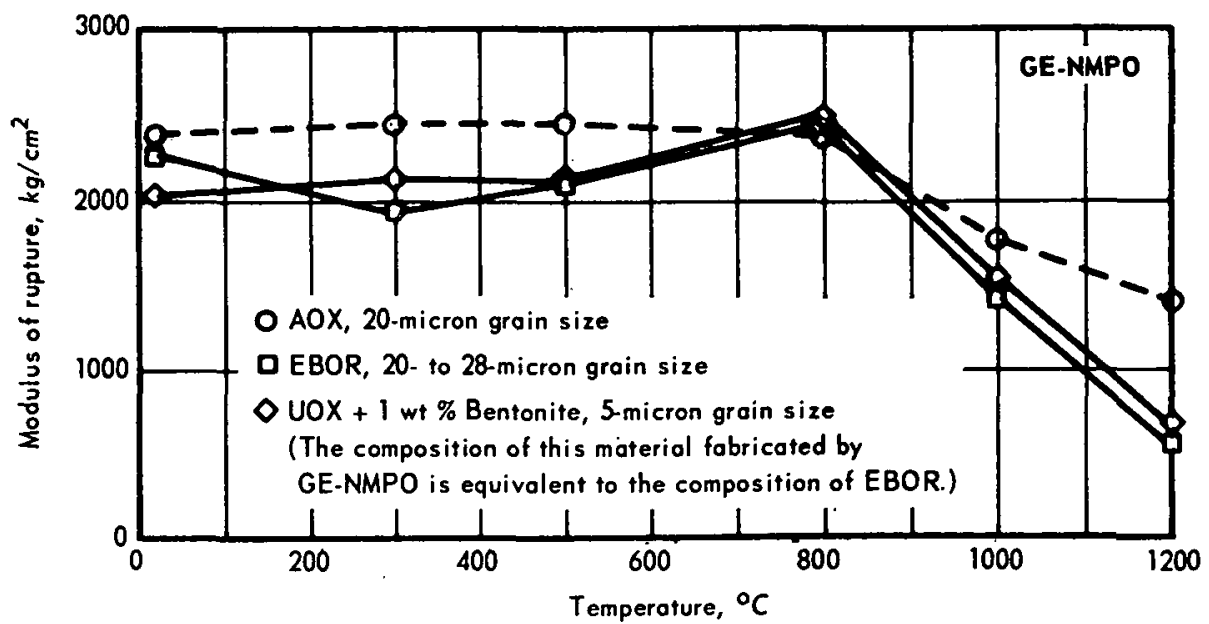

Fig. 5.1-Comporison of stiength - temperature properties of EBOR, EBOR-composition (UOX + 1 wt \% Bentonite), and AOX-grode BeO 
TABLE 5. 2

MODULUS OF RUPTURE OF UNIRRADIATED BEO

\begin{tabular}{|c|c|c|c|c|c|c|c|c|c|c|c|c|c|c|c|c|c|c|c|c|}
\hline \multirow[b]{3}{*}{ Composition $^{\mathrm{b}}$} & \multirow{3}{*}{$\begin{array}{c}\text { Nominal } \\
\text { Grain } \\
\text { Size, } \\
\text { microns }\end{array}$} & \multirow{3}{*}{$\begin{array}{l}\text { Nominal } \\
\text { Density, } \\
\mathrm{g} / \mathrm{cm}^{3}\end{array}$} & \multirow{3}{*}{$\begin{array}{l}\text { Test } \\
\text { Span, } \\
\mathrm{cm}\end{array}$} & \multicolumn{14}{|c|}{ Modulus Of Rupture ${ }^{a}$} & \multirow{2}{*}{\multicolumn{3}{|c|}{$1200^{\circ} \mathrm{C}$}} \\
\hline & & & & & Room Ter & mperature & \multicolumn{2}{|c|}{$300^{\circ} \mathrm{C}$} & \multicolumn{3}{|c|}{$500^{\circ} \mathrm{C}$} & \multicolumn{3}{|c|}{$800^{\circ} \mathrm{C}$} & \multicolumn{3}{|c|}{$1000^{\circ} \mathrm{C}$} & & & \\
\hline & & & & $\mathrm{N}^{\mathrm{c}}$ & $10^{3} \mathrm{psi}$ & $10^{3} \mathrm{~kg} / \mathrm{cm}^{2}$ & $\overline{\mathrm{N} 10^{3}} \overline{\mathrm{psi}}$ & $10^{3} \mathrm{~kg} / \mathrm{cm}^{3}$ & $\bar{N}$ & $10^{3} \overline{\mathrm{psi}}$ & $10^{3} \mathrm{~kg} / \mathrm{cm}^{2}$ & & $10^{3} \mathrm{psi}$ & $10^{3} \mathrm{~kg} / \mathrm{cm}^{2}$ & $\bar{N}$ & $10^{3} \mathrm{psi}$ & $10^{3} \mathrm{~kg} / \mathrm{cm}^{2}$ & & $10^{3} \mathrm{psi} 10$ & $0^{3} \mathrm{~kg} / \mathrm{cm}^{3}$ \\
\hline vox ${ }^{d}$ & 20 & 2.90 & 2.22 & 4 & 24.9 & 1.75 & - & - & 3 & 29.7 & 2.09 & 3 & 26.1 & 1.84 & 2 & 9.1 & 0.640 & - & - & - \\
\hline vOX-MgOe & 5 & 2.90 & 2.22 & 3 & 27.8 & 1.95 & - & - & 3 & 30.4 & 2.14 & 2 & 30.7 & 2.16 & 3 & 26.8 & 1.88 & - & - & - \\
\hline & 20 & 2.90 & 2.22 & 13 & 20.0 & 1.41 & - & - & - & - & - & - & - & - & - & - & - & - & - & - \\
\hline $\mathrm{UOX}+3$ wt $\mathrm{z}_{\mathrm{ZrO}}$ & 5 & 2.90 & 2. 22 & 5 & 35.2 & 2.48 & - & - & 3 & 28.1 & 1.98 & - & - & - & 4 & 31.6 & 2.22 & - & - & - \\
\hline $\mathrm{vOX}+1$ wt $\% \mathrm{Al}_{2} \mathrm{O}_{3}$ & 5 & 2.90 & 3.18 & 7 & 26.7 & 1.89 & - & - & - & - & - & - & - & - & - & - & - & - & - & - \\
\hline $\mathrm{UOX}+1$ wt $\%$ low $\mathrm{SiO}_{2}$ glass & 5 & 2.90 & 2.22 & 5 & 23.9 & 1.68 & 28.3 & 1.99 & 5 & 23.6 & 1.66 & 5 & 26.7 & 1.88 & 5 & 24.1 & 1.69 & 6 & 13.8 & 0.97 \\
\hline $\mathrm{UOX}+1$ wt $\%$ medium $\mathrm{SiO}_{2}$ glass & is 5 & 2. 90 & 3.18 & 13 & 30.9 & 2.17 & - & - & 1 & 36.7 & 2. 58 & 2 & 40.8 & 2. 87 & - & - & - & - & - & - \\
\hline & 20 & 2.90 & 2.22 & 5 & 31.3 & 2. 20 & $4 \quad 30.5$ & 2.14 & 4 & 30.8 & 2.16 & 5 & 43.6 & 3. 07 & 5 & 30.1 & 2.12 & 6 & 12.2 & 0.86 \\
\hline vOX +1 wt $\%$ high $\mathrm{SiO}_{2}$ glass & 20 & 2.90 & 3.18 & 6 & 38.2 & 2.69 & $4 \quad 34.9$ & 2.45 & 5 & 37.6 & 2.64 & 5 & 40.2 & 2. 83 & 5 & 38.2 & 2. 69 & $\mathbf{5}$ & 19.0 & 1.34 \\
\hline vOX +2 wt $\%$ high $\mathrm{SiO}_{2}$ glass & 20 & 2.90 & 2.22 & 9 & 28.2 & 1.98 & - & - & - & - & - & - & - & - & - & - & - & - & - & - \\
\hline vox +1 wt $\%$ Bentonite & 5 & 2.90 & 2.22 & 5 & 28.9 & 2.03 & 30.5 & 2.14 & 4 & 30.1 & 2.12 & 4 & 35.5 & 2.50 & 5 & 21.9 & 1.54 & 6 & 9.8 & 0.69 \\
\hline & 20 & 2.90 & 3.18 & 15 & 33.4 & 2. 35 & - & - & - & - & - & - & - & - & - & - & - & - & - & - \\
\hline vOX +2 wt $\%$ Bentonite & 5 & 2.90 & 4.45 & 3 & 25.3 & 1.78 & - & - & - & - & - & - & - & - & - & - & - & _- & - & - \\
\hline & 20 & 2.90 & 3.18 & 2 & 27.9 & 1.96 & - & - & - & - & - & - & - & - & - & - & - & - & - & - \\
\hline $\mathrm{vOX}+1 \mathrm{wt} \% \mathrm{Be}$ & 20 & 2.90 & 2.22 & 5 & 31.0 & 2.18 & - & - & - & - & - & - & - & - & - & - & - & - & - & - \\
\hline$v O X+2$ wt $\% \mathrm{Be}^{\mathrm{d}}$ & 20 & 2.90 & 2.22 & 4 & 30.4 & 2.14 & - & - & - & - & - & - & - & - & - & - & - & - & - & - \\
\hline Thermalox-995 $A^{f}$ & 9 & 2.90 & 2.22 & 5 & 24.2 & 1.70 & - & - & - & - & - & - & - & - & - & - & - & - & - & - \\
\hline EBOR $^{f}$ & $20-28$ & 2.90 & 2.22 & 33 & 32.2 & 2.26 & 27.6 & 1.94 & 8 & 29.9 & 2.10 & 8 & 34.7 & 2.44 & 9 & 20.2 & 1.42 & 7 & 8.1 & 0.57 \\
\hline NGK BeO ${ }^{e, g}$ & $1-2$ & 2.65 & 2.22 & 5 & 18.4 & 1.29 & - & - & - & - & - & - & - & - & - & - & - & - & - & - \\
\hline & $3-4$ & 2.85 & 2.22 & 3 & 25.8 & 1.81 & - & - & - & - & - & - & - & - & 4 & 20.5 & 1.44 & - & - & - \\
\hline WGK $\mathrm{BeO}+2$ wt $\% \mathrm{Be}^{d}$ & 5 & 2.97 & 2.22 & 3 & 39.3 & 2. 76 & - & - & 2 & 41.2 & 2. 90 & 2 & 35.1 & 2.47 & 2 & 28.1 & 1.98 & - & - & - \\
\hline
\end{tabular}

a The specimens were of several different lengths and both 3 - and 4-point loading was employed. For comparison, all modulus-of-rupture values have been normalized to the values obtained with specimens under 4-point loading over a $7.62-\mathrm{cm}$ span. Actual modulus-of-rupture values obtained with 3-point loading on $2.22-$ or $3.18-\mathrm{cm}$ span were normalized by multiply ing by 0.3 , those for 1-point loacing on $4.45-\mathrm{cm}$ span by the factor 0.86 . Normalization factors were established in previous comparative tests.

All zompositior.s were extruded except those noted.

Number of samples.

dCompositions were hot-pressed.

Compositions were isostatically pressed.

fCompositions were cold-pressed and sintered.

BNGE--grade BeO is a product of NGK Insulators, Ltd., Nagoya, Japan. 


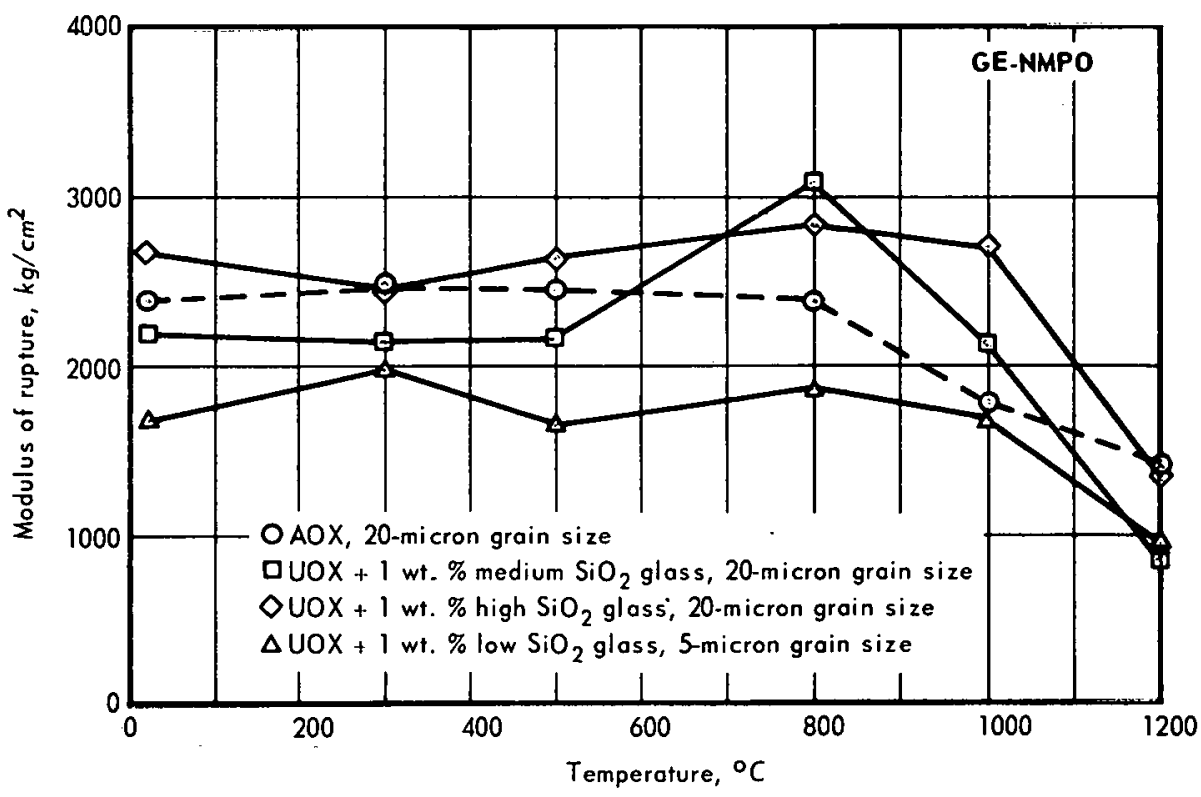

Fig. 5.2 - Comporison of strength - temperature properties of AOX-grade BeO and $\mathrm{UOX}$-grade $\mathrm{BeO}$ contoining 1 weight percent additives of various silica glosses

The curves in Figure 5.2 show that while the silica glass additives adversely affect the strength of 5-micron materials, they increase the strength in specimens of 20 -micron grain size. The increased strength extends at least to $1000^{\circ}$ to $1200^{\circ} \mathrm{C}$ and appears to increase with increasing silica content of the additive.

\section{MEASUREMENTS OF IRRADIATED BEO}

High-Dosage Irradiation at $1000^{\circ} \mathrm{C}$

Specimens irradiated to dosages of 3.5 to $4.7 \times 10^{21} \mathrm{nvt}(\geq 1 \mathrm{Mev})$ at $1000^{\circ} \mathrm{C}$ (test $33 \mathrm{MT}-111$ ) were examined for changes in dimensions, open porosity, elastic constants, and strength. The exposure extended over seven reactor cycles and the samples were subjected to 127 thermal cycles, due to changes in reactor power, in which the temperature dropped at least $300^{\circ} \mathrm{C}$. Temperature control was nominally maintained at $1000^{\circ}$ $\pm 50^{\circ} \mathrm{C}$; four of the six thermocouples were lost at various times during the irradiation, however, and it was assumed for temperature control purposes that the temperature profile over the cartridge was the same throughout the irradiation. This assumption is supported by test data in previous tests and by thermal analysis considering the dimensional changes of the specimens.

The specimens in this test received the highest dosages yet attained in this program and appeared to be in sound condition. A summary of the data is given in Table 5.3. Expansion of the AOX and UOX-MgO materials of 5-micron grain size was 2 to 3 percent, approximately 0.5 percent larger than that of specimens exposed at $1000^{\circ} \mathrm{C}$ to dosages of 2.5 to $3 \times 10^{21}$ nvt. Only a few strength data were obtained since most of these specimens were inserted in test GEFP2-132 for further irradiation; those few data indicated that the strength of the specimens of 5-microns grain size was about equal to the unirradiated value while that of the EBOR material decreased approximately 40 percent.

Since the pattern of strength changes on irradiation appears to be an increase up to the point at which microcracking occurs, the lack of change in some of the 5-micron materials probably indicates a limited amount of microcracking. (Similar specimens at the 
TABLE 5.3

SUMMARY OF RADIATION EFFECTS IN BEO SPECIMENS IRRADIATED AT APPROXIMATELY $1000^{\circ} \mathrm{C}$ TO 3.5 TO $4.7 \times 10^{21} \mathrm{nvt}(\geq 1 \mathrm{Mev}$ )

\begin{tabular}{|c|c|c|c|c|c|c|c|c|c|c|c|c|c|c|c|c|c|c|}
\hline \multirow{2}{*}{$\begin{array}{l}\text { Specimen } \\
\text { Composition }\end{array}$} & \multirow{2}{*}{$\begin{array}{c}\text { n Descrip } \\
\text { Grain } \\
\text { Size, } \\
\text { microns }\end{array}$} & \multirow{2}{*}{$\begin{array}{l}\text { ption } \\
\begin{array}{l}\text { Density, } \\
\mathrm{g} / \mathrm{cm}^{3}\end{array}\end{array}$} & \multicolumn{2}{|c|}{$\begin{array}{c}\begin{array}{c}\text { Irradiation } \\
\text { Conditions }\end{array} \\
\text { Dosage, }\end{array}$} & & & & \multirow{2}{*}{$\begin{array}{c}\text { Increase } \\
\text { In Open } \\
\text { Porosity, } \\
\% \\
\end{array}$} & \multicolumn{7}{|c|}{ Elastic Constants } & \multicolumn{3}{|c|}{$\begin{array}{l}\text { Room Temperature } \\
\text { Modulus Of Rupture }\end{array}$} \\
\hline & & & $\begin{array}{l}\text { Dosage, } \\
10^{21} \text { nvt } \\
(>1 \mathrm{Mev})\end{array}$ & $\begin{array}{l}\text { Flux } \\
10^{14}\end{array}$ & \multicolumn{3}{|c|}{ Expansion, percent } & & $\begin{array}{r}\text { Yol } \\
10^{6} \text { psi d }\end{array}$ & $\begin{array}{l}\frac{\text { ung's Mod }}{10^{20}} \\
\text { yne } / \mathrm{cm}^{2}\end{array}$ & $\begin{array}{l}\text { Pulus } \\
\text { Percent Of } \\
\text { Original }\end{array}$ & $10^{6} \mathrm{psi}$ & $\begin{array}{c}\text { Shear Mod } \\
10^{20} \\
\text { dyne } / \mathrm{cm}^{2}\end{array}$ & $\begin{array}{l}\text { dulus } \\
\text { Percent Of } \\
\text { Unirradiated }\end{array}$ & $\begin{array}{c}\text { Apparent } \\
\text { Poisson's } \\
\text { Ratio } \\
\end{array}$ & \multicolumn{2}{|c|}{$\begin{array}{c}10^{3} \\
10^{3} \mathrm{psi} \mathrm{kg} / \mathrm{cm}^{2}\end{array}$} & \multirow{2}{*}{$\begin{array}{c}\text { Percent of } \\
\text { Unirradiated } \\
-\end{array}$} \\
\hline \multirow[t]{13}{*}{$\mathrm{UOX}+\mathrm{MgO}$} & 4 & 2.60 & 4.3 & 2.6 & 0.7 & 0.8 & 2.2 & 10 & 38.9 & 2.68 & 94 & 15.6 & 1.08 & 94 & 0.24 & - & - & \\
\hline & & & 4.3 & 2.6 & 0.8 & 0.9 & 2.5 & $\sim 12$ & 38.3 & 2.64 & 91 & 15.3 & 1.05 & 91 & 0.25 & - & - & - \\
\hline & & & 4.6 & 2.7 & 0.7 & 0.8 & 2.2 & 1.8 & 40.0 & 2.76 & 95 & 16.0 & 1.10 & 95 & 0.25 & - & - & - \\
\hline & & & 4.7 & 2.8 & 0.8 & 0.8 & 2.4 & $\sim 14$ & - & - & - & - & - & - & - & 23.6 & 1.66 & 78 \\
\hline & 5 & 2.75 & 4.4 & 2.6 & 0.5 & 0.5 & 1.5 & 2.0 & 43.5 & 3.00 & 97 & 17.7 & 1.22 & 96 & 0.23 & 31.8 & 2.24 & 100 \\
\hline & & & 4.6 & 2.7 & 0.7 & 0.9 & 2.3 & 2.4 & - & - & - & - & - & - & - & - & - & - \\
\hline & & & 4.7 & 2.7 & 0.6 & 0.7 & 1.9 & 1.6 & 42.9 & 2.96 & 95 & 17.5 & 1.21 & 95 & 0.23 & - & - & - \\
\hline & 5 & 2.90 & 4.4 & 2.6 & 0.5 & 0.6 & 1.6 & 0.9 & 50.2 & 3.46 & 97 & 20.2 & 1.39 & 92 & 0.25 & - & - & - \\
\hline & & & 4.6 & 2.7 & 0.6 & 0.8 & 2.0 & 0.2 & 51.0 & 3.52 & 95 & 20.7 & 1.43 & 94 & 0.23 & - & - & - \\
\hline & & & 4.7 & 2.7 & 0.8 & 1.0 & 2.6 & 0.1 & 50.3 & 3.47 & 94 & 20.6 & 1.42 & 94 & 0.22 & - & - & - \\
\hline & & & 4.2 & 2.5 & 0.7 & 1.0 & 2.4 & 1.5 & 50.2 & 3.46 & 94 & 20.5 & 1.41 & 93 & 0.22 & 29.6 & 2.08 & 96 \\
\hline & 7 & 2.90 & 4.4 & 2.6 & 0.6 & 0.8 & 2.0 & 0.3 & 51.1 & 3.52 & 94 & 20.6 & 1.42 & 96 & 0.24 & 36.0 & 2.53 & 105 \\
\hline & 17 & 2.90 & 4.4 & 2.6 & 0.5 & 0.7 & 1.7 & 0 & 52.7 & 3.63 & 95 & 20.2 & 1.39 & 96 & 0.31 & - & - & - \\
\hline \multirow[t]{6}{*}{ AOX } & 2 & 2.60 & 3.5 & 2.0 & 0.6 & 0.8 & 2.0 & $\sim 8$ & 40.3 & 2.78 & 94 & 16.6 & 1.14 & 90 & 0.22 & - & - & - \\
\hline & & & 4.6 & 2.7 & 0.8 & 0.8 & 2.4 & $\sim 8$ & 40.1 & 2.76 & 94 & 16.6 & 1.14 & 91 & 0.21 & 21.8 & 1.53 & 101 \\
\hline & & & 4.6 & 2.7 & 0.9 & 0.9 & 2.7 & $\sim 8$ & 40.1 & 2.76 & 94 & 16.6 & 1.14 & 91 & 0.20 & - & - & - \\
\hline & 5 & 2.90 & 4.6 & 2.7 & 0.7 & 0.8 & 2.2 & 0.9 & 47.2 & 3.25 & 95 & 19.5 & 1.34 & 95 & 0.21 & - & - & - \\
\hline & & & 4.6 & 2.7 & 1.0 & 1.0 & 3.0 & 1.1 & 46.4 & 3.20 & 93 & 19.2 & 1.32 & 93 & 0.21 & - & - & - \\
\hline & 17 & 2.90 & 4.4 & 2.6 & 0.7 & 0.7 & 2.1 & 1.9 & 39.9 & 2.75 & 76 & 16.2 & 1.12 & 75 & 0.23 & - & - & - \\
\hline \multirow[t]{2}{*}{ Uor: } & 6 & 2.90 & 4.6 & 2.7 & 0.7 & 0.8 & 2.2 & 0.4 & 50.2 & 3.46 & 93 & 20.3 & 1.40 & 96 & 0.21 & - & - & - \\
\hline & & & 4.2 & 2.5 & 0.9 & 1.1 & 2.9 & 1.5 & 28.1 & 1.94 & 52 & 11.6 & 0.80 & 55 & 0.24 & - & - & - \\
\hline \multirow[t]{3}{*}{$\mathrm{UOX}+\mathrm{ZrO}_{2}$} & 5 & 2.90 & 4.7 & 2.8 & 0.9 & 1.0 & 2.8 & 1.2 & 48.1 & 3.32 & 98 & 19.0 & 1.31 & 93 & 0.27 & - & - & - \\
\hline & & & 4.6 & 2.7 & 0.8 & 1.0 & 2.6 & 0.8 & 47.7 & 3.29 & 97 & 19.6 & 1.35 & 96 & 0.22 & - & - & - \\
\hline & & & 3.5 & 2.0 & 0.7 & 0.8 & 2.2 & 0.2 & 49.1 & 3.38 & 100 & 20.3 & 1.40 & 99 & 0.21 & - & - & - \\
\hline \multirow[t]{3}{*}{ EBOR } & 29 & 2.90 & 4.6 & 2.7 & 1.3 & 1.4 & 4.0 & 3.3 & 35.3 & 2.43 & 75 & 14.7 & 1.01 & 75 & 0.20 & - & - & - \\
\hline & & & 4.5 & 2.6 & 1.2 & 1.3 & 3.7 & 2.6 & 38.0 & 2.62 & 81 & 15.9 & 1.10 & 81 & 0.20 & - & - & - \\
\hline & & & 4.4 & 2.6 & 1.4 & 1.4 & 4.2 & 4.2 & 33.4 & 2.30 & 71 & 13.9 & 0.96 & 73 & 0.20 & 18.7 & 1.32 & 58 \\
\hline \multirow[t]{3}{*}{$\mathrm{UOX}+\mathrm{Al}_{2} \mathrm{O}_{3}$} & 5 & 2.90 & 4.5 & 2.6 & 0.6 & - & 2.7 & 0.5 & - & - & - & - & - & - & - & - & - & - \\
\hline & 3 & & 4.7 & 2.7 & 1.6 & 1.9 & 5.1 & 7.6 & 38.2 & 2.63 & 67 & $16 . \dot{2}$ & 1.12 & 76 & 0.18 & 22.4 & 1.58 & 84 \\
\hline & 17 & & 4.6 & 2.7 & 1.0 & 1.2 & 3.2 & 0.6 & 46.7 & 3.22 & 82 & 17.9 & 1.23 & 89 & 0.30 & - & - & - \\
\hline
\end{tabular}


2.5 to $3.0 \times 10^{21}$ dosage exhibited strength increases ranging up to 40 percent.) Open porosity and elastic constant measurements also indicate that some microcracking occurred. The open porosity increased 1 to 2 percent in most of the specimens of 5-micron grain size; however, in a few of the specimens the increase was only 0.1 to 0.2 percent. In the EBOR specimens, which were of the largest grain size in this test, the open porosity increased about 4 percent. The elastic constants decreased 5 to 7 percent in most of the specimens but in a few instances larger decreases were observed, notably in the EBOR specimens which decreased about 20 percent. Previous experience has indicated that decrease in elastic constants of 15 to 20 percent is reasonably sound evidence of microcracking.

Thermal Diffusivity - Thermal Conductivity

Thermal diffusivity measurements were completed on the first irradiated BeO specimen following check-out runs on Armco iron and unirradiated BeO. The test method utilized is the flash or transient heat flow method wherein a radiant heat pulse is applied to the front surface of a specimen maintained at the test temperature and the thermal diffusivity is derived from the time dependence of the temperature rise on the back surface. ${ }^{1,2}$ Under ideal conditions of uniform thermal irradiation of the specimen surface, the diffusivity, $\alpha$, is obtained from the expression:

$$
\alpha=0.139 \mathrm{~L}^{2} / \mathrm{t}_{1 / 2}
$$

where $L$ is the specimen length and $t_{1 / 2}$ is the elapsed time between application of the pulse and the time at which the temperature rise on the back surface attains half of its maximum value. Thermal conductivity values, $K$, are att ainable from the relation:

$$
\mathrm{K}=\alpha \mathrm{C}_{\mathrm{p}} \rho
$$

where $C_{p}$ is the specific heat at constant pressure and $\rho$ is the specimen density.

This method appears ideal for measurements of irradiated specimens because of the small specimen size. The $B e O$ specimens used range from 0.114 to $0.165 \mathrm{~cm}$ in length by $0.6 \mathrm{~cm}$ diameter, a size obtainable from irradiated specimens. Based on experience thus far, the method is capable of great precision (within 1\%) and the major source of error would appear to be possible inhomogeneity in the small specimens.

The GE-NMPO equipment utilizes a laser for application of the heat pulse, furnace heating of the sample, and a lead sulfide detector. The laser is cylindrically reflected and has a total output of 4.5 joules; about 1.5 to 2 joules impinge on the specimen after collimation of the beam. The specimen is supported in a knife edge holder located in the center of a standard $35.6-\mathrm{cm}$-long platinum resistance furnace. With the large heated zone and the collimation baffles, the specimen approaches black-body conditions and radiation losses should be minimized. The temperature history of the back surface of the specimen following a heat pulse is determined from a Polaroid Land photograph of oscilloscope tracings of the output of a lead sulfide detector operated at liquid nitrogen temperature. With this detector, the lower temperature limit for measurements is approximately $300^{\circ} \mathrm{C}$.

Initial measurements with the equipment were made on Armco iron for purposes of verifying the equipment and experimental procedures. The GE-NMPO diffusivity data are

\footnotetext{
${ }^{1}$ W. J. Parker, R. J. Jenkins, C. P. Butler, and G. L. Abbott, "Flash Method of Determining Thermal Diffusivity, Heat Capacity, and Thermal Conductivity." Jourual of Applied Pliysirs. Vol. 32, 1961, p. 1679.

${ }^{2}$ R. L. Rudkin, R. J. Jenkins, and W. J. Parker, "Thermal Diffusivity Measurements on Metals at High Temperatures," Revien of Sicienlific Instrume'nts, Vol. 33, 1962, p. 21.
} 
compared to previous data ${ }^{3,4,5}$ in Figure 5.3 and the detailed data are tabulated in Table 5.4. In general, good agreement was obtained with the previous work.

The diffusivity measurements on $\mathrm{BeO}$ were made on $\mathrm{UOX}+0.5$ weight percent $\mathrm{MgO}$ specimens of 4 -micron grain size and $2.9 \mathrm{~g} / \mathrm{cm}^{3}$ density. Both the unirradiated and irradiated samples were obtained from specimens of the same extrusion and sintering batch. The irradiated specimen had expanded 2.0 percent due to the irradiation exposure but was not microcracked as evidenced by a strength increase of 40 percent. Because of the relatively large variation of the diffusivity of $\mathrm{BeO}$ over the temperature range of $300^{\circ}$ to $1000^{\circ} \mathrm{C}$, two samples were required to establish the curves. Samples $0.165 \mathrm{~cm}$ long were used up to $600^{\circ} \mathrm{C}$ and samples $0.114 \mathrm{~cm}$ long were used in the range from $500^{\circ}$ to $1000^{\circ} \mathrm{C}$, the overlap in temperature providing a further check on the precision of the measurements.

TABLE 5.4

COMPARISON OF THERMAL DIFFUSIVITY DATA ON ARMCO IRON

\begin{tabular}{|c|c|c|c|c|c|c|c|}
\hline \multicolumn{2}{|c|}{ NMPO Data ${ }^{a}$} & \multicolumn{2}{|c|}{$\begin{array}{c}\text { Data of } \\
\text { Sidles and Danielson }{ }^{b}\end{array}$} & \multicolumn{2}{|c|}{$\begin{array}{c}\text { Data of } \\
\text { Cody, AbeIs, and Beers }{ }^{c}\end{array}$} & \multicolumn{2}{|c|}{$\begin{array}{c}\text { Data of } \\
\text { Godfrey, et ald }\end{array}$} \\
\hline$\underset{{ }^{\circ} \mathrm{C}}{\text { Temperature, }}$ & $\begin{array}{c}\text { Thermal } \\
\text { Diffusivity, } \\
\mathrm{cm}^{2} / \mathrm{sec}\end{array}$ & $\begin{array}{c}\text { Temperature, } \\
{ }^{\circ} \mathrm{C}\end{array}$ & $\begin{array}{c}\text { Thermal } \\
\text { Diffusivity, } \\
\mathrm{cm}^{2} / \mathrm{sec}\end{array}$ & $\begin{array}{c}\text { Temperature, } \\
{ }^{\circ} \mathrm{C}\end{array}$ & $\begin{array}{c}\text { Thermal } \\
\text { Diffusivity, } \\
\mathrm{cm}^{2} / \mathrm{sec}\end{array}$ & Temperature, & $\begin{array}{c}\text { Thermal } \\
\text { Diffusivity, } \\
\mathrm{cm}^{2} / \mathrm{sec}\end{array}$ \\
\hline 303 & $0.123_{g}$ & 300 & 0.129 & 270 & 0.132 & 300 & 0.1227 \\
\hline 350 & $0.113_{6}^{7}$ & 350 & 0.118 & 350 & 0.110 & 400 & 0.1012 \\
\hline 403 & $0.103_{5}$ & 400 & 0.107 & 440 & 0.096 & 500 & 0.0832 \\
\hline 447 & 0.0960 & 450 & 0.097 & 550 & 0.078 & 600 & 0.0664 \\
\hline 499 & $0.087_{3}$ & 500 & 0.087 & 555 & 0.075 & 700 & 0.0471 \\
\hline 554 & $0.077_{8}$ & 550 & 0.077 & 620 & 0.064 & 720 & 0.0428 \\
\hline 599 & $0.069_{9}$ & 600 & 0.069 & 660 & 0.057 & 730 & 0.0408 \\
\hline 652 & $0.061_{0}$ & 650 & 0.060 & 720 & 0.045 & 750 & 0.0362 \\
\hline 704 & $0.051_{3}$ & 700 & 0.050 & 740 & 0.041 & 760 & 0.0327 \\
\hline 725 & $0.046_{8}$ & 750 & 0.037 & 740 & 0.040 & 780 & 0.0396 \\
\hline 749 & $0.041_{0}$ & 770 & 0.033 & 760 & 0.033 & 800 & 0.0437 \\
\hline 767 & $0.034_{1}$ & 800 & 0.045 & 775 & 0.040 & 820 & 0.0462 \\
\hline 801 & $0.035_{8}$ & 850 & 0.052 & 790 & 0.043 & 850 & 0.0491 \\
\hline 853 & $0.050_{7}^{\circ}$ & 867 & 0.054 & 800 & 0.044 & 900 & 0.0520 \\
\hline 900 & $0.053_{2}$ & 925 & 0.062 & 820 & 0.047 & 925 & 0.0601 \\
\hline 949 & 0.0627 & 950 & 0.063 & 845 & 0.049 & 950 & 0.0604 \\
\hline \multirow[t]{8}{*}{1005} & $0.064_{3}$ & 1000 & 0.064 & 860 & 0.049 & 1000 & 0.0610 \\
\hline & & & & 900 & 0.054 & & \\
\hline & & & & 900 & 0.053 & & \\
\hline & & & & 920 & 0.062 & & \\
\hline & & & & 920 & 0.060 & & \\
\hline & & & & 950 & 0.061 & & \\
\hline & & & & 950 & 0.060 & & \\
\hline & & & & 1000 & 0.061 & & \\
\hline
\end{tabular}

${ }^{a}$ We are indebted to $\mathrm{H}$. W. Deem of Battelle Memorial Institute for the Armco Iron sample material. The material is of the same heat, but not the specific pieces, as the BMI "round robin" thermal conductivity material.

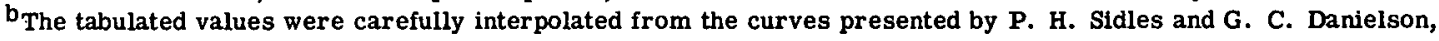
"Thermal Diffusivity Measurements at High Temperatures," Thermoelectricity, P. H. Egli, Ed., John Wiley and Sons, Inc., New York, 1960, p. 279.

cG. D. Cody, B. Abeles, and D. S. Beers, "Thermal Diffusivity of Armco Iron," Transactions of Metallurgical Society, AIME, Vol. 221, 1961, p. 25.

dT. G. Godfrey, W. Fulkerson, T. G. Kollie, J. P. Moore, and D. L. McElroy, "Thermal Conductivity of Uranium Dioxide and Armco Iron by an Improved Radial Heat Flow Technique," ORNL-3556, June 1964, p. 57.

${ }^{3}$ P. II. Sidles and G. C. Danielson, "Thermal Diffusivity Measurements at High Temperatures," Thromor/r.rririty;

P. H. Egli, Ed., John Wiley and Sons, Inc., New York, 1960, p. 279.

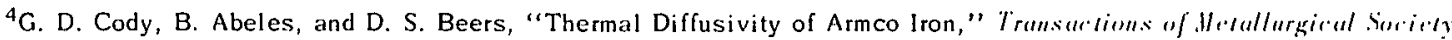
IIIIl:, Vol. 221, 1961, p. 25.

${ }^{5}$ T. G. Godfrey, W. Fulkerson, T. G. Kollie, J. P. Moore, and D. L. McElroy, "Thermal Conductivity of Uranium Dioxide and Armco Iron by an Improved Radial Heat Flow Technique," ORNL-3556, June 1964, p. 57. 


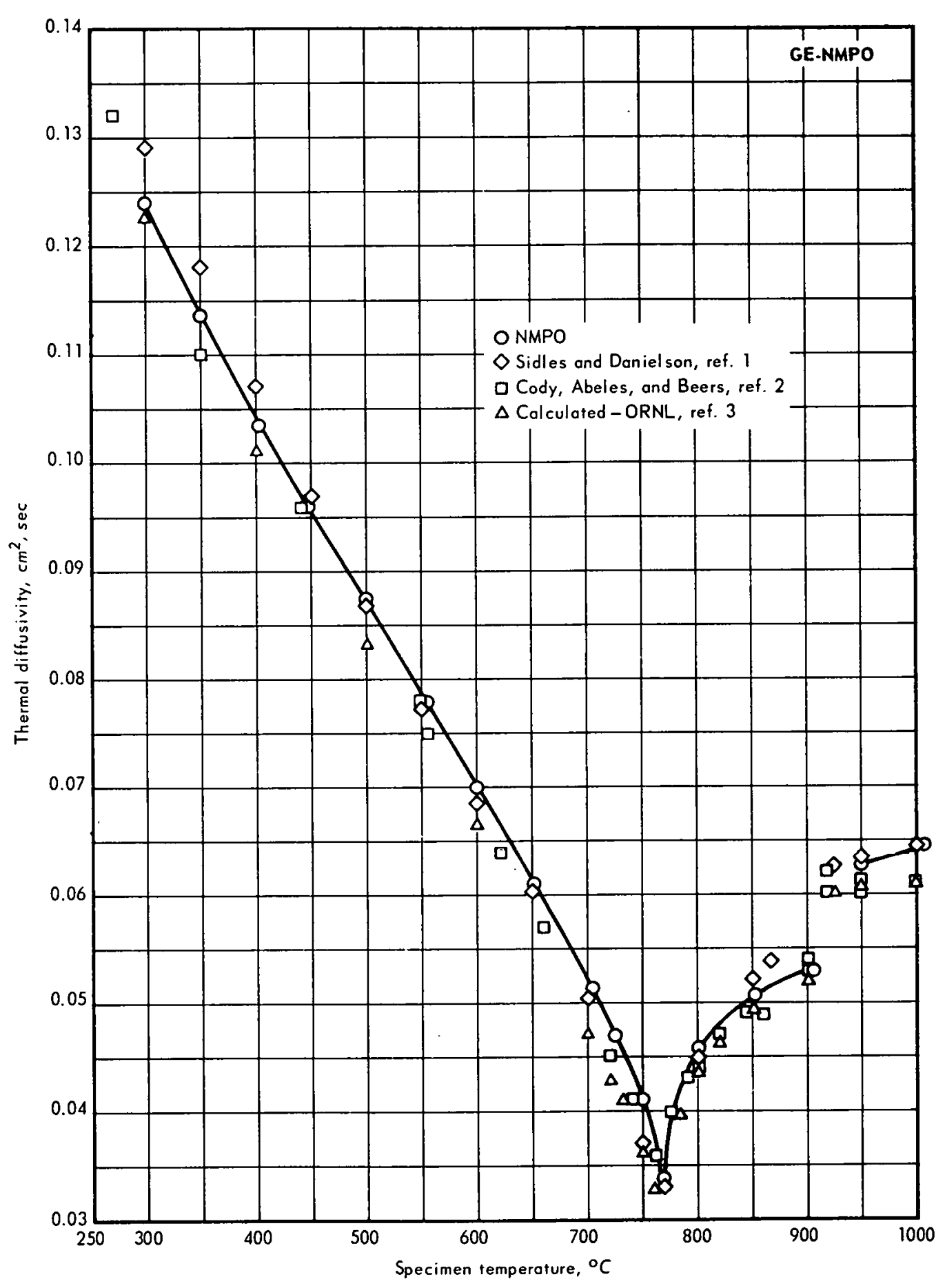

Fig. 5.3 - Thermal diffusivity of Armco iron 
Since BeO is semi-transparent to the laser light, coating of the surfaces of the specimens was necessary to meet the surface energy absorption requirements of the method. Tungsten coatings of approximately 5 microns thickness on the front and back surface proved satisfactory. These coatings were applied in electron-beam welding equipment.

Data for the unirradiated specimen, Table 5.5, are in reasonably good agreement with the data of Rudkin ${ }^{6}$ and of Taylor ${ }^{7}$ for BeO specimens of comparable density, as shown in Figure 5.4. The extent to which the UOX-MgO composition should compare with pure BeO is not established at present; however, it seems unlikely that the 0.5 weight percent $\mathrm{MgO}$ appreciably affects the diffusivity.

TABLE 5.5

COMPARISON OF THERMAL DIFFUSIVITY DATA ON UNIRRADIATED BEO

\begin{tabular}{|c|c|c|c|c|c|c|c|}
\hline \multirow{2}{*}{\multicolumn{2}{|c|}{ NMPO Data ${ }^{a, b}$}} & \multirow{2}{*}{\multicolumn{2}{|c|}{ Data of Rudkin ${ }^{\mathrm{c}, d}$}} & \multicolumn{4}{|c|}{$\begin{array}{l}\text { Data derived from thermal conductivity measurements } \\
\text { of Taylor } e, f\end{array}$} \\
\hline & & & & & & & Calculated \\
\hline $\begin{array}{l}\text { Temperature, } \\
{ }^{\circ} \mathrm{C}\end{array}$ & $\begin{array}{c}\text { Thermal } \\
\text { Diffusivity, } \\
\mathrm{cm}^{2} / \mathrm{sec}\end{array}$ & $\begin{array}{l}\text { Temperature, } \\
{ }^{\circ} \mathrm{C}\end{array}$ & $\begin{array}{c}\text { Thermal } \\
\text { Diffusivity, } \\
\mathrm{cm}^{2} / \mathrm{sec}\end{array}$ & $\begin{array}{l}\text { Temperature, } \\
{ }^{\circ} \mathrm{C}\end{array}$ & $\begin{array}{l}\text { Specific Heat, } \mathrm{g} \\
\text { cal } / \mathrm{g}-{ }^{\circ} \mathrm{C}\end{array}$ & $\begin{array}{l}\text { Thermal } \\
\text { Conductivity, } \\
\mathrm{cal} / \mathrm{cm}-\mathrm{sec}-{ }^{\circ} \mathrm{C}\end{array}$ & $\begin{array}{c}\text { Thermal } \\
\text { Diffusivity, } \\
\mathrm{cm}^{2} / \mathrm{sec}\end{array}$ \\
\hline 300 & $0.199_{2}$ & 797 & 0.0795 & 627 & 0.4597 & 0.132 & 0.096 \\
\hline 322 & $0.191_{3}$ & 797 & 0.0772 & 677 & 0.4659 & 0.117 & 0.084 \\
\hline 348 & 0.1807 & 805 & 0.0735 & 727 & 0.4717 & 0.105 & 0.075 \\
\hline 371 & $0.172_{0}$ & 807 & 0.0715 & 777 & 0.4771 & 0.096 & 0.067 \\
\hline 404 & $0.161_{0}$ & 810 & 0.0693 & 827 & 0.4822 & 0.088 & 0.061 \\
\hline 447 & $0.146_{9}$ & 837 & 0.0643 & 877 & 0.4870 & 0.081 & 0.055 \\
\hline 501 & $0.129_{1}$ & 840 & 0.0627 & 927 & 0.4916 & 0.075 & 0.051 \\
\hline 555 & $0.114_{5}^{2}$ & 873 & 0.0590 & 1000 & 0.498 & 0.068 & 0.046 \\
\hline 598 & $0.105_{3}$ & 880 & 0.0582 & & & & \\
\hline 500 & $0.129_{3}$ & 995 & 0.0513 & & & & \\
\hline 598 & $0.125_{0}$ & 1005 & 0.0507 & & & & \\
\hline 698 & 0.0857 & & & & & & \\
\hline 798 & $0.072_{4}$ & & & & & & \\
\hline 900 & $0.060_{9}$ & & & & & & \\
\hline 996 & $0.053_{1}$ & & & & & & \\
\hline
\end{tabular}

apecimen: UOX +0.5 weight percent MgO of 4 -micron grain size and density of $2.92 \mathrm{~g} / \mathrm{cm}^{3}$.

$b_{D a t a}$ above and below the line were obtained from specimens of different lengths.

$c_{R}$. L. Rudkin, "Thermal Diffusivity on Metals and Ceramics at High Temperatures," ASD-TDR-62-24, Part II, 1963, pp. 1-16.

d Specimen: BeO, 97 percent of theoretical density.

e R. E. Taylor, "Thermal Conductivity and Thermal Expansion of BeO at Elevated Temperatures," NAA-SR-4905, July 1960.

f Specimen: BeO, 99 percent of theoretical density.

gSpecific heat values were derived from: A. C. Victor and T. B. Douglas, Journal of Research, NBS Vol. 67A, No. 4, July-August 1963.

The diffusivity of the irradiated $\mathrm{BeO}$ specimens was lower than that of the unirradiated specimen by amounts ranging from 15 percent at $400^{\circ} \mathrm{C}$ to 4 percent at $1000^{\circ} \mathrm{C}$, as indicated in Figure 5.5. The measurements, summarized in Table 5.6, were made in ascending order of temperature and at $600^{\circ} \mathrm{C}$ some thermal annealing of damage in the specimen occurred as the specimen was maintained at this temperature overnight. Although some further annealing probably occurred at still higher temperatures, the diffusivity curve appears consistent with, but slightly displaced from, the $400^{\circ}$ to $600^{\circ} \mathrm{C}$ portion of the curve. The reason for annealing at $600^{\circ}$ in a sample irradiated at $1000^{\circ} \mathrm{C}$ is readily explained by a short low temperature exposure at the end of the irradiation. At reactor start-up of the final exposure, the temperature of the samples in the test cartridge could

${ }^{6}$ R. L: Rudkin, "Thermal Diffusivity on Metals and Ceramics at High Temperatures," ASD-TDR-62-24, Part II, 1963. pp. 1-16.

${ }^{7}$ R. E. Taylor, "Thermal Conductivity and Thermal Expansion of BeO at Elevated Temperatures," NAA-SR-4905, July 1960. 


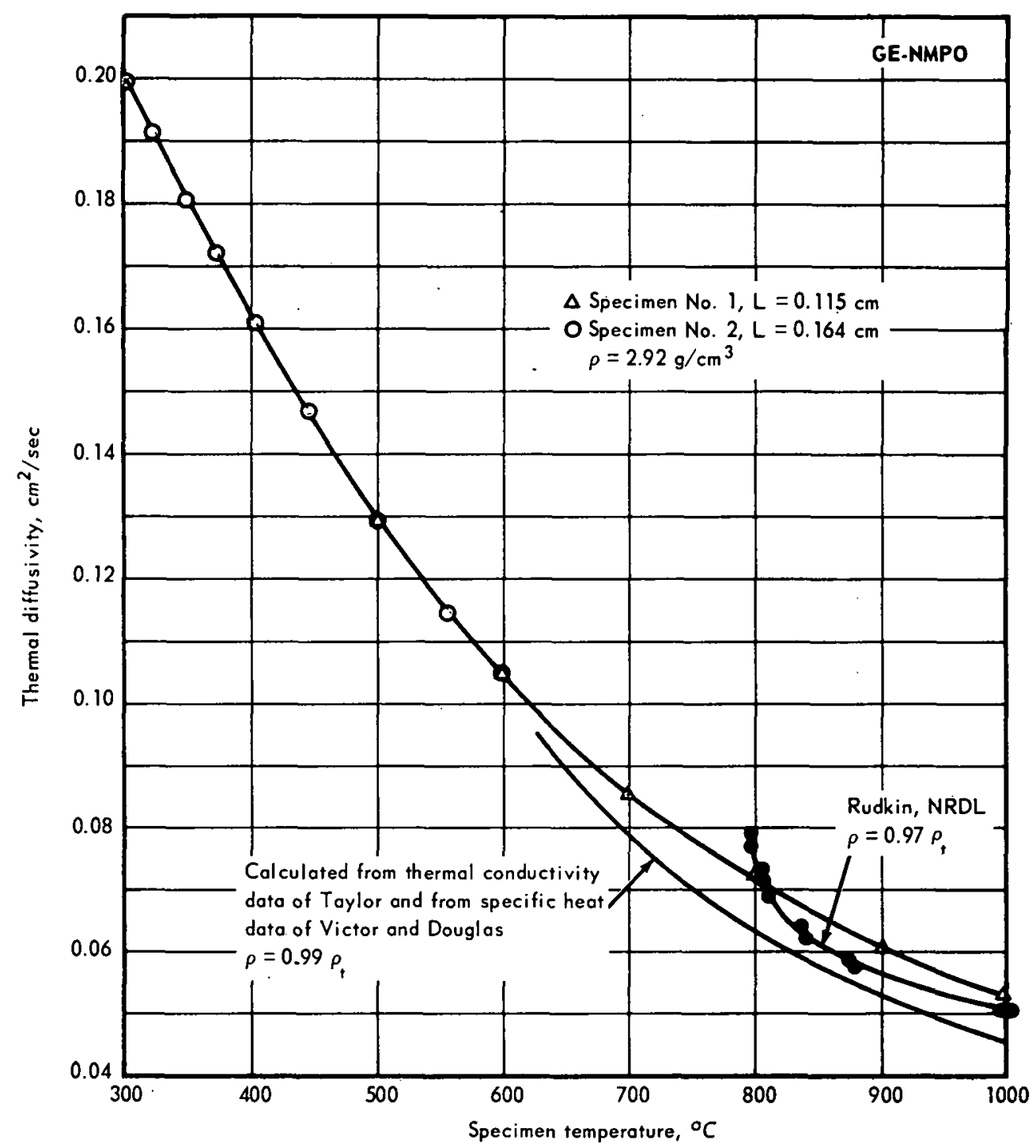

Fig. 5.4 - Thermal diffusivity of $\mathrm{BeO}(\mathrm{UOX}+0.5 \mathrm{MgO})$

not be raised above $650^{\circ} \mathrm{C}$. The trouble could not be located and the samples were removed from the reactor at the earliest opportunity - two days or approximately $5 \times 10^{19}$ nvt later. Because of this short low-temperature exposure, the decrease in the diffusivity of the irradiated sample is undoubtedly slightly larger than would otherwise have occurred. Nevertheless, the overall decrease in diffusivity is relatively small considering the high dosage to which the sample was exposed.

WORK PLANNED FOR NEXT PERIOD

Changes in the dimensions, porosity, elastic constants, and strength will be determined for $\mathrm{BeO}$ compositions containing glass-phase and $\mathrm{Be}$ additive irradiated at $100^{\circ} \mathrm{C}$ to dosages in the range 1 to $5 \times 10^{20} \mathrm{nvt}$.

Thermal diffusivity measurements will be continued on specimens irradiated at $1000^{\circ} \mathrm{C}$ to various dosages. 


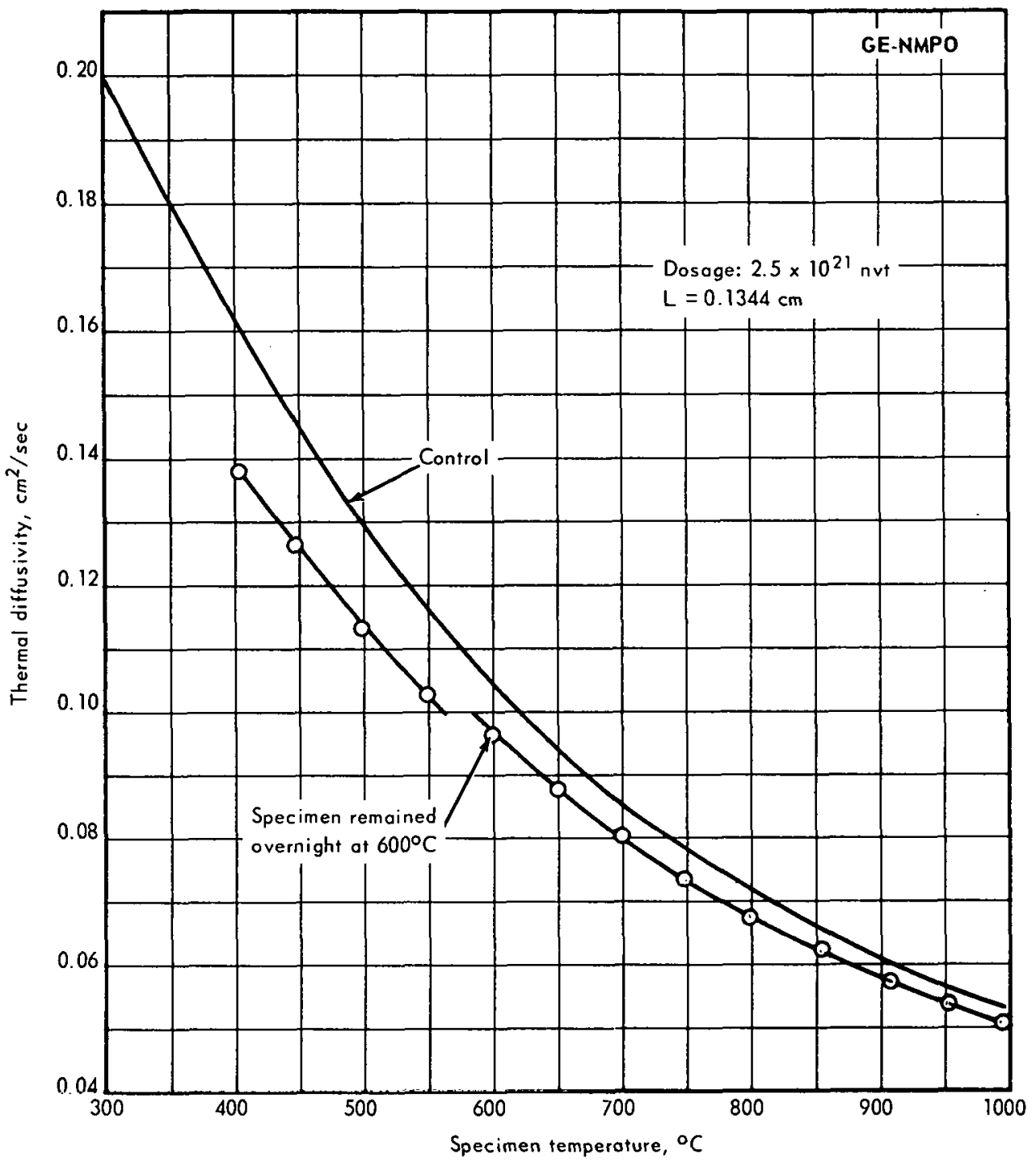

Fig. 5.5 - Thermal diffusivity of irradiated $\mathrm{BeO}$ 
TABLE 5.6

THERMAL DIFFUSIVITY OF UOX-MgO BeO ${ }^{2}$ BEFORE AND AFTER IRRADIATION TO $2.5 \times 10^{21}$ nvt ( $\left.\geq 1 \mathrm{Mev}\right)$ AT APPROXIMATELY $1000^{\circ} \mathrm{C}$

\begin{tabular}{|c|c|c|c|}
\hline \multicolumn{2}{|c|}{ Unirradiated } & \multicolumn{2}{|c|}{ Irradiated } \\
\hline $\begin{array}{c}\text { Temperature, } \\
{ }^{\circ} \mathrm{C}\end{array}$ & $\begin{array}{c}\text { Thermal } \\
\text { Diffusivity, } \\
\mathrm{cm}^{2} / \mathrm{sec}\end{array}$ & $\begin{array}{c}\text { Temperature, } \\
{ }^{\circ} \mathrm{C}\end{array}$ & $\begin{array}{l}\text { Thermal } \\
\text { Diffusivity, } \\
\mathrm{cm}^{2} / \mathrm{sec}\end{array}$ \\
\hline 300 & $0.199_{2}$ & 406 & $0.137_{5}$ \\
\hline 322 & $0.191_{3}$ & 448 & 0.1257 \\
\hline 348 & 0.1807 & 502 & $0: 1129$ \\
\hline 371 & $0.172_{0}$ & 550 & $0.102_{4}^{8}$ \\
\hline 404 & 0.1610 & 600 & $0.095_{8}^{2}$ \\
\hline 447 & 0.1469 & 650 & $0.087_{1}$ \\
\hline $501^{b}$ & $0.129_{1}$ & 700 & $0.080_{0}$ \\
\hline 555 & $0.114_{5}$ & 749 & 0.073 ? \\
\hline $598^{b}$ & $0.105_{3}$ & 801 & $0.067_{3}$ \\
\hline $500^{b}$ & $0.129_{5}$ & 855 & $.0 .061_{9}$ \\
\hline $598 b$ & $0.105_{0}^{\circ}$ & & 0.056 \\
\hline 698 & $0.085_{7}$ & 907 & 8 \\
\hline 798 & $0.072_{4}$ & 952 & \\
\hline 900 & $0.060_{g}^{7}$ & & \\
\hline 996 & 0.0531 & & \\
\hline
\end{tabular}

a Specimens were UOX +0.5 weight percent $\mathrm{MgO}$ of 4-micron grain size. Densities were $2.92 \mathrm{~g} / \mathrm{cm}^{3}$ unirradiated and $2.86 \mathrm{~g} / \mathrm{cm}^{3}$ irradiated.

bWhere duplicate temperatures are cited the measurements were made on different specimens. 


\section{FISSION PRODUCT TRANSPORT PROCESSES IN REFRACTORY-METAL FUEL SYSTEMS}

(57070)

The objective of this program is to study fission product transport processes in refractory-metal fuel systems at temperatures exceeding $1700^{\circ} \mathrm{C}$ in inert and reducing atmospheres.

As part of the overall evaluation of refractory metals for reactor applications, fission product migration, and the effect of fission product impurities on the mechanical properties of refractory metals and their alloys are being investigated. The current work is divided into four major areas: (1) diffusion of rare gases $\left(\mathrm{Kr}^{85}\right)$ in arc-cast tantalum, (2) permeation of rare gases ( $\left.\mathrm{Kr}^{85}\right)$ through arc-cast tantalum, (3) transport of fission products in refractory metals, and (4) effect of fission product impurity atoms on mechanical properties of refractory metals.

\section{DIFFUSION STUDIES}

Diffusion in Tantalum

Studies on the in-diffusion of krypton into self-resistively heated arc-cast tantalum samples were continued using the glow discharge technique ${ }^{1}$ for sample loading. The samples are subsequently sectioned via the anodization-stripping technique $e^{2}$ in $100 \AA$ or $200 \AA$-thick sections in order to obtain distribution profiles.

A summary of typical sample loading data and $\mathrm{Kr} 85$ diffusion results are presented in Table 6.1 and typical distribution profiles are shown in Figures 6.1 to 6.3 for samples prepared to date. Because complicating factors such as grain growth and stress could affect the transport of krypton, some samples were heat treated above $2000^{\circ} \mathrm{C}$ prior to glow discharge to stabilize the grain size; other samples are being prepared in configurations other than simple flat plates to avoid inducing stress in a sample as it expands between two fixed electrodes upon heating. Other variables being studied are temperatures in the range $1430^{\circ}$ to $1730^{\circ} \mathrm{C}$, applied voltage, and krypton pressure.

As shown in the table, those as-received samples (2-micron grain size) in which grain size was stabilized between 35 and 45 microns upon annealing prior to discharge acquired less activity than those not so heat treated but which underwent grain growth (4 to $12 \mathrm{mi}-$ crons depending on temperature) during discharge. The distribution profiles of a typical pair of such samples are given in Figure 6.1. These loading and distribution data consistently illustrate that although the ratio of grain-size to depth-of-sectioning is greater than 100 to 1 for both the fine-grained and the larger, grain-stabilized (annealed) material,

\footnotetext{
1"Fourth Annual Report - High-Temperature Materials and Reactor Component Development Programs, Volume IMatertals," LE-NMPU, GEMP-334A, rebruary 26, 1965, p.174.

${ }^{2}$ Ibid., p. 176.
} 
TABLE 6.1

SUMMARY DATA ON $\mathrm{Kr}^{85}$ MIGRATION IN ARC-CAST TANTALUM SAMPLES PREPARED UNDER GLOW DISCHARGE AND SIMULTANEOUS RESISTANCE HEATING

\begin{tabular}{|c|c|c|c|c|c|c|c|c|c|c|c|}
\hline $\begin{array}{l}\text { Fun } \\
\text { No. }\end{array}$ & $\begin{array}{c}\text { Temperature, } \\
{ }^{\circ} \mathrm{C} \\
\end{array}$ & $\begin{array}{c}\text { Pressure, } \\
\text { Torr }\end{array}$ & $\mathrm{Kr}^{85}$, mole fraction, & $\begin{array}{l}\text { Applied } \\
\text { Voltage }\end{array}$ & $\begin{array}{l}\text { Time, } \\
\text { min }\end{array}$ & $\begin{array}{l}\text { Grain Size } \\
\text { Stabilized }^{\text {a }}\end{array}$ & $\begin{array}{l}\text { Unstressed } \\
\text { Mounting }\end{array}$ & $\begin{array}{l}\text { Total Relative } \\
\text { Activity, cpm }\end{array}$ & $\begin{array}{l}\text { Section } \\
\text { Thickness, } \\
\AA\end{array}$ & $\begin{array}{l}\text { Final } \\
\text { Grain Size, } \\
\text { microns }\end{array}$ & $\begin{array}{c}\text { Linear Dependence of Ln } \\
\text { Activity On Distance } \\
\text { In First } 500 \AA\end{array}$ \\
\hline 40 & 1730 & 0.05 & 1.3 & $300^{\circ}$ & 26 & Yes & No & 850 & 100 & 42 & Indefinable \\
\hline 41 & 1730 & 0.05 & 1.3 & 300 & 10 & Yes & No & 450 & 200 & 42 & Erratice \\
\hline 42 & 1730 & 0.05 & 1.3 & 300 & 10 & No & No & 1200 & 200 & 9 & First power or square ${ }^{d}$ \\
\hline 43 & 1730 & 0.05 & 1.3 & 300 . & 10 & Yes & No & 450 & e & 42 & - \\
\hline 44 & 1630 & 0.05 & 1.3 & 300 & 10 & No & No & 1130 & 100 & 12 & First power or square $d$ \\
\hline 45 & 1530 & 0.05 & 1.3 & 300 & 10 & No & No & 1100 & 100 & 5.8 & Erratic ${ }^{c}$ \\
\hline 46 & 1430 & 0.05 & 1.3 & 300 & 10 & No & No & $10 \mathrm{f}$ & - & 4 & - \\
\hline 47 & 1430 & 0.05 & 2.6 & 500 & 10 & No & No & 3600 & 100 & 4 & First power or-square $\mathrm{d}^{d}$ \\
\hline 48 & 1730 & 0.05 & 2.6 & 500 & 10 & No & Yes & $10 \mathrm{~g}$ & - & - & - \\
\hline 49 & 1530 & 0.05 & 2.6 & 500 & 10 & No & Yes & 9500 & 200 & 7.8 & Square \\
\hline 50 & 1530 & 0.009 & 2.6 & 500 & 10 & No & Yes & 3500 & 200 & 8 & First power or square d \\
\hline 51 & 1530 & 0.008 & 2.6 & 300 & 10 & No & Yes & h & - & 7.8 & - \\
\hline 52 & 1530 & 0.008 & 2.6 & 400 & 10 & No & Yes & 15 & 200 & 7.8 & In process \\
\hline 53 & 1530 & 0.24 & 2.6 & 500 & 10 & No & Yes & 2022 & $-i$ & 8 & - \\
\hline 55 & 1630 & 0.02 & 2.6 & 500 & 10 & No & Yes & 4750 & 200 & 9 & First power or square ${ }^{d}$ \\
\hline 56 & 1730 & 0.05 & 2.6 & 300 & 10 & Yes & Yes & 500 & 100 & - & Erratic $c$ \\
\hline 57 & 1430 & 0.05 & 2.6 & $350-500$ & 10 & No & Yes & 400 & 200 & 4 & i \\
\hline 59 & $<700$ & 0.24 & 2.6 & 500 & 15 & Yes & Yes & 3000 & 200 & - & See Figure 6.2 \\
\hline 61 & 1830 & 0.5 & 2.6 & 625 & 30 & Yes & Yes & g & - & 29.6 & - \\
\hline
\end{tabular}

a Grain size of as-recelved samples was 2 microns. As the data on final grain size indicate, grain growth occurred during sample preparation. Some samples

wer heat-treated prior to the initiation of glow discharge to obtain both large grain size and to overcome dynamic changes in grain size during sample preparation.

boriginal sample configuration was a flat plate which could expand between two fixed electrodes upon heating to the run temperature, introducing some stress in the sample. The present sample configuration contains a loop to accommodate the expansion and a flat section which is used for the sample.

Within several sections the data became erratic as typified by the lower curve in Figure 6.1.

Within data scatter, both first-power and square dependence possible for first few data points (300 to $600 \AA$ depth). Data from subsequent sections generally

support linear dependence with first power of distance but a very short-range square dependence cannot be ruled out. (See Figure 6. 3.)

esarpple used for autoradiogram.

f Iow activity due to low applied voltage.

BHigh current on discharge indicating space charge interference.

ho activity - apparently no discharge.

'Data were erratic because of either fluctuating current or applied voltage during discharge. 


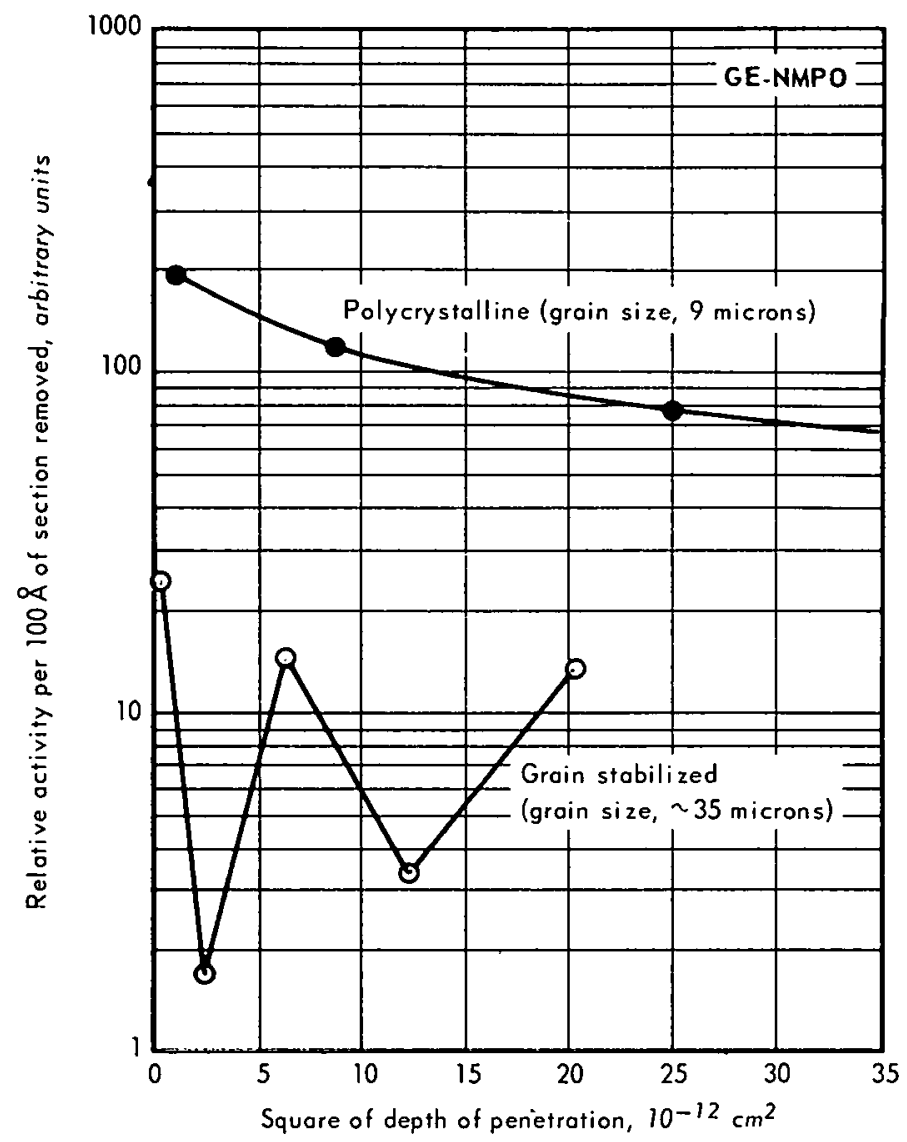

Fig. 6.1-Distribution profiles for two tantalum samples of different grain sizes loaded under stressed conditions of $1730^{\circ} \mathrm{C}$ for 10 minutes under krypton pressure of 0.05 Torr

the samples of the latter material contain less krypton and yield lower, erratic, and only gradually decreasing distribution profiles. This implies that:

1. The solubility of krypton in the tantalum lattice is quite low $\left(<10^{-4}\right.$ mole fraction) below $1730^{\circ} \mathrm{C}$.

2. Below $1730^{\circ} \mathrm{C}$, the range of true volume diffusion is immeasurably short in these samples.

3. The major portion of the material transported in the krypton - tantalum system is via grain boundaries, dislocation pipes, short interconnected dislocation pipes, or other high diffusivity mechanisms.

The short-circuiting concept is further supported by the fact that a calculated activation energy for $\mathrm{Kr}^{85}$ diffusion is much lower than would be expected for volume diffusion. For example, a value of $10 \mathrm{kcal} / \mathrm{mole}$ could be inferred from the $1430^{\circ}$ to $1730^{\circ} \mathrm{C}$ data in Figure 6.2 for the region near the surface $(<500 \AA)$. Variations in slope occur among identically prepared samples, but in no case could an activation energy greater than 30 $\mathrm{kcal} / \mathrm{mole}$ be inferred. The greater attention has been given to the region near the surface because the longer range distribution profile is typical of low-solubility systems in which rapid transport occurs along internal surfaces and dislocations.

The rate controlling process (or processes) leading to the observed distributions near the surfaces of unannealed and stressed samples are as yet undefined owing to the lack 


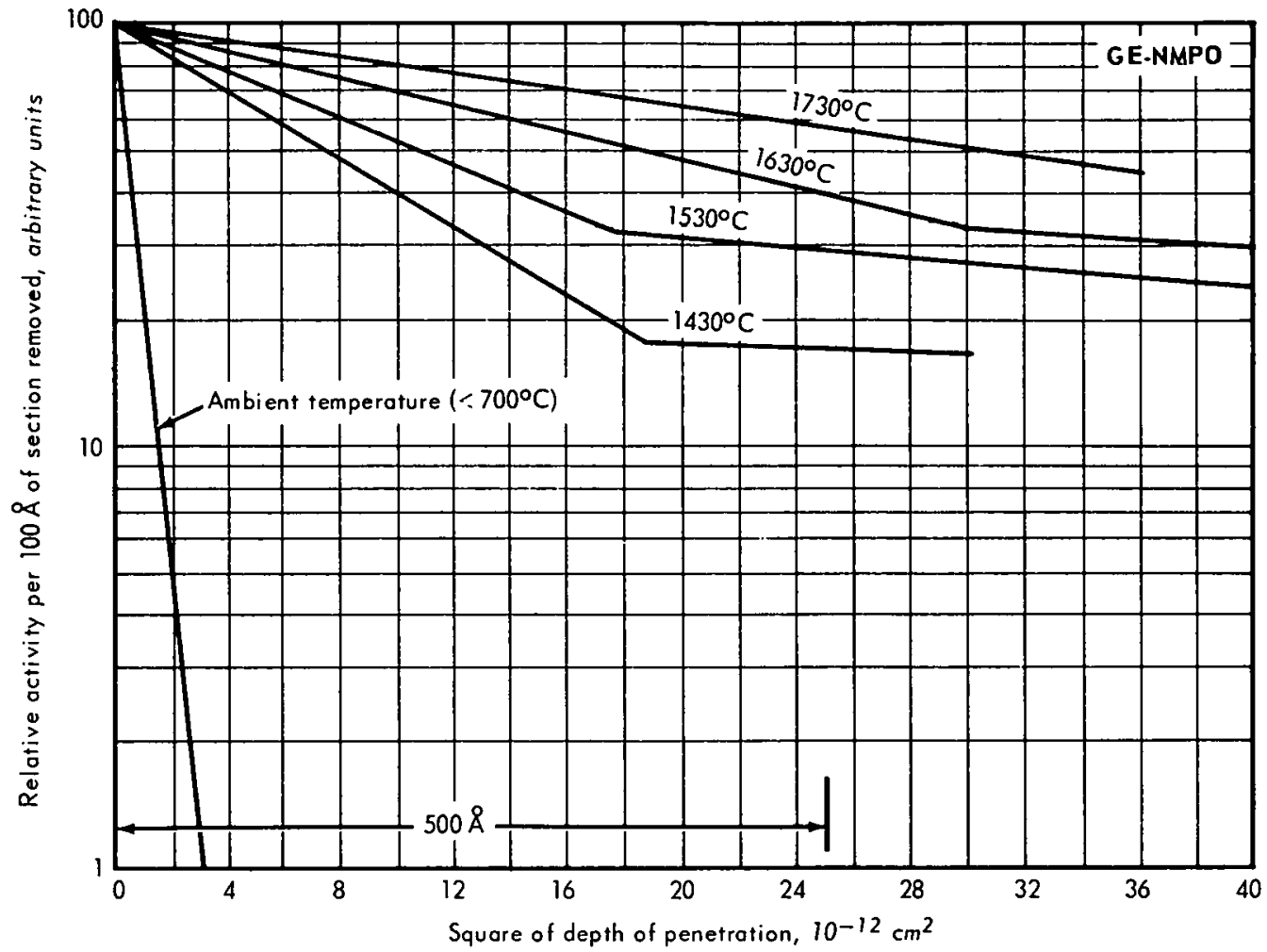

Fig. 6.2-Distribution profiles of various stressed tantalum samples looded for 10 minutes at various temperatures
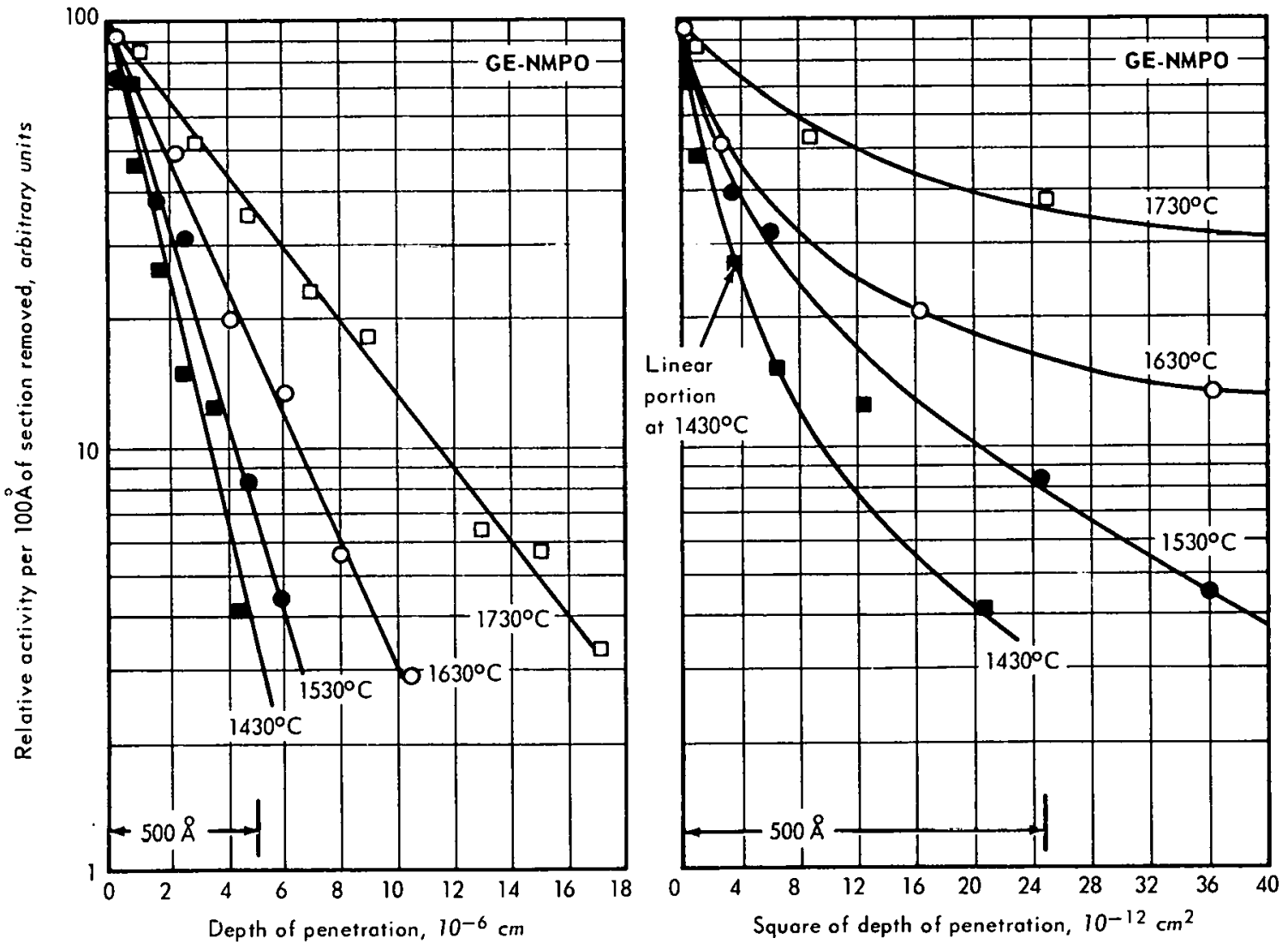

Fig. 6.3-Comparison of krypton distribution data with depth of penetration and depth of penetration squared 
of consistency in the character of the distribution curves in this region. For example, the linear dependence of the natural $\log$ of relative concentration is usually, but not exclusively, found to be better with the first power of the depth of penetration (Figure 6.3) than with the square of the depth, although the first few points could have either dependence. Consequently, the possibility of very short-range volume diffusion cannot be ruled out. In addition, the erratic distribution profiles occasionally begin at the very surface of some unannealed samples. More data on unstressed samples may clarify this situation.

At higher temperatures than $1730^{\circ} \mathrm{C}$, it is hoped that the range of volume diffusion might be sufficiently increased to provide for its detection. To date, this effort has been thwarted by the fact that the electron emission from the tantalum cathode is so great at temperatures exceeding $1730^{\circ} \mathrm{C}$ that a space charge is generated which prevents sample loading under the usual conditions of pressure and voltage. The use of higher voltages and lower pressures for sample loading is presently being investigated in an effort to overcome this problem.

Diffusion in W-30Mo - 25Re

Study of the transport of krypton in $\mathrm{W}-30 \mathrm{Mo}-25 \mathrm{Re}$ at high temperatures was initiated. Samples prepared by powder metallurgy techniques and subsequently rolled and annealed are being used for this purpose. The processed alloy samples were theoretically dense, single-phase, and, based on electron microprobe data, homogeneous to 1-micron resolution.

The initial objective of this effort is the development of procedures for preparing highly polished samples from which parallel submicron sections can be taken. By electropolishing the alloy in a 6:1 methanol - sulfuric acid bath at $-70^{\circ} \mathrm{C}$, mirror finishes are achieved at anodic current densities of 5 to $10 \mathrm{amps} / \mathrm{cm}^{2}$. These alloy samples were found to undergo slow anodic oxidation with the formation of a partially protective oxide film in an electrolytic bath composed of acetone saturated with potassium, sodium, or ammonium nitrate. The resultant oxide films were rapidly removed by dilute $(<1 \%)$ potassium hydroxide solution. More development is required before this sectioning procedure can be used in a quantitative fashion but initial results indicate that it will be suitable for sectioning accurately to about $200 \AA$.

\section{RARE GAS PERMEATION STUDIES}

Metallographic examination of a section of the wall of the evacuated arc-cast tantalum permeation specimen ( $\mathrm{Ta}-9$ ) which was penetrated by krypton did not reveal the surface layer of alpha-tantalum pentoxide which $\mathrm{X}$-ray diffraction examination had previously indicated. ${ }^{3}$ Neither was the oxide layer apparent from electron microprobe data, indicating that it was lost during subsequent reheating to $2400^{\circ} \mathrm{C}$ for 2 hours in a krypton atmosphere, or during handling and preparation of the sample for these studies. Metallographic examination did reveal a network of faint parallel and perpendicular intragranular lines as shown in Figure 6.4, suggesting that oxygen had penetrated the specimen wall. ${ }^{4,5}$ Such a situation may account for the penetration of krypton into this sample in 50 hours of testing at $2400^{\circ} \mathrm{C}$ since several other specimens tested under similar conditions for longer periods of time, but not exhibiting oxygen penetration, did not give evidence of krypton penetration. ${ }^{6}$ The exact mode of krypton penetration is not yet known.

\footnotetext{
3،"High-Temperature Materials Program Progress Report No. 48, Part A," GE-NMPO, GEMP-48A, June 25, 1965, p. 13.

${ }^{4}$ R. W. Anderson, "Metallographic Characteristics of Oxides, Nitrides, and Carbides in Alpha Tantalum," TID-11526, October 1962.

${ }^{5}$ Based on an interpretation by G. Korton, GE-NMPO; to be published.

6،"High-Temperature Materials Program Progress Report No. 46, Part A," GE-NMPO, GEMP-46A, April 15, 1965, p. 12.
} 


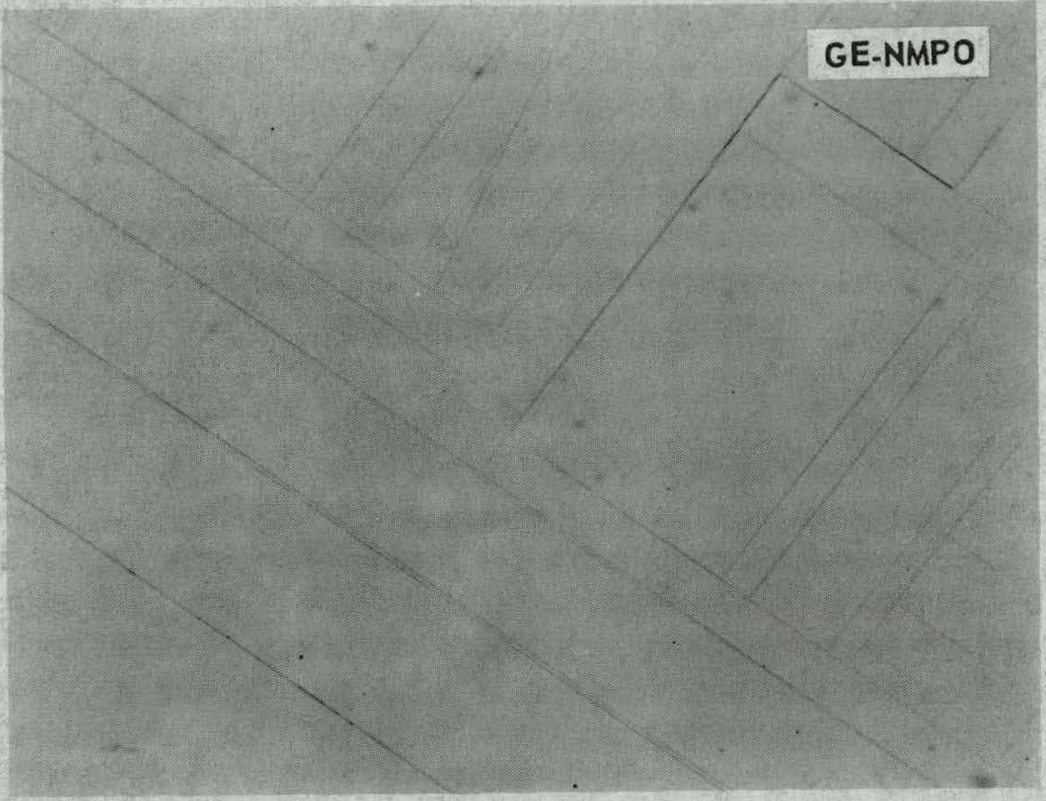

Fig. 6.4-Photomicrograph of arc-cast tantalum specimen wall (Ta-9) after 100 hours of testing at $2400^{\circ} \mathrm{C}$ in krypton. Gray lines are thought to be $\mathrm{B}-\mathrm{Ta}_{2} \mathrm{O}_{5}$ (Neg. $\left.6719,250 \mathrm{X}\right)$

\section{TRANSPORT OF FISSION PRODUCTS IN REFRACTORY METALS}

Determination of the migration and release rates of non-noble gas fission products in refractory metals during irradiation at temperatures up to $2000^{\circ} \mathrm{C}$ was continued in two phases: (1) determination of the fission product distribution in refractory metals used to contain fuel during irradiation at high temperatures and (2) determination of the extent of release of non-noble gas fission products by measuring the amount of specific fission products deposited on the in-pile test assembly adjacent to the canned sample and in the exit gas line.

\section{Determination of Fission Product Distribution}

Tantalum cans with the same dimensions as the irradiated specimens were neutronactivated for use as control samples during remote sectioning and sampling. Specimens of W-Mo-Re were prepared for activation.

\section{Determination of Fission Product Release}

Analysis of the fission product release from a W-Mo-Re canned fuel sample irradiated for 1015 hours at $2000^{\circ} \mathrm{C}$ was essentially completed and the results are shown in Table 6.2. The data were obtained by leaching the primary containment vessel and offgas ducting and then analyzing the leach solution for the six isotopes listed. Deposition in the off-gas line was found to be less than 1 percent of the total deposited $I^{131}$, the only isotope thus far determined for this section. This isotope, due to its high volatility, is assumed to have penetrated farther down the exit gas line than any of the other isotopes; verification of this assumption will be pursued via analysis for the remaining isotopes. With the exception of the data for $\mathrm{Cs}^{137}$, the release of solid fission products is in the range predicted based on rare-gas release measured during the irradiation and the interpretation that the release occurred via recoil from fuel contamination on the surface. The high value for $\mathrm{Cs}^{137}$ is thought to be due to contamination in the radioactive materials laboratory during handling. Based on these data, the W-Mo-Re alloy relained the indicated fission products during the irradiation test. 
TABLE 6. 2

DEPOSITION OF FISSION PRODUCTS IN AN IN-PILE TEST ASSEMBLY CONTAINING A W-Mo-Re ALLOY FUEL CONTAINER IRRADIATED FOR 1015 HOURS AT $2000^{\circ} \mathrm{C}$

\begin{tabular}{|c|c|c|}
\hline Isotope & $\begin{array}{c}\text { Total Deposition, }^{\mathrm{a}} \\
\text { disintegrations per min }\end{array}$ & $\begin{array}{c}\text { Predicted Disintegrations } \\
\text { Per Minute }\end{array}$ \\
\hline $\mathrm{Cs}^{137}$ & $2.5 \times 10^{4}$ & $3-8 \times 10^{3}$ \\
\hline $\mathrm{Ba}^{140}$ & $9.8 \times 10^{5}$ & $5-10 \times 105$ \\
\hline $\mathrm{I}^{131}$ & $5.2 \times 10^{5^{a}}$ & $4-10 \times 10^{5}$ \\
\hline $\mathrm{Sr}^{89}$ & $4.0 \times 10^{5}$ & $3-10 \times 10^{5}$ \\
\hline $\mathrm{Ce}^{144}$ & $1.5 \times 10^{5}$ & $0.7-2 \times 10^{5}$ \\
\hline $\mathrm{Zr}^{95}$ & $2.7 \times 10^{5}$ & $3-10 \times 10^{5}$ \\
\hline \multicolumn{3}{|c|}{$\begin{array}{l}\text { a To date, only } \mathrm{I}^{131} \text { has been obtained from the exit gas } \\
\text { ducting. } \\
\text { b predicted on the basis of rare gas release of } \\
R / B=1-3 \times 10^{-8} \text {. }\end{array}$} \\
\hline
\end{tabular}

\section{Effect of Fission Products on Mechanical Properties}

Final design of the irradiation capsule for high-temperature in-pile impregnation of refractory-metal creep specimens with fission products was completed and component' materials were ordered. Work was begun on the fabrication of $\mathrm{UO}_{2}$ sheath tubes which are to surround the wire creep specimens and act as the source of both heat and fission products.

Design studies for the high-temperature vacuum creep apparatus were initiated. An order was placed for a vacuum system with ultra-high vacuum $\left(10^{-9}\right.$ to $10^{-11}$ Torr $)$ capability. Orders for specimen materials are being placed.

\section{WORK PLANNED FOR NEXT PERIOD}

Investigation of unstressed tantalum samples at various temperatures and pressures will be continued. Low-pressure discharges at temperatures greater than $1730^{\circ} \mathrm{C}$ will be conducted. Single-crystal tantalum specimens will also be prepared, charged with krypton at temperature, and sectioned. Work on the development of a submicron sectioning procedure for $\mathrm{W}-\mathrm{Mo}-\mathrm{Re}$ will be continued. The sectioning of the end of a high-temperature irradiated tantalum cylinder which contained fuel will be performed in order to construct the distribution profile for the solid fission products. The ordering and construction of equipment for creep studies of refractory-metal samples containing fission products will proceed. 
THIS PAGE

\section{WAS INTENTIONALLY \\ LEFT BLANK}




\section{PHYSICO-CHEMICAL STUDIES OF CLAD UO ${ }_{2}$ IN POTENTIAL MELTDOWN ENVIRONMENTS}

(57075)

The objective of this program is to determine the behavior of $\mathrm{Zr}$-alloy-and stainless steel-clad $\mathrm{UO}_{2}$ fuel elements in steam and steam plus air from $1200^{\circ} \mathrm{C}$ to the melting point of $\mathrm{UO}_{2}$ and includes the measurement, where necessary, of the physical and mechanical properties of the claddings, the oxidized claddings, and $\mathrm{UO}_{2}$ to their respective melting points.

The behavior of $\mathrm{Zr}$-alloy-clad and stainless steel-clad $\mathrm{UO}_{2}$ fuel elements during temperature excursions to the melted condition in the presence of steam and/or air has not been studied in sufficient detail to allow suitable hazard analyses. Consequently, this program is directed to developing data concerning the reactions that occur during meltdown in these atmospheres at rates of heating which approximate those likely to be encountered in nuclear afterheat temperature excursions when the coolant has been lost. This data development specifically involves the rates of oxidation of the metal claddings; the reactions that may occur between the molten clad metal and $\mathrm{UO}_{2}$; the behavior of the clad $\mathrm{UO}_{2}$ during the meltdown; and the compilation of the physical and mechanical properties of these materials to their melting points (including the behavior of reaction products such as the oxidized metal cladding). In addition, data will also be developed on clad $\mathrm{UO}_{2}$ fuel element behavior under varying simulated reactor prompt critical conditions. Part of the initial literature review will be preparation of a special report of the available data on the physical and mechanical properties of these materials so that these data can be used in model hazard analyses calculations.

Work on this program has been started with the initial effort placed on (1) tests of a dynamic nature to measure the behavior of the cladding metals during temperature excursions to their melting points in a steam atmosphere at heating rates of $0.5^{\circ} \mathrm{F}$ and $5.0^{\circ} \mathrm{F}$ per second; (2) isothermal tests of metal - steam reactions from $1200^{\circ}$ to $1600^{\circ} \mathrm{C}$; (3) molten cladding - $\mathrm{UO}_{2}$ reactions; (4) mechanical properties of the cladding metals to their melting points; and (5) the literature survey concerning the material behavior aspects. The current status of these items with appropriate background references as a result of the literature survey is described below.

REACTION MECHANISMS AND KINETICS

Zirconium-Base Alloy Reaction with Water Vapor (Steam)

Lustman ${ }^{1}$ made a study of the amount of reaction that would occur between zirconium and water (or steam) should the PWR core suffer loss of the coolant and thus cause the zirconium alloy in the core structure to become heated. He considered the corrosion during the heating-up period and the consequences of the zirconium melting and dripping into the water. He concluded from his theoretical treatment of the zirconium-water reaction that a self-sustaining reaction is possible but highly unlikely. Esptein ${ }^{2}$ made a 
later and more complete theoretical treatment of this problem including calculations of temperature rise as a function of molten-metal droplet size to show that droplet size can determine whether there is a positive or a negative slope for the temperature versus time curve describing the reaction. He agreed with Lustman's conclusions.

Experiments involving the oxidation of zirconium and zirconium alloys at or near the melting point of the metal have been performed by a number of workers to determine when the reaction becomes explosive in character. Bostrom ${ }^{3}$ studied the corrosion of Zircaloy -2 to $1860^{\circ} \mathrm{C}$ in $\mathrm{H}_{2} \mathrm{O}$ by measuring the amount of $\mathrm{H}_{2}$ generated and calculating the amount of oxide formed. Milich and King ${ }^{4}$ measured the $\mathrm{H}_{2}$ evolved in molten zirconium - steam reactions and found that the amount of $\mathrm{H}_{2}$ increased as the steam pressure increased. Higgins ${ }^{5}$ showed indirectly that finely dispersed molten zirconium reacted violently with water. Layman ${ }^{6}$ showed that under certain conditions the reaction of molten zirconium with $\mathrm{H}_{2} \mathrm{O}$ is one of combustion. Higgins and Schultz $z^{7}$ measured the effect of molten-metal droplet size on the reaction rate and concluded that the reaction is explosive under certain conditions. Fur man ${ }^{8}$ measured the oxidation of zirconium up to $1700^{\circ} \mathrm{C}$ using He as the carrier gas for steam and found that the rate was linear. Nelson and Richardson ${ }^{9}$ measured the effect of molten zirconium droplet size on the explosive nature of the reaction with air. Lower temperature (i.e., $950^{\circ} \mathrm{C}$ ) explosive rates were found by Wallwork, et al. ${ }^{10}$ when oxygen with a trace of $\mathrm{H}_{2} \mathrm{O}$ was used to oxidize zirconium.

Testing - The present experimental work involves tests of a dynamic nature to measure the gross behavior of Zircaloy -4 in water vapor (steam) at temperatures from 12000 to $1850^{\circ} \mathrm{C}$ at rates of $0.5^{\circ} \mathrm{F}$ and $5.0^{\circ} \mathrm{F}$ temperature rise per second. Assembly of the equipment for these tests is about 95 percent complete.

Reaction Rate Measurements - Pemsler ${ }^{11}$ reviewed the status of work of the oxidation of zirconium and conducted experiments to show that the rates are not linear to $1050^{\circ} \mathrm{C}$, which is the highest temperature reported with oxidation rates in detail. His review of the previous work points out that there is considerable question about the nature of the true oxidation rates as a function of temperature in the range of $800^{\circ}$ to $1000^{\circ} \mathrm{C}$. He discounts previous work which gives a linear rate for the oxidation of zirconium at high temperatures primarily because of uncertainty in the measurements.

There is an obvious need to extend these data to higher temperatures to develop a better understanding of the reaction, especially when air is mixed with $\mathrm{H}_{2} \mathrm{O}$ vapor. Equipment is being assembled for these isothermal measurements to $1600^{\circ} \mathrm{C}$ using corrosion rate measuring equipment described previously. ${ }^{12}$

Zirconium Alloy - $\mathrm{UO}_{2}$ Reactions

The above listed literature data on the zirconium alloy - water reaction all suggest that the zirconium alloy cladding on the $\mathrm{UO}_{2}$ may not be completely oxidized during the temperature excursion to the melting point of zirconium $\left(\sim 1850^{\circ} \mathrm{C}\right)$. Consequently, it is likely that molten zirconium alloy will be in contact with the $\mathrm{UO}_{2}$ which may result in the formation of uranium metal.

The reaction between zirconium and $\mathrm{UO}_{2}$ has been studied to $700^{\circ} \mathrm{C}$ by Mallett, et al. ${ }^{13}$ They showed theoretically and experimentally that zirconium will reduce $\mathrm{UO}_{2}$ at this temperature.

These data need to be exlended and experiments are in progress to determine the probable extent of this reaction using Zircaloy-4. The initial study is a series of isothermal tests at temperatures of $1900^{\circ} \mathrm{C}$ and above for short periods of time in an $\mathrm{Ar}$ atmosphere. These tests are merely of the "couple" type where the metal is contained in a small crucible of $\mathrm{UO}_{2}$. From these tests, it is expected that the relative extent of the reaction can 
be measured. Samples have been run for 30 -minute times at $1900^{\circ}$ to $2200^{\circ} \mathrm{C}$ in $50^{\circ} \mathrm{C}$ intervals. The samples for tests through $2150^{\circ} \mathrm{C}$ remained intact but the one at $2200^{\circ} \mathrm{C}$ resulted in the Zircaloy -4 reacting and melting through the $\mathrm{UO}_{2}$ crucible (through about $3 \mathrm{~mm}$ of $\mathrm{UO}_{2}$ ). These samples are being analyzed.

\section{PHYSICAL AND MECHANICAL PROPERTIES OF THE CLADDING AND $\mathrm{UO}_{2}$}

Definition of a model calculating reactor hazards resulting from loss of coolant requires a knowledge of the physical and mechanical properties of the materials and their reaction products formed during the temperature excursion. Consequently, there is need for these data on zirconium alloys, Type 304 stainless steel, the oxidation products resulting from these metals reacting with water vapors and/or air, and $\mathrm{UO}_{2}$ to their melting points.

Mechanical Properties

The strength of zirconium and Zircaloy -2 to $500^{\circ} \mathrm{C}$ have been summarized by Schober, et al. ${ }^{14}$ and Zima. ${ }^{15}$ More recently Mishima, et al. ${ }^{16}$ extended the data for Zircaloy-2 and Type 304 stainless steel to $700^{\circ} \mathrm{C}$. These data need to be extended to higher temperatures and samples are being prepared for this work.

Physical Properties

The physical properties of zirconium are generally known. ${ }^{17}$ The physical properties of Zircaloy-2 and Zircaloy-4 are considered to be sufficiently similar to the data on zir conium to be used where these are needed in the hazard model calculations.

The critical physical properties of $\mathrm{ZrO}_{2}$ are also generally known. Cox has recently measured the thermal conductivity ${ }^{18}$ and the emissivity ${ }^{19}$ to $2500^{\circ} \mathrm{C}$. These data are probably sufficient for the hazard model calculations.

The physical properties of $\mathrm{UO}_{2}$ are known ${ }^{20}$ except for details of the thermal conductivity above about $2500^{\circ} \mathrm{C}$. Consequently, measurements for these data to the melting point will be undertaken.

\section{WORK PLANNED FOR NEXT PERIOD}

The engineering tests of Zircaloy-4 - water vapor (steam) reactions will be started. This test equipment will be expanded to include provision for mixing heated air with the steam.

The isothermal test equipment will be completed and initial tests run to check out the equipment.

Zircaloy-4 - $\mathrm{UO}_{2}$ reaction tests will be continued. 


\section{REFERENCES}

1. Lustman, B., "Zirconium-Water Reaction Data and Application to PWR Loss-ofCoolant Accident, " Westinghouse-APD, WAPD-SC-543, May 1957.

2. Epstein, L. F., "Metal-Water Reactions: VII, Reactor Safety Aspects of MetalWater Reactions," GE-APD, GEAP-3335, January 31, 1960.

3. Bostrom, W. A., "The High Temperature Oxidation of $\mathrm{Zr-2}$ in $\mathrm{H}_{2} \mathrm{O}$," WestinghouseAPD, WAPD-104, March 19, 1954.

4. Milich, W., and King, E. C., "Technical Report No. 44: Molten Metal-Water Reactions," NP-5813, November 9, 1955.

5. Higgins, H. M., "A Study of the Reactions of Metals and Water," AECD-3664, April 15, 1955.

6. Layman, D. C., "Some Qualitative Observations of Zirconium-Water Reactions," Knolls Atomic Power Lab., KAPL-1534, April 23, 1956.

7. Higgins, H. M., and Schultz, R. D., "The Reaction of Metals with Water and Oxidizing Gases at High Temperatures," Aerojet General Corp., IDO-28000, April 30, 1957.

8. Furman, S. C., "Metal-Water Reactions: V, The Kinetics of Metal-Water Reactions at Low Pressures," GE-APD, GEAP-3208, July 31, 1959.

9. Nelson, L. S., and Richardson, N. L., "The Use of Flash Heating to Study Combustion of Metal Droplets," CONF-327-9, January 1964.

10. Wallwork, G. R., Rosa, L. J., and Smeltzer, W. W., "Breadaway Phenomena in the Oxidation of Zirconium at $850^{\circ} \mathrm{C}$ and $950^{\circ} \mathrm{C}$, " Corrosion Science, Vol. 5, No. 2, 1965, pp. 113-170.

11. Pemsler, J. P., "Studies on the Oxygen Gradients in Oxidizing Metals III. Kinetics of the Oxidation of Zirconium at High Temperatures," J. Electrochem. Soc., Vol. 112, No. 5, 1965 , pp. 477-484.

12. "High-Temperature Materials Program Progress Report No. 38, Part B," GENMPO, GEMP-38B, August 19, 1964, pp. 50-51.

13. Mallett, M. W., Gerds, A. F., Lemmon, A. W., and Chase, D. L., "The Kinetics of the $\mathrm{Zr}-\mathrm{UO}_{2}$ Reactions, "Battelle Memorial Institute, BMI-1028, August 15, 1955.

14. Schober, F. R., VanEcho, J. A., Marsh, L. L., Jr., and Kaeler, J. R., "The Mechanical Properties of $\mathrm{Zr}$ and $\mathrm{Zr-2,"} \mathrm{Battelle} \mathrm{Memorial} \mathrm{Institute,} \mathrm{BMI-1168,}$ February 19, 1965.

15. Zima, G. E., "A Review of the Properties of Zr-2," GE-HAPO, HW-60908, October 14, 1959.

16. Mishima, Y., et al., "An Experimental Study of the Mechanical Strength of Fuel Cladding Tubes under Loss of Coolant Accident Conditions of Water Cooled Reactors," A/CONF. 28/P/438, May 1964.

17. Lustman, B., and Kerze, F., Jr., The Metallurgy of Zirconium, McGraw-Hill, New York, 1955.

18. Cox, R. L., et al., "Interim Technical Report on Physical Properties Tests on Dyna Soar Nose Cap Materials," Vought Astronautics, AST/EIR-17890, April 18, 1961.

19. Cox, R. L., "Emittance of Zirconium to $4600^{\circ} \mathrm{F}$," Boeing Co., AD-434003, April 30, 1962.

20. Belle, J., Ed., Uranium Dioxide: Properties and Nuclear Applications, U. S. Government Printing Office, 1961. 


\section{PHYSICO-CHEMICAL STUDIES OF Fe-Cr-Al-CLAD FUEL SYSTEMS}

(57076)

The objective of this program is to define and to understand the reactions which occur between oxidation-resistant $\mathrm{Fe}-\mathrm{Cr}-\mathrm{Al}$ alloys and $\mathrm{UO}_{2}$ in the temperature region of $500^{\circ}$ to $1200^{\circ} \mathrm{C}$.

\section{NEED FOR THE PROGRAM}

Many gas-cooled reactor applications require fuel element materials which are stable in contact with air or steam. Fuel element cladding alloys for use in high-temperature oxidizing environments must be oxidation resistant and be compatible with the fuel. For metallic claddings, the alloys which possess the greatest potential are the $\mathrm{Fe}-\mathrm{Cr}-\mathrm{Al}$ type alloys (i.e., $\mathrm{Fe}-25 \mathrm{Cr}-4 \mathrm{Al}-1 \mathrm{Y}$ ). In early attempts to apply the $\mathrm{Fe}-\mathrm{Cr}-\mathrm{Al}$ type alloys as claddings for $\mathrm{UO}_{2}$ or metal - $\mathrm{UO}_{2}$ cermet cores, an undesirable result was the appearance of uranium as surface contamination. The tentative explanation of this result is that reduction of $\mathrm{UO}_{2}$ by $\mathrm{Al}$ produced $\mathrm{U}$ which diffused to the surface.

Recent experimental data obtained on $\mathrm{Fe}-\mathrm{Cr}-\mathrm{Al}-\mathrm{Y}$-clad cermet compatibility specimens demonstrated improved stability between the core and the cladding. This work has reopened the question of reaction between $\mathrm{UO}_{2}$ and the $\mathrm{Fe}-\mathrm{Cr}-\mathrm{Al}$ type cladding alloys. It is important that the question of reactivity between $\mathrm{UO}_{2}$ and $\mathrm{Fe}-\mathrm{Cr}-\mathrm{Al}-\mathrm{Y}$ alloys be resolved so that the time - temperature limitations of any particular fuel element configuration can be predicted.

The current trend in cladding alloy development is to decrease the $\mathrm{Cr}$ content and increase the Al content in order to improve structural stability. Such an increase may increase the chemical potential of $\mathrm{Al}$ in the alloy. The probable result would be an increase in the rate of reduction of $\mathrm{UO}_{2}$ at a given temperature or a lowering of the threshold temperatures at which the rate of $U$ production becomes significant.

\section{WORK PROGRAM}

From a physico-chemical viewpoint, a metallic fuel element with cladding intact may be considered to be a closed or an open chemical system. The choice depends on the rates of diffusion of oxygen into the system and of reaction products (e.g., U) out of the system, as compared with the rate of attainment of chemical equilibrium between potential reactants in the core - cladding complex. Thus, conclusions from thermodynamics, chemical kinetics, and diffusion studies are important in understanding this complex system.

The first point to be elucidated is the mechanism of uranium production. Available thermodynamic information indicates that the reaction of pure $\mathrm{Al}$ with $\mathrm{UO}_{2}$ to give $\mathrm{Al}_{2} \mathrm{O}_{3}$ and free $U$ is not favored, but any reliable prediction must take into account the actual chemical potentials of $\mathrm{Al}$ and $\mathrm{U}$. To do this, it is necessary to examine the $\mathrm{Fe}-\mathrm{Cr}-\mathrm{Al}-\mathrm{Y}-$ $\mathrm{U}-\mathrm{O}$ system for stable $\mathrm{U}$-bearing phases. A thorough investigation of this type would re- 
quire an excessive amount of work. A simplified approach, which will be tried first, is to form diffusion couples between representative $\mathrm{Fe}-\mathrm{Cr}-\mathrm{Al}$ alloys and $\mathrm{U}$, or some more dilute source of $U$ such as $U \mathrm{Fe}_{2}$. Heat-treated couples will be examined for evidence of compound formation.

Various methods are available for determining the chemical potential of components of alloy solutions. These methods will be evaluated for applicability to the specific system under study. It seems probable that measurement of the emf of cells with molten salt electrolytes will be most suitable in the case of alloys. On the other hand, study of the composition of the gas in equilibrium with a solid solution of $\mathrm{UO}_{2}$ probably will be most useful in determining chemical potentials in those phases.

The alloy diffusion couples mentioned above will also give useful information on the diffusion of uranium through the cladding. The results of these tests will be used in planning any necessary additional tests relating to diffusion.

\section{WORK PLANNED FOR NEXT PERIOD}

Capsules for diffusion couples will be designed, materials selected, and fabrication of capsules started. Evaluation of methods for determining chemical potential of components of alloys will be continued. 


\section{FISSION GAS DIFFUSION IN UNFUELED CERAMIC MATERIALS}

(57069)

The objective of this program was to advance the basic knowledge of fission gas diffusion and radiation damage in unfueled ceramic materials.

This work was concerned with the diffusion of $\mathrm{Kr}, \mathrm{Xe}$, and I atoms in ceramic oxides ( $\mathrm{MgO}, \mathrm{BeO}, \mathrm{Al}_{2} \mathrm{O}_{3}$, and $\mathrm{ZrO}_{2}$ ) subsequent to their injection via ion bombardment. The diffusion characteristics of these heavy atoms were deduced by an analysis of the amount of diffusant remaining in a sample as a function of time at constant temperature.

\section{ION BOMBARDMENT STUDIES}

The experimental procedure consisted of three steps: (1) target preparation, (2) injection of $35 \mathrm{-kev}$ krypton ions into the targets, and (3) measurement of the amount of krypton diffusant remaining in a target specimen as a function of time at constant temperature.

The targets were discs of sapphire or beryllia.

The sapphire targets were high-purity single crystals, $0.95 \mathrm{~cm}$ in diameter with a measured density (displacement method) of $3.987 \mathrm{~g} / \mathrm{cm}^{3}$ at $26^{\circ} \mathrm{C}$ in agreement with the accepted value. ${ }^{1}$ Crystallographic examination of these crystals showed that the $c$-axis was either perpendicular to the beam trajectory or made an angle of between 35 and 45 degrees with the injected surface. Light interference methods showed that the plane surfaces were also optically flat except for minor curvature at the edges.

The beryllia targets were prepared by polishing 6-mm discs sectioned from high-purity rods. Microscopic examination of the polished surfaces revealed a nominal grain size of 20 microns. The measured densities of the targets were $2.90 \mathrm{~g} / \mathrm{cm}^{3}$. The optical flatness of the BeO targets could not be ascertained by light interference; therefore, the plane surfaces were replicated for examination with the electron microscope to deter mine sur face characteristics. Prior to krypton injection all targets were degreased in trichloroethylene then annealed for 2 hours at the same temperature at which they were to be tested.

Three or four targets were positioned in a target holder ${ }^{2}$ and bombarded simultaneously with 35 -kev krypton ions focused to a beam cross section of $2.8 \mathrm{~cm}$. The bombarding conditions were as follows: the source was operated with Matheson' s reagent-grade krypton (99.999 percent pure) containing a $3.72 \times 10^{2}$ ratio of $\mathrm{Kr}$ to $\mathrm{Kr}^{85}$. Typical source and chamber pressures during a bombardment were $1 \times 10^{-4}$ and $2.0 \times 10^{-6}$ Torr, respectively, at a pumping rate of approximately $640 \mathrm{liters} / \mathrm{sec}$. The ion flight path; i. e., the distance from the Einzel lens to the targets was $45 \mathrm{~cm}$. Total ion fluxes of $10^{12}$ atoms/ $\mathrm{cm}^{2}$ were obtained after 10 minutes of bombarding. The krypton-injected samples were

1"'Standard X-ray Diffraction Powder Patterns," NBS Circular 539, Vol. 9, 1960, p. 3.

2"'High-Temperature Materials Program Progress Report No. 48, Part A," GE-NMPO, GEMP-48A, June 25, 1965 , p. 9. 
heated in a resistance-type furnace at $1100^{\circ} \mathrm{C}$ and $1200^{\circ} \mathrm{C}$, and their loss in radioactivity determined periodically by beta-counting the sample with an end-window proportional counter. Less than 4 minutes were required for a sample to attain test temperature from room temperature.

Tentative krypton release data from $\mathrm{Al}_{2} \mathrm{O}_{3}$ and $\mathrm{BeO}$ targets bombarded in fluxes of approximately $2 \times 10^{12}$ atoms $/ \mathrm{cm}^{2}$ are shown in Figures 9.1 and 9.2, respectively. The fractional release is shown as function of the square root of time merely for the convenience of presenting the data and not to infer a "bulk" diffusion model.

The observed release at $1100^{\circ} \mathrm{C}$ and $1200^{\circ} \mathrm{C}$ in $\mathrm{Al}_{2} \mathrm{O}_{3}$ suggests that the crystal lattice orientation during injection influences the magnitude of the initial release or "burst" from ion bombarded material. Targets with the c-axis perpendicular to the trajectory of the ions (the top two curves of Figure 9.1), had initial releases 2 to 2.5 times greater than targets with the $c$-axis inclined at approximately 40 degrees (the two bottom curves of Figure 9.1).

A temperature-dependent release in $\mathrm{Al}_{2} \mathrm{O}_{3}$, Figure 9.1, is not apparent. Such behavior is not consistent with the results obtained by other worker ${ }^{3}$ investigating the release of $X$ from single crystals of sapphire bombarded at $40 \mathrm{kev}$ in ion fluxes of $4 \times 10^{13}$ ions/ $\mathrm{cm}^{2}$, where fractional releases of approximately $0.1,0.3$, and 0.47 were found after 20 minutes of heating at temperatures of $1000^{\circ} \mathrm{C}, 1100^{\circ} \mathrm{C}$, and $1130^{\circ} \mathrm{C}$, respectively. The crystal lattice orientation of the targets in respect to the ion beam during bombardment was not specified in the referenced work.

The krypton release from $\mathrm{BeO}$ (Figure 9.2) indicates a temperature dependency. Complete evaluation of this material is dependent upon obtaining further experimental data.

\section{WORK PLANNED FOR NEXT PERIOD}

This program terminated at the end of Fiscal Year 1965. A topical report is being issued covering the details of the work on results achieved during the period July 1 , 1963, through June 30, 1965.

\footnotetext{
${ }^{3}$ R. Kelly and F. Brown, "Release Processes in Metal and Oxide Targets Following Bombardments with Xe at Energies of up to $40 \mathrm{KeV}$," Acıa Melallurgica, Vol. 13, 1965, p. 169.
} 


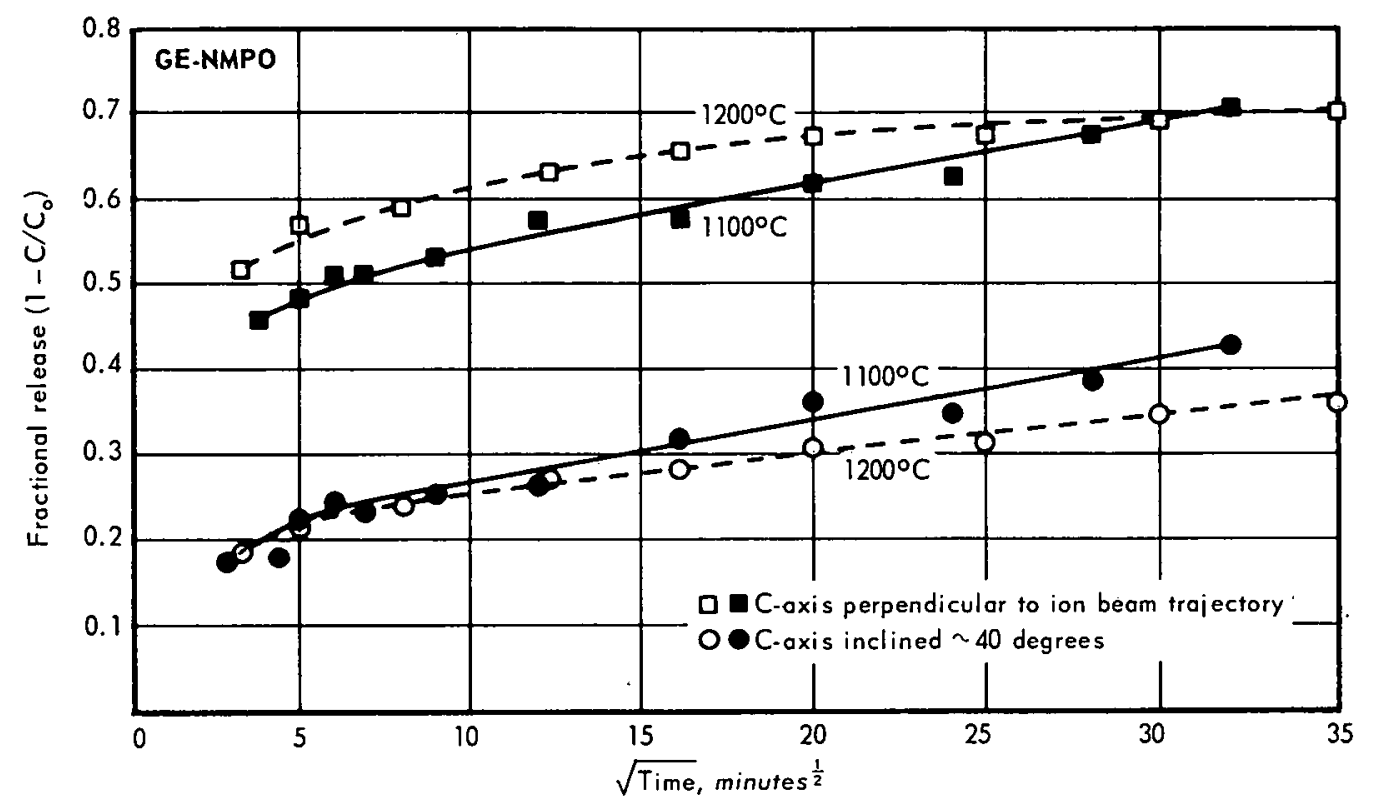

Fig. 9.1-Krypton fractional release from single crystals of $\mathrm{Al}_{2} \mathrm{O}_{3}$ (sopphire) bombarded at $35 \mathrm{kev}$ to a total flux of about $2 \times 10^{12}$ atoms $/ \mathrm{cm}^{2}$

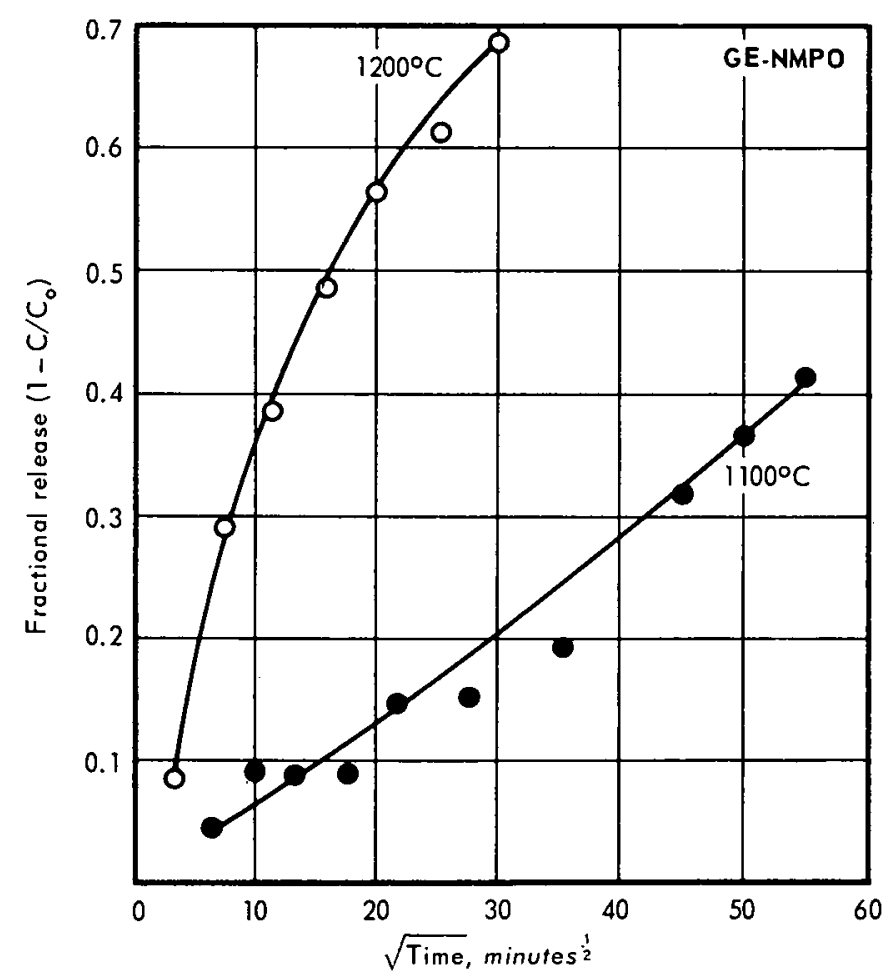

Fig. 9.2 -Krypton fractional release from $\mathrm{BeO}$ bombarded at 35 kev to a total flux of about $2 \times 10^{12}$ ions $/ \mathrm{cm}^{2}$ 
THIS PAGE

\section{WAS INTENTIONALLY LEFT BLANK}




\section{INTERNAL CONVERSION CERAMIC FUEL ELEMENT RESEARCH}

(57072)

The objectives of this program were to study the chemistry involved in the use of a fertile material (thoria) in stabilized fuel - BeO systems and to develop its capability as an internal conversion fuel element.

This is the final report under this task which terminated at the end of FY-65. The cur rent in-pile test program and the evaluation of its results will be reported in the future under Job 57068, "Burnup Capability of $\mathrm{Y}_{2} \mathrm{O}_{3}$-Stabilized $\mathrm{UO}_{2}$ and BeO-Stabilized Fuel Materials."

A brief summary of the major accomplishments during this program is as follows:

1. Nuclear studies established the feasibility of $\mathrm{ThO}_{2}$ additions to $\mathrm{BeO}$-base fuel elements to increase reactor lifetimes up to a factor of three compared with similar fuel elements containing undiluted $\mathrm{UO}_{2}$.

2. Significant advances were made in the state of the art in preparing and identifying the most stable solid solutions in the $\mathrm{UO}_{2}-\mathrm{ThO}_{2}-\mathrm{Y}_{2} \mathrm{O}_{3}$ ternary system.

3. Optimum conditions were established for sintering $\mathrm{BeO}$ fueled with $\mathrm{UO}_{2}-\mathrm{ThO}_{2}-\mathrm{Y}_{2} \mathrm{O}_{3}$ solid solutions -1 hour at $1800^{\circ} \mathrm{C}$ in hydrogen.

4. BeO-base fuel elements containing 7 to 25 volume percent $\mathrm{UO}_{2}-\mathrm{ThO}_{2}-\mathrm{Y}_{2} \mathrm{O}_{3}$ were developed which exhibited good physical and mechanical properties and excellent fuel retention in air, $\mathrm{He}, \mathrm{CO}_{2}$, and $\mathrm{N}_{2}$. Extrapolation of the data from tests in air for 5000 hours at $1200^{\circ} \mathrm{C}$ and 2000 hours at $1400^{\circ} \mathrm{C}$ indicated all specimens were capable of 15,000 hours operation in air at $1200^{\circ} \mathrm{C}$ with $\mathrm{UO}_{2}$ losses of 1 percent or less; the loss at $1400^{\circ} \mathrm{C}$ would be less than 2 percent.

5. Dynamic irradiation testing at $1250^{\circ}$ to $1550^{\circ} \mathrm{C}$ of BeO fueled with 25 volume percent $\mathrm{UO}_{2}-\mathrm{ThO}_{2}-\mathrm{Y}_{2} \mathrm{O}_{3}$ showed no time, temperature, or half-life dependence for fission gas release indicating recoil to be the dominant release process. All previous irradiation tests of other stabilized $\mathrm{UO}_{2}-\mathrm{BeO}$ sy stems exhibited a significant diffusion contribution to fission gas release at $1350^{\circ} \mathrm{C}$ and higher.

\section{EVALUATION OF BeO-BASE FUEL ELEMENTS}

Studies were continued on homogeneously fueled, BeO-base fuel elements containing 25 volume percent $\mathrm{UO}_{2}-\mathrm{ThO}_{2}-\mathrm{Y}_{2} \mathrm{O}_{3}$ solid solutions. The current studies are primarily concerned with in-pile testing of uncoated and BeO-coated fuel elements, bench tests in support of the in-pile tests, and methods to improve BeO-coatings.

Irradiation Testing

Stalus of the irradiation program is summarized in Table 10.1. The ETR tests are run in sealed capsules to determine the effect of high fuel burnup on physical integrity and fission product release. Two tests (GEFP2-19 and -23) of uncoated fuel elements have have operated satisfactorily for 3400 hours at approximately $1250^{\circ} \mathrm{C}$. A third test (GEFP2-22) of BeO-coated fuel elements has operated for 900 hours between $1000^{\circ}$ and 
TABLE 10.1

IRRADIATION TEST PROGRAM OF BeO FUELED WITH UO $2-\mathrm{ThO}_{2}-\underline{\mathbf{Y}}_{2} \underline{\mathrm{O}}_{3}$ COMPOSITIONS

\begin{tabular}{|c|c|c|c|c|c|c|c|c|c|c|}
\hline \multirow{2}{*}{$\begin{array}{c}\text { Test } \\
\text { Number }\end{array}$} & \multirow{2}{*}{$\begin{array}{c}\text { Test } \\
\text { Facility }\end{array}$} & \multirow{2}{*}{$\begin{array}{c}\text { Specimen } \\
\text { Designation }^{2} \\
\end{array}$} & \multicolumn{3}{|c|}{$\begin{array}{l}\text { Fuel Composition, } \\
\text { mole ratio }\end{array}$} & \multirow[b]{2}{*}{ Coating } & \multicolumn{2}{|c|}{ Operating Conditions } & \multirow{2}{*}{$\begin{array}{l}\text { Desired Burnup, } \\
10^{20} \text { fissions } / \mathrm{cm}^{3}\end{array}$} & \multirow[b]{2}{*}{ Status } \\
\hline & & & $\mathrm{UO}_{2}$ & Tho & $\mathrm{Y}_{2} \mathrm{O}_{3}$ & & $h \mathbf{r}$ & ${ }^{\circ} \mathrm{C}$ & & \\
\hline GEFP2-19 & ETR & 11. $5 B F-230$ & 1 & 3 & 0.55 & None & 3400 & $1000-1250$ & 2 to 5 & In progress \\
\hline GEFP2-22 & ETR & $6 B F-243$ & 1 & 7 & 0.55 & $\mathrm{BeO}^{\mathrm{b}}$ & 900 & $1000-1200$ & 1 to 2.5 & In progress \\
\hline GEFP2-23 & ETR & 11. $5 \mathrm{BF}-230$ & 1 & 3 & 0.55 & None & 3400 & $1000-1250$ & 2 to 5 & In progress \\
\hline LTC-73 & LITR & 11. 5BF-230 & 1 & 3 & 0.55 & None & 931 & $1250-1550$ & $-\mathbf{c}$ & $\begin{array}{l}\text { Test complete, } \\
\text { evaluation in progress }\end{array}$ \\
\hline LTC-74 & LTRR & 11. 5BF-230 & 1 & 3 & 0.55 & $\mathrm{BeO}^{\mathrm{b}}$ & 817 & $1250-1500$ & $-\mathbf{c}$ & $\begin{array}{l}\text { Test complete, } \\
\text { evaluation in progress }\end{array}$ \\
\hline
\end{tabular}

The first number of the fuel element designation is the $\mathrm{UO}_{2}$ content of the specimen in weight percent. All fuel elements contain 25 volume percent fuel additive in BeO.

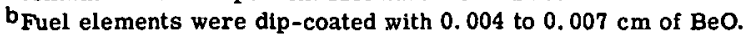

cBurnup is not applicable; this is a low flux dynamic test, the primary purpose of which is to determine fission product release kinetics.

$1200^{\circ} \mathrm{C}$. Non-nuclear bench test specimens being run to duplicate the ETR tests have shown essentially no change under similar time and temperature conditions.

LITR Test LTC-74 - Six fueled specimens of the 11.5BF-230 composition coated with $\mathrm{BeO}$ were irradiated in the LITR in an atmosphere of flowing air. Maximum indicated specimen temperatures were maintained at about $1250^{\circ} \mathrm{C}$ for 303 hours, at $1370^{\circ} \mathrm{C}$ for 330 hours, and at $1500^{\circ} \mathrm{C}$ for 92 hours after a 92 hour period of fluctuation between $1370^{\circ} \mathrm{C}$ and $1500^{\circ} \mathrm{C}$; total test time was 817 hours. The high reading thermocouples were lost prior to operation at $1500^{\circ} \mathrm{C}$; analysis of the thermocouple data indicates that the maximum test temperature could have been $1550^{\circ} \mathrm{C}$ during this period of the test.

The effluent gas stream was sampled with carbon traps at regular intervals for released fission products. Fractional release data are presented in Table $\mathbf{1 0 . 2}$ and are shown along with specimen thermal history in Figure 10.1. The data indicate a transient release rate of fission gases, typical of ceramic coatings, on first going to $1250^{\circ} \mathrm{C}$ and immediately following the temperature increase to $1370^{\circ} \mathrm{C}$. At each of these temperature levels the release generally decreased to a steady-state value for each isotope with increasing test time $\left(\mathrm{R} / \mathrm{B}=2 \times 10^{-6}\right.$ for $\mathrm{Kr}^{87}$ and $1 \times 10^{-5}$ for $\mathrm{Xe}^{133}$ with $\mathrm{Kr}^{88}, \mathrm{Kr}^{85 \mathrm{~m}}$, and $\mathrm{Xe}^{135}$ at intermediate values). This level of release during steady-state operation at $1250^{\circ} \mathrm{C}$ and $1370^{\circ} \mathrm{C}$ is a factor of 20 for $\mathrm{Xe}^{133}$ to 100 for $\mathrm{Kr}^{87}$ lower than that from the uncoated 11. 5BF-230 specimens irradiated in test LTC-73 discussed previously. ${ }^{1}$ Examination of the steady-state release data with respect to half-lives of the various isotopes indicates that release probably resulted from a combination of limited diffusion in the cladding and recoil from the cladding surface; alpha-count data and metallography of as-sintered specimens indicated that some fuel was present in the cladding as shown in Figure 10.2.

At $1500^{\circ} \mathrm{C}$ the trap data indicated that the release increased exponentially with time. If the slope of these data is extrapolated back through the time period of fluctuating temperature, the release appears to have increased exponentially during this time interval as well. The exponential increase in release at temperatures above $1370^{\circ} \mathrm{C}$ appears to be caused primarily by fuel migration in the cladding. Both the $\mathrm{Xe}^{138}$ and $\mathrm{Kr}^{87}$ data indicate that the recoil release had increased substantially by the start of the $1500^{\circ} \mathrm{C}$ period of operation. Additionally, the release data have a tendency to become less halflife sensitive during the period of increasing release.

LITR Test LTC-73 - Modulus-of-rupture strength measurements ${ }^{2}$ were made on the specimens irradiated in test LTC-73 and on similar unirradiated bench test specimens.

1"'Fourth Annual Report - High-Temperature Materials and Reactor Component Development Programs, Volume I -

Materials," GE-NMPO, GEMP.334A, February 26, 1965, pp. 196-199.

${ }^{2}$ Modulus-of-rupture measurements made at room temperature on hexagonal external configuration tubes $0.76 \mathrm{~cm}$ across flats with $0.5 \mathrm{~cm}$ circular bore using four-point loadings on a $4.45-\mathrm{cm}$ span and $0.152 \mathrm{~cm} / \mathrm{min}$ crosshead travel. 


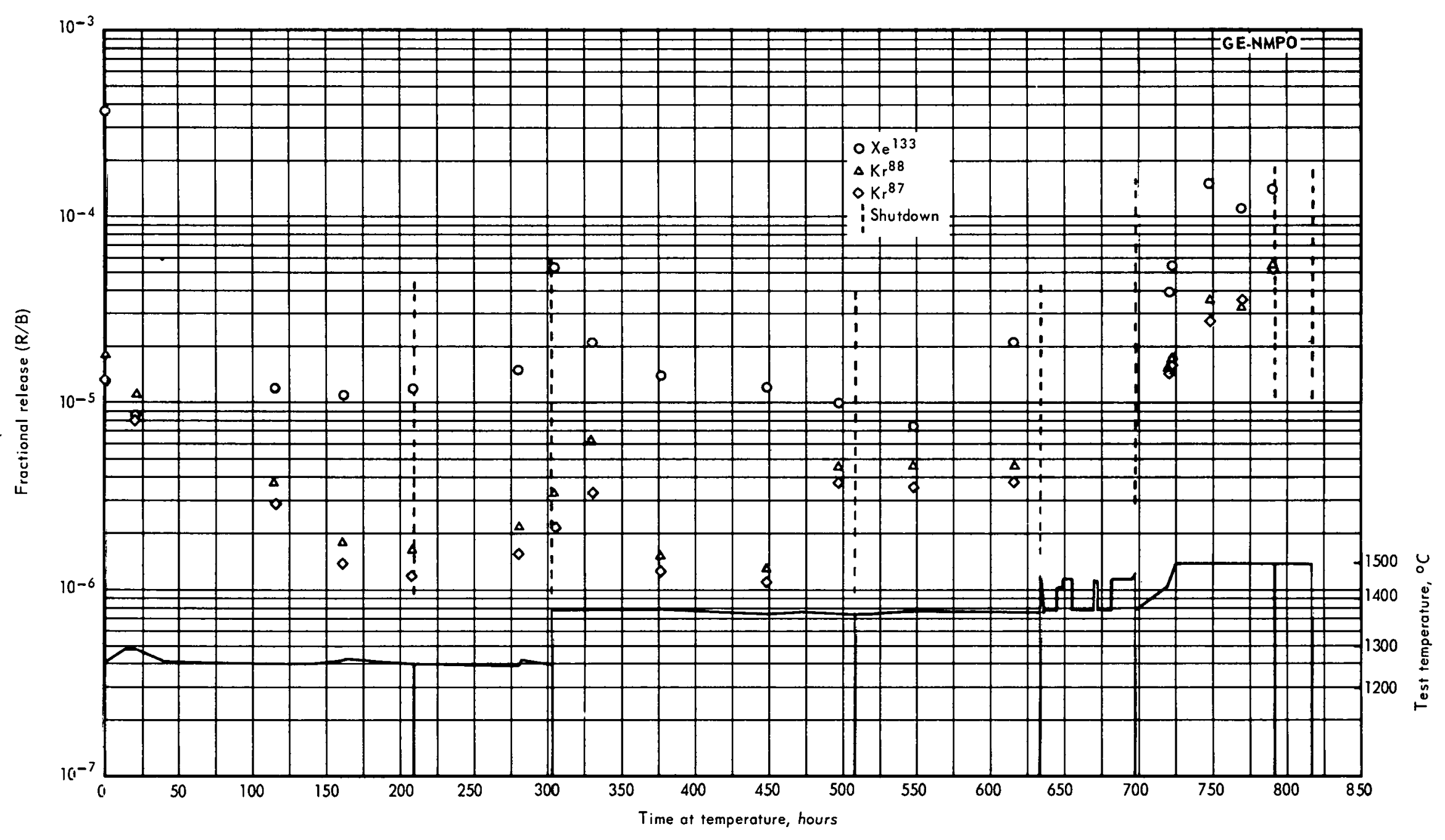

Fig. 10.1 - Fission gas release and thermal history of irradiation test LTC.74 
TABLE 10.2

FISSION PRODUCT RELEASE FROM TEST LTC-74

\begin{tabular}{|c|c|c|c|c|c|c|c|c|}
\hline \multirow[b]{2}{*}{ Trap No. } & \multirow{2}{*}{$\begin{array}{c}\text { Time, } \\
\mathrm{hr}\end{array}$} & \multirow{2}{*}{$\begin{array}{c}\text { Temperature, } \\
{ }^{\circ} \mathrm{C} \\
\end{array}$} & \multicolumn{6}{|c|}{ Fractional Release $(\mathrm{R} / \mathrm{B})^{\mathrm{a}}$} \\
\hline & & & $\mathrm{Kr}^{87}$ & $\mathrm{Kr}^{88}$ & $\mathrm{Kr}^{85 \mathrm{~m}}$ & $\mathrm{Xe}^{135}$ & $\mathrm{Xe}^{133}$ & $\mathrm{Xe}^{138}$ \\
\hline$C-1$ & 0.6 & 1255 & $1 \times 10^{-5}$ & $2 \times 10^{-5}$ & $2 \times 10^{-5}$ & $3 \times 10^{-5}$ & $4 \times 10^{-4}$ & - \\
\hline$C-2$ & 20.3 & 1290 & $8 \times 10^{-6}$ & $1 \times 10^{-5}$ & $2 \times 10^{-5}$ & $2 \times 10^{-5}$ & $9 \times 10^{-6}$ & $1 \times 10^{-6}$ \\
\hline$C-3$ & 114.3 & 1250 & $3 \times 10^{-6}$ & $4 \times 10^{-6}$ & $7 \times 10^{-6}$ & $7 \times 10^{-6}$ & $1 \times 10^{-5}$ & - \\
\hline$C-4$ & 161.4 & 1255 & $1 \times 10^{-6}$ & $2 \times 10^{-6}$ & $3 \times 10^{-6}$ & $5 \times 10^{-6}$ & $1 \times 10^{-5}$ & - \\
\hline C-5 & 208.5 & 1250 & $1 \times 10^{-6}$ & $2 \times 10^{-6}$ & $3 \times 10^{-6}$ & $5 \times 10^{-6}$ & $1 \times 10^{-5}$ & - \\
\hline Shutdown & 209.2 & & & & & & & \\
\hline C-6 & 280.5 & 1260 & $2 \times 10^{-6}$ & $2 \times 10^{-6}$ & $4 \times 10^{-6}$ & $4 \times 10^{-6}$ & $2 \times 10^{-5}$ & - \\
\hline Shutdown & 303.5 & & & & & & & \\
\hline$C-7$ & 304.6 & 1370 & $2 \times 10^{-6}$ & $3 \times 10^{-6}$ & $7 \times 10^{-6}$ & $7 \times 10^{-6}$ & $5 \times 10^{-5}$ & - \\
\hline$C-8$ & 329.2 & 1370 & $3 \times 10^{-6}$ & $6 \times 10^{-6}$ & $1 \times 10^{-5}$ & $3 \times 10^{-6}$ & $2 \times 10^{-5}$ & $8 \times 10^{-6}$ \\
\hline$C-9$ & 375.8 & 1370 & $1 \times 10^{-6}$ & $2 \times 10^{-6}$ & $3 \times 10^{-6}$ & $2 \times 10^{-6}$ & $1 \times 10^{-5}$ & - \\
\hline$C-10$ & 448. 3 & 1360 & $1 \times 10^{-6}$ & $1 \times 10^{-6}$ & $2 \times 10^{-6}$ & $4 \times 10^{-6}$ & $1 \times 10^{-5}$ & - \\
\hline$C-11$ & 497.1 & 1360 & $4 \times 10^{-6}$ & $5 \times 10^{-6}$ & $7 \times 10^{-6}$ & $3 \times 10^{-6}$ & $1 \times 10^{-5}$ & - \\
\hline Shutdown & 508.4 & & & & & & & \\
\hline$C-12$ & 547.6 & 1365 & $4 \times 10^{-6}$ & $5 \times 10^{-6}$ & $6 \times 10^{-6}$ & $3 \times 10^{-6}$ & $7 \times 10^{-6}$ & - \\
\hline$C-13$ & 615.5 & 1360 & $4 \times 10^{-6}$ & $5 \times 10^{-6}$ & $9 \times 10^{-6}$ & $3 \times 10^{-6}$ & $2 \times 10^{-5}$ & - \\
\hline Shutdown & 633.5 & & & & & & & \\
\hline Shutdown & 697.4 & & & & & & & \\
\hline $\mathrm{C}-14$ & 719.9 & 1430 & $2 \times 10^{-5}$ & $2 \times 10^{-5}$ & $4 \times 10^{-5}$ & $1 \times 10^{-5}$ & $4 \times 10^{-5}$ & - \\
\hline$C-15$ & 722.6 & 1480 & $2 \times 10^{-5}$ & $2 \times 10^{-5}$ & $5 \times 10^{-5}$ & $1 \times 10^{-5}$ & $6 \times 10^{-5}$ & - \\
\hline C-16 & 747.2 & 1500 & $3 \times 10^{-5}$ & $4 \times 10^{-5}$ & $1 \times 10^{-4}$ & $2 \times 10^{-5}$ & $2 \times 10^{-4}$ & $4 \times 10^{-5}$ \\
\hline C -17 & 769.4 & 1500 & $4 \times 10^{-5}$ & $3 \times 10^{-5}$ & $9 \times 10^{-5}$ & $4 \times 10^{-5}$ & $1 \times 10^{-4}$ & - \\
\hline$C-18$ & 791.0 & 1510 & $5 \times 10^{-5}$ & $6 \times 10^{-5}$ & $1 \times 10^{-4}$ & $5 \times 10^{-5}$ & $1 \times 10^{-4}$ & - \\
\hline Shutdown & 791.5 & & & & & & & \\
\hline Shutdown & 816.7 & End of test & & & & & & \\
\hline
\end{tabular}

${ }^{a}$ Fractional release is defined as the ratio of the rate of release of atoms from the specimen to the equilibrium production rate.

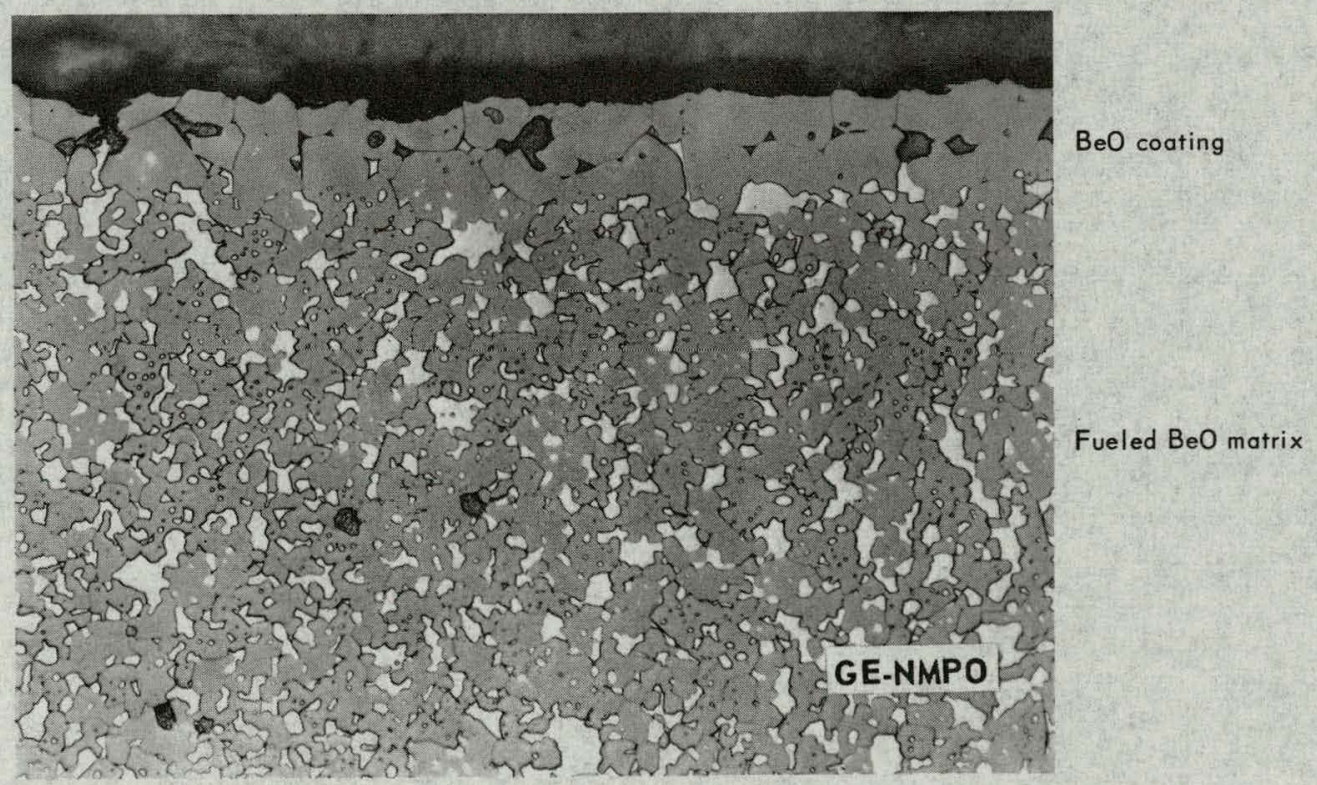

Fig. 10.2-Photomicrograph showing a cross section of $\mathrm{BeO}$-coated 11.5BF-230 fuel element (LTC-74) sintered for 1 hour at $1800^{\circ} \mathrm{C}$ in hydrogen (Neg. 5778, as-polished, 250X) 
The strength of the irradiated specimens was $2120 \mathrm{~kg} / \mathrm{cm}^{2}$, a decrease of 28 percent from the $2930 \mathrm{~kg} / \mathrm{cm}^{2}$ strength of the bench test specimens. The latter value was in agreement with the average as-sintered strength. The loss of strength upon irradiation indicates some damage results from irradiation and correlates with the previously reported $^{3}$ dimensional increase and density decrease.

\section{BeO Coating Studies}

BeO coatings applied to fuel elements have proved to be exceptionally effective in reducing $\mathrm{UO}_{2}$ loss during elevated-temperature testing in air and in reducing total fission product release during irradiation; however, these coatings do not have optimum characteristics. For example, the BeO-coatings on fuel elements used in LITR irradiation test LTC-74 were large grained, relatively porous, and contained macroscopic fuel particles (see Figure 10.2). To reduce grain growth and aid in densification, 3 weight percent $\mathrm{ZrO}_{2}$ sol was added to the $\mathrm{BeO}$ coating. The $11.5 \mathrm{BF}-230$ tubes were coated and separate specimens were sintered at $1675^{\circ} \mathrm{C}$ and at $1800^{\circ} \mathrm{C}$ in hydrogen. The microstructures after sintering are shown in Figure 10.3. The $\mathrm{ZrO}_{2}$-modified $\mathrm{BeO}$ coatings show considerable improvement in density but no decrease in grain size or fuel content. The light phase distributed throughout the coating was identified as fuel. Alpha counting of the fuel elements indicated the $\mathrm{ZrO}_{2}$-modified $\mathrm{BeO}$ coatings contain at least as much fuel as the unmodified $\mathrm{BeO}$ coatings; therefore, the advantage of using $\mathrm{ZrO}_{2}-$ modified coatings appears to be limited to increased density obtained at lower temperatures.

\section{WORK PLANNED FOR NEXT PERIOD}

This program terminated at the end of FY-65. The in-pile test program and corresponding bench test program initiated under this program will be continued and, in the future, reported under Job 57068. 


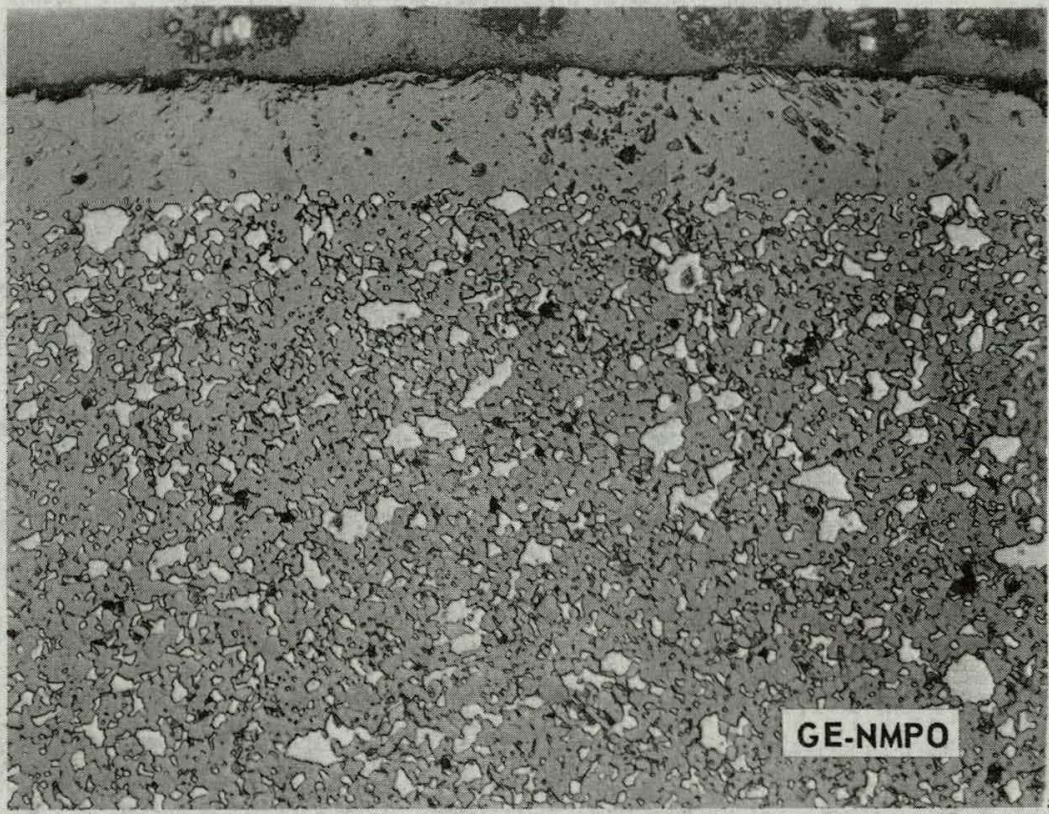

$\mathrm{BeO}-3 \mathrm{ZrO}_{2}$ sol coating

Fueled $\mathrm{BeO}$ matrix

Sintered for 2 hours at $1675^{\circ} \mathrm{C}$ in $\mathrm{H}_{2}$ (Neg. 5982)

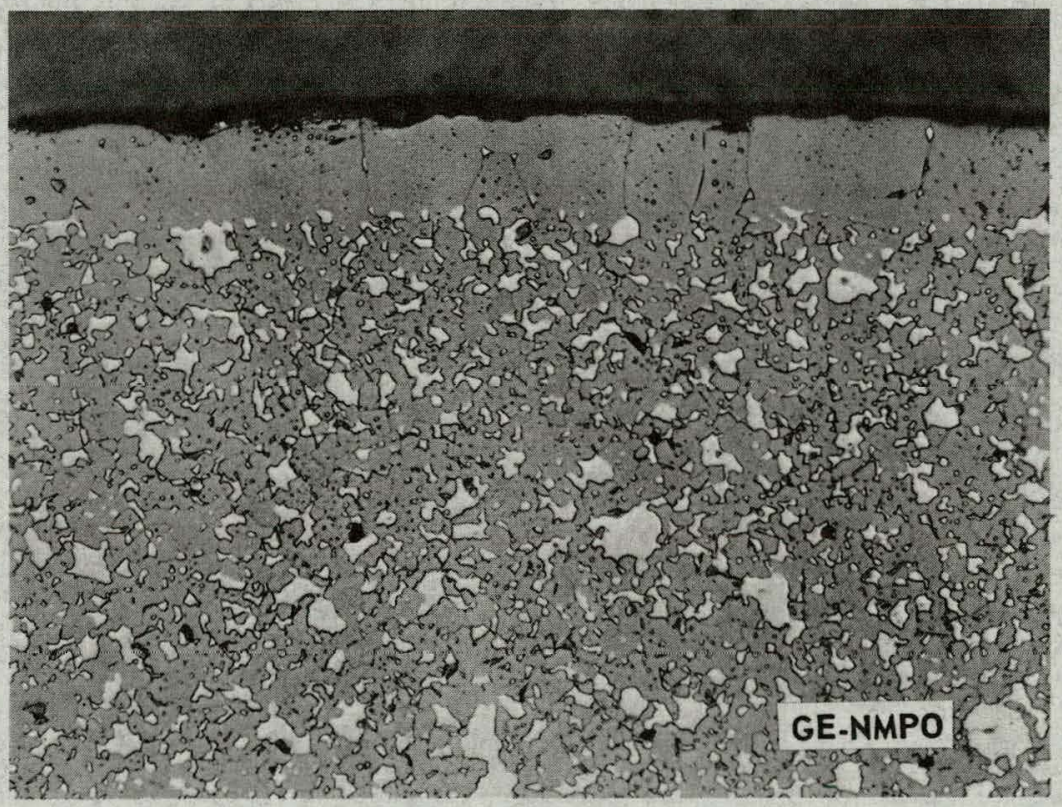

$\mathrm{BeO}-3 \mathrm{ZrO}_{2}$ sol coating

Fueled BeO matrix

Sintered for 1 hour of $1800^{\circ} \mathrm{C}$ in $\mathrm{H}_{2}$ (Neg. 5983)

Fig. 10.3-Photomicrographs showing sections of BeO coatings modified with 3 weight percent $\mathrm{ZrO}_{2}$ sol on $11.5 \mathrm{BF}-230$ fuel elements sintered at different temperatures (As-polished, 250X) 


\section{APPENDIX}

The "High-Temperature Materials Program Progress Reports" previously issued in this series are listed below. The first two reports were each issued as one document, containing both the classified and unclassified portions. The subsequent reports were issued as two documents; part $A$, the unclassified portion and part $B$, the classified portion.

\begin{tabular}{|c|c|}
\hline Report No. & Report Period \\
\hline EMP-1 & May 1961 - June 30, 1961 \\
\hline EMP-2 & July 1,1961 - July 31,1961 \\
\hline EMP-3, $A$ and $B$ & July 1, 1961 - August 31, 1961 \\
\hline EMP-4, A and B & August 1, 1961 - September 30, 1961 \\
\hline SEMP $-5, A$ and $B$ & August 15, 1961 - October 15, 1961 \\
\hline SEMP $-6, A$ and $B$ & September 15, 1961 - November 15, 1961 \\
\hline EMP $-7, A$ and $B$ & October 15, 1961 - December 15, 1961 \\
\hline 106, $A$ and $B$ & \\
\hline (Firs & Calendar Yeas \\
\hline GEMP-9, $A$ and $B$ & 2 - February 15, 1962 \\
\hline EMP-10, $A$ and $B$ & January 1, 1962 - March 15, 1962 \\
\hline EMP-11, $A$ and $B$ & February 15, 1962 - April 15, 1962 \\
\hline EMP-12, $A$ and $B$ & March 15, 1962 - May 15, 1962 \\
\hline GEMP-13, A and B & April 15, 1962 - June 15, 1962 \\
\hline GEMP-14, $A$ and $B$ & May 15, 1962 - July 15, 1962 \\
\hline GEMP-15, $A$ and $B$ & June $15,1962-$ \\
\hline EMP-16, $A$ and $B$ & July $15,1962-\mathrm{S}$ \\
\hline SEMP-17, A and B & August 15,1962 - October 15,1962 \\
\hline EMP-18, $A$ and $B$ & 32 - November 15, 1962 \\
\hline $\begin{array}{l}\text { GEMP-19, } A \text { and } B \\
\text { GEMP-177, } A \text { and B }\end{array}$ & - December 15, 1962 \\
\hline ((Second Annual Report) & Cale \\
\hline GEMP-21, $A$ and $B$ & January 1, 1963 - February 15, 1963 \\
\hline GEMP-22, $A$ and $B$ & January 1, 1963 - March 15, 1963 \\
\hline EMP-23, A and B & 63 - April 15, 1963 \\
\hline EMP-24, $A$ and $B$ & $\operatorname{March} 15,196$ \\
\hline GEMP-25, $A$ and $B$ & April 15, 1963 - June 15, 1963 \\
\hline GEMP-26, $A$ and $B$ & May 15,1963 - July 15,1963 \\
\hline EMP-27, $A$ and $B$ & June 15, 1963 - August 15, 1963 \\
\hline GEMP-28, $A$ and $B$ & July 15, 1963 - September 15, 1963 \\
\hline GEMP-29, $A$ and $B$ & August 15, 1963 - October 15, 1963 \\
\hline GEMP-30, $A$ and $B$ & September 15, 1963 - November 15, 1963 \\
\hline GEMP- $31, A$ and $B$ & October 15, 1963 - December 15, 1963 \\
\hline & - \\
\hline
\end{tabular}

Publication Date July 15, 1961 August 15, 1961 September 15, 1961 October 15, 1961 November 15, 1961 December 15, 1961 January 15, 1962

February 28, 1962

March 30, 1962 April 16, 1962

May 15, 1962

June 15, 1962

July 31, 1962

August 15, 1962

September 15, 1962

October 15, 1962

November 15, 1962

December 14, 1962

January 25, 1963

February 28, 1963

April 23, 1963

April 30, 1963

May 31, 1963

June 28, 1963

July 31, 1963

August 16, 1963

September 30, 1963

November 11, 1963

November 29, 1963

December 31, 1963

January 24, 1964

February 28, 1964 
Report No.

GEMP-34, $A$ and $B$ GEMP-35, $A$ and $B$ GEMP-36, $A$ and $B$ GEMP-37, $A$ and $B$ GEMP-38, $A$ and $B$ GEMP-39, $A$ and $B$ GEMP-40, $A$ and $B$ GEMP-41, $A$ and $B$ GEMP-42, $A$ and $B$ GEMP-43, $A$ and $B$ GEMP-334, A and $B$

(Fourth Annual Report) January 31, 1964 - January 31, 1965

GEMP-46, $A$ and $B$ GEMP-47, $A$ and $B$ GEMP-48, $A$ and $B$ GEMP-49, $A$ and $B$
Report Perlod

February 1, 1964 - March 15, 1964

February 1, 1964 - April 15, 1964

March 15, 1964 - May 15, 1964

April 15, 1964 - June 15, 1964

May 15, 1964 - July 15, 1964

June 15, 1964 - August 15, 1964

July 15, 1964 - September 15, 1964

August 15, 1964 - October 15, 1964

September 15, 1964 - November 15, 1964

October 15, 1964 - December 15. 1964

February 1, 1965 - March 15, 1965

February 1, 1965 - April 15, 1965

March 15, 1965 - May 15, 1965

April 15, 1965 - June 15, 1965
Publication Date

April 15, 1964

May 28, 1964

June 19, 1964

July 31, 1964

August 19, 1964

September 30, 1964

October 15, 1964

November 30, 1964

December 18, 1964

January 29, 1965

February 26, 1965

April 15, 1965

May 28, 1965

June 25, 1965

July 28, 1965 
ATOMIC PRODUCTS DIVISION

GENERAL (gof ELETRIC 